\title{
AN ABSOLUTE DETERMINATION OF THE OHM
}

\author{
By Harvey L. Curtis, Charles Moon, and C. Matilda Sparks
}

\section{ABSTRACT}

The value of the absolute ohm has been determined from the mean solar second and the absolute henry. The mean solar second depended on the time signals of the U. S. Naval Observatory, and the absolute henry depended on the computed self-inductance of helices wound on nonmagnetic forms. The time signals were used to calibrate a piezoelectric oscillator which controlled a 100-c/s generator. The self-inductance was computed for three inductors which had different dimensions and were wound on forms of different materials, namely, porcelain, Pyrex glass, and fused quartz. The electrical measurements called for an intermediary capacitance, so that a resistance was first measured in terms of inductance and capacitance by an alternating-current bridge, then the capacitance was measured in terms of resistance and time by the charge and discharge method of a Maxwell bridge. Assuming that the capacitance was the same under the two conditions stated, it was eliminated between the two bridge equations.

The result of this investigation is:

\section{NBS International $\mathrm{Ohm}=1.000450$ Absolute $\mathrm{Ohms}$}

The authors estimate that this result differs from the true value by less than 20 parts in a million. The greatest uncertainty arises from irregularities in the pitch of the winding.

\section{CONTENTS}

I. Introduction

II. Previous absolute determinations of the ohm

III. Method employed in this investigation

IV. Construction of the self-inductors

1. Preparation of the forms.

2. Winding of the inductors

3. Testing for leakage between turns

V. Methods of measuring the dimensions

1. Determination of pitch from the distance between turns.--

2. Outside diameter of the helix

3. Diameter of the wire

VI. Computation of an inductance in absolute units

1. Inductance of a helix

(a) Snow's formula for the inductance of a helix

(b) Numerical example illustrating Snow's formula

2. Effect of irregularities in pitch

3. Inductance of leads and substitution inductor

4. Effect of an error in the measured dimensions

5 . Effect of the permeability of the form. 
VII. Measurement of an inductance in NBS international electrical units

1. Maxwell-Wien alternating-current bridge

(a) Bridge resistors

(b) Capacitors $\ldots$

(c) Auxiliary and substitution inductors

(d) Detectors

(e) Bridge equations

(f) Alternating-current power supply

(g) Effect of magnetic material in the neighborhood of the inductors

2. Maxwell capacitance bridge

(a) Correction factor......

(b) Calibration of the bridge

(c) Galvanometers

(d) Apparatus for charging and discharging the capacitors.

(e) Capacitors.

(f) Accuracy of the capacitance measurements by the Maxwell bridge.

3. Resistance comparisons

4. Evaluation of an inductance from the electrical measurements

5. Accuracy of the

VIII. Observational data and results . . . .

1. Porcelain inductor
(a) Measurements of the dimensions of the porcelain inductor

(1) Outside diameter of porcelain inductor

(2) Pitch of the winding on the porcelain inductor

(3) Diameter of wire on the porcelain inductor...

(b) Computation of the inductance of the porcelain inductor...

(c) Electrical measurements on the porcelain inductor...

2. Glass inductor

(a) Measurements of the dimensions of the glass inductor.

(1) Diameter of the glass inductor

(2) Pitch of the winding on the glass inductor..--

(3) Diameter of the wire on the glass inductor...-

(b) Computation of the inductance of the glass inductor.-

(c) Electrical measurements on the glass inductor
(1) Effect of the steel reinforcement of the build-

(2) Measured inductance.

3. Quartz inductor

(a) Measurements of the dimensions of the quartz inductor-
(1) Outside diameter of the quartz inductor

(2) Pitch of the quartz inductor

(3) Irregularities in winding

(4) Diameter of wire on the quartz inductor

(b) Computation of the inductance of the quartz inductor--

(c) Electrical measurements on the quartz inductor....-

(1) Effect of frequency

(2) Effect of the steel reinforcement

(3) Measured inductance

IX. Value of a resistance in NBS international ohms and in absolute ohms

$\mathrm{X}$. Discussion of uncertainties affecting the result.

$\mathrm{XI}$. Results of recent investigations

\section{INTRODUCTION}

At the National Bureau of Standards an absolute determination of the ohm, based on the units of time and inductance, has been completed. The unit of time, the mean solar second, depended on the 
time signals sent out daily by the U. S. Naval Observatory. The unit of inductance, the absolute henry, depended on the inductance of a helix of wire, the value of the inductance being computed from the geometrical dimensions of the helix. This paper describes the methods of measuring the dimensions of a helix, of computing the inductance from the measured dimensions, and of determining the value of a resistance in terms of inductance and time, and gives data and results on three helices.

A similar research was started in 1906 by the late E. B. Rosa, who developed a formula ${ }^{1}$ for the calculation of the self-inductance of a helix, and had constructed two helices; one wound on a marble form ${ }^{1 a}$ in which the adjacent turns of enamel-insulated wire touched each other, the other on a plaster of paris form ${ }^{2}$ in which a double screw thread was cut to hold two independent windings of enamel wire. An absolute value of the ohm was determined from measurements ${ }^{3}$ made on these inductors. The mechanical imperfections ${ }^{4}$ in the inductors were so pronounced that the accuracy of the computed inductance was only a part in 10000 . About 1910 experimental work was discontinued, and was not resumed until 1921, when the construction of new inductors was undertaken. This paper describes the work which has been done since that time.

\section{PREVIOUS ABSOLUTE DETERMINATIONS OF THE OHM}

Absolute determinations of the unit of resistance have been made for more than 80 years. In $1851 \mathrm{~W}$. Weber ${ }^{5}$ devised the absolute system of electrical units and measured the unit of resistance, but his results differed among themselves by nearly 10 percent. In 1861 the British Association for the Advancement of Science appointed a committee on electrical units and standards. This committee decided that the practical electrical units should be based on the centimeter-gram-second (cgs) system of mechanical units, and appointed a subcommittee consisting of Maxwell, Stewart, and Jenkin to make an absolute determination of the unit of resistance. The value obtained by this committee ${ }^{6}$ was used to establish the BA unit. While the BA unit is now known to differ from the absolute ohm by 1.5 percent, it was nearly 20 years before the discrepancy was definitely established. In the decade between 1880 and 1890 , there were some 15 absolute-ohm determinations. Most of the results of this period were expressed in terms of the length of a mercury column having a cross section of $1 \mathrm{~mm}^{2}$ and maintained at the temperature of melting ice. Since 1900 there have been only two complete determinations ${ }^{7}$ but, in these, the accuracy was so increased that the uncertainty in the absolute ohm is now only a few parts in 100000 . Investigations in this and other national laboratories are in progress to reduce this uncertainty.

\footnotetext{
1 Bul. BS \%, 161 (1906) S31.

1a This inductor is described by Coffin. Bul. BS 2, 87 (1906) S29.

2 The form was the one used in the absolute electrodynamometer of Guthe, Bul. BS 2, 33 (1906) S27. Rosa had it rewound.

3 The senior author of this paper assisted in the measurements made at that time.

4 The imperfection which introduced the greatest uncertainty was the variation in the thickness of the enamel on the wire. The thickness of enamel was about $40 \mu$ (microns), and the variation in the thickness at least $10 \mu$ introducing the possibility of an error of $30 \mu$ or $40 \mu$ in the mean diameter, and hence an uncertainty or more than one in 10000 in the inductance.

5 Ann. phys. Chem. 82, 337 (1851). Translated in Phil. Mag. [4] 22, 226 and 261 (1861).

6 Brit. Assn. Advancement Sci. Rep. 33, 163 (1863).

7 F. E. Smith, Phil. Trans. 214A, 27 (1914); Grüneisen and Giebe, Ann. Phys. 368, 179 (1920).
} 
The improvement in absolute-ohm determinations which has been made in the last half century is illustrated in figure 1. In this chart are shown the values obtained at different times and the methods

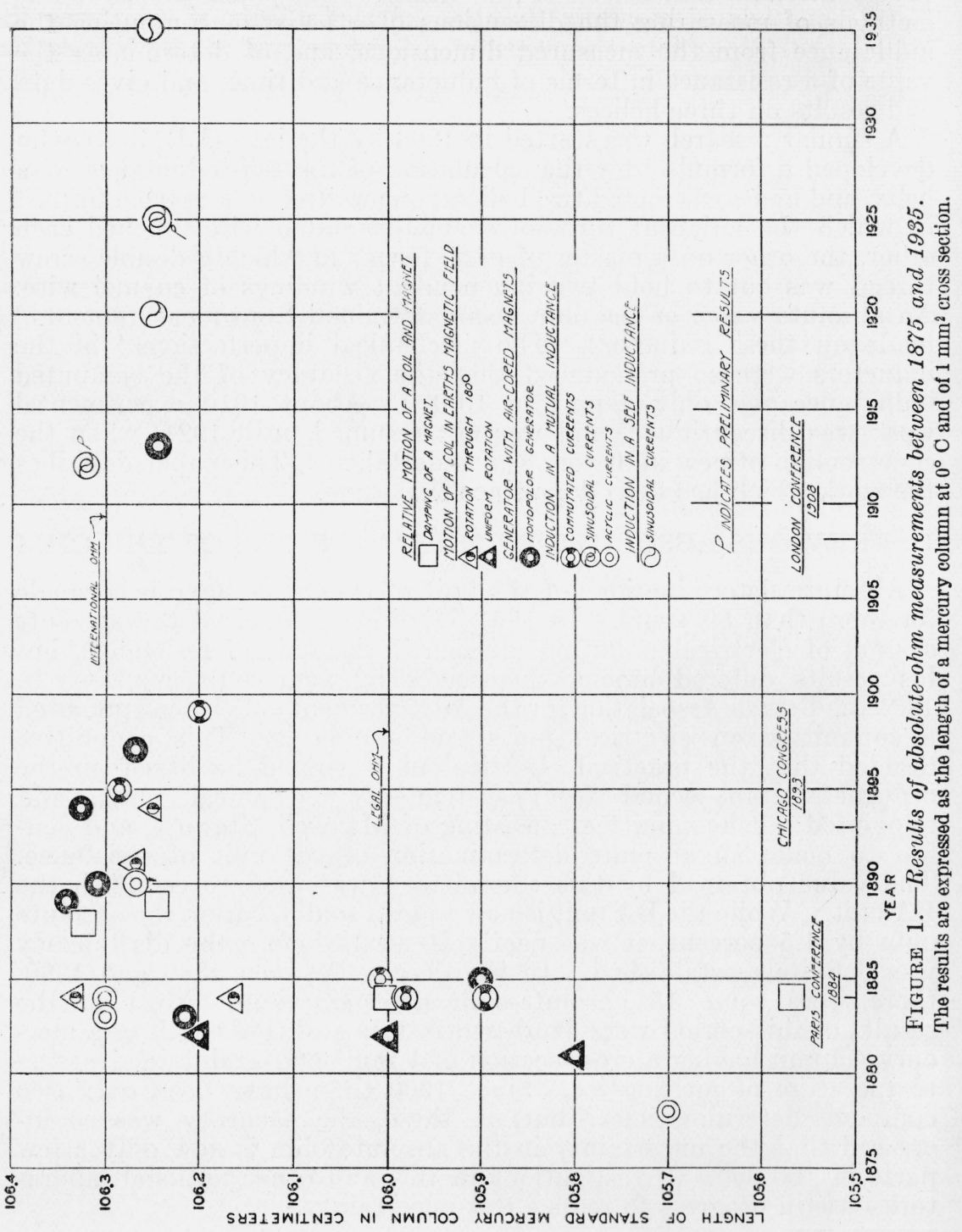

used. The earlier results differed by nearly 1 percent, but the recent results agree so closely that their variations do not appear on the scale to which this chart is plotted. 


\section{METHOD EMPLOYED IN THIS INVESTIGATION}

The method employed in this investigation determined a resistance in terms of the absolute henry and the mean solar second. The value of a resistance so determined is in absolute ohms. The description of the method naturally falls under four headings: (1) Construction of the self inductors; (2) measurement of their dimensions; (3) computation of the inductance in absolute henrys; and (4) electrical measurements.

\section{CONSTRUCTION OF THE SELF-INDUCTORS}

Each inductor was a single-layer solenoid of round wire wound as a helix on a cylindrical form. For this research, three inductors were constructed, the first on a porcelain form, the second on a Pyrex-glass form, and the third on a fused-quartz form. In this paper, they are designated as the porcelain inductor, the glass inductor, and the quartz inductor. They were constructed in the order named. The method of preparation of the form was changed as experience showed that improvements could be made, but the method of winding the wire was the same for all. The approximate dimensions of the finished cylinders were:

\begin{tabular}{|c|c|c|c|}
\hline Inductors & Length & Diameter & $\begin{array}{l}\text { Wall thick } \\
\text { ness }\end{array}$ \\
\hline $\begin{array}{l}\text { Porcelain } \\
\text { Glass___- } \\
\text { Quartz }\end{array}$ & $\begin{array}{r}\mathrm{cm} \\
45 \\
30 \\
110\end{array}$ & $\begin{array}{c}\mathrm{cm} \\
29 \\
46 \\
28\end{array}$ & $\begin{array}{l}\mathrm{cm} \\
2.5 \\
7.5 \\
2.5\end{array}$ \\
\hline
\end{tabular}

\section{PREPARATION OF THE FORMS}

The tube for the porcelain form was made by the Locke Insulator Co., using the wet process of making electrical porcelain. It was burned at a temperature to produce a very hard and dense material. In the Bureau shop, the tube was mounted on a mandrel by clamping between metal end plates, and its outer surface ground in a lathe using a tool-post grinder. The tube was not removed from the mandrel until the winding was completed. The inner surface of the tube was left in the condition in which it came from the kiln. This resulted in a varying wall thickness, so that the deformation produced by winding the wire modified the shape of the cylinder.

The Pyrex-glass form was cast in a brick mold by the Corning Glass Co., and annealed by them. At this Bureau it was rough ground on the interior and exterior surfaces, then mounted on a mandrel by means of end plates for the final grinding of the exterior surface with special laps. The method used in the final grinding was further improved in preparing the quartz form.

The fused-quartz form was constructed and rough ground on both the exterior and interior surfaces by the firm of Quartz et Silice, Paris. For the final grinding, it was mounted on a mandrel by means of the pneumatic device shown in figure 2 . Rubber tubing of about $2 \mathrm{~cm}$ diameter was wound on each of two flanged, wooden pulleys having faces $25 \mathrm{~cm}$ wide. The tubing was collapsed by closing one end and attaching the other end to a vacuum pump. When in this condition, 
the cylinder was easily placed in position. The rubber tubing was then inflated, the pressure being about $0.5 \mathrm{~kg} / \mathrm{cm}^{2}$ above atmospheric pressure. When inflated, the rubber tubing gripped the cylinder firmly without producing measurable distortion. The distance between the pulleys was chosen so that the sagging of the cylinder was a minimum. This mounting did not accurately aline the axis of the cylinder with the axis of the shaft, but such alinement was not required by the method of grinding employed.

The grinding was accomplished by means of a long and a short lap, which are shown in both figures 2 and 3 . The long lap was used for the main part of the grinding; the short lap was employed in the figuring. The long lap was made from cast aluminum. It consisted of 2 grinding bars joined by 2 handles. The grinding bars were about two-thirds the length of the cylinder. Each grinding bar had 3 grooves running the entire length, leaving 4 ridges on each bar. When the lap was placed on the cylinder as shown in figure 3 , the surfaces of all these ridges rested on the cylinder. During the grinding, the cylinder was turned at a speed of about $30 \mathrm{rpm}$. The grinding material was carborundum ${ }^{8}$ mixed with water. With the surface of the rotating cylinder covered with the carborundum mixture, the long lap was slowly moved by hand to traverse the cylinder from end to end. The traversing speed of the lap was kept as nearly constant as possible, and its stroke was of such length that, when reversed at an end, about one-fourth of the lap projected beyond the end of the cylinder. After a number of strokes the grinding was stopped, the cylinder cleaned, and its diameter measured at several points along the cylinder. On account of the low thermal expansivity of the quartz cylinder, the measurements of diameter could be made as soon as the cleaning was finished. If measurements of the diameter showed that the center was grinding faster than the ends, the length of stroke was increased. If the center was grinding more slowly, the stroke was decreased. When the stroke of the long lap was such that the center and ends were grinding at the same rate, there were two sections about one-fourth the distance from each end where the grinding was less rapid than at the center and ends. To reduce these sections to the same diameter as the center and ends, the short lap was constructed. It consisted of 6 brass bars about $6 \mathrm{~mm}$ square and $15 \mathrm{~cm}$ long, held on a block of paraffined wood by a thick layer of paraffin. By pressing the lap against the cylinder while the paraffin was still soft, a very accurate fit of the lap was obtained. By careful local use of this lap, the sections having large diameters were reduced, after which, in order to remove the slight irregularities introduced by the short lap, the long lap was used for a few minutes before measuring the diameter. By repeating this process, using finer and finer grades of abrasive, the figuring was carried to a point where the variations in diameter were less than a micron.

The micrometer used in measuring the variations in the diameter during the grinding is shown in figure 3 , on the left end of the cylinder. It was a modified micrometer caliper supported by a wooden frame which rested as a saddle on the cylinder. To the micrometer head was attached a large circular scale and a crank with a wooden handle. The scale was graduated in 500 divisions, each division representing a

${ }^{8}$ Commercial carborundum was used in grinding this cylinder. However, this contained some iron,
and the removal of this from the pores, after the grinding was completed, proved difficult. Iron-free and the removal of this from 


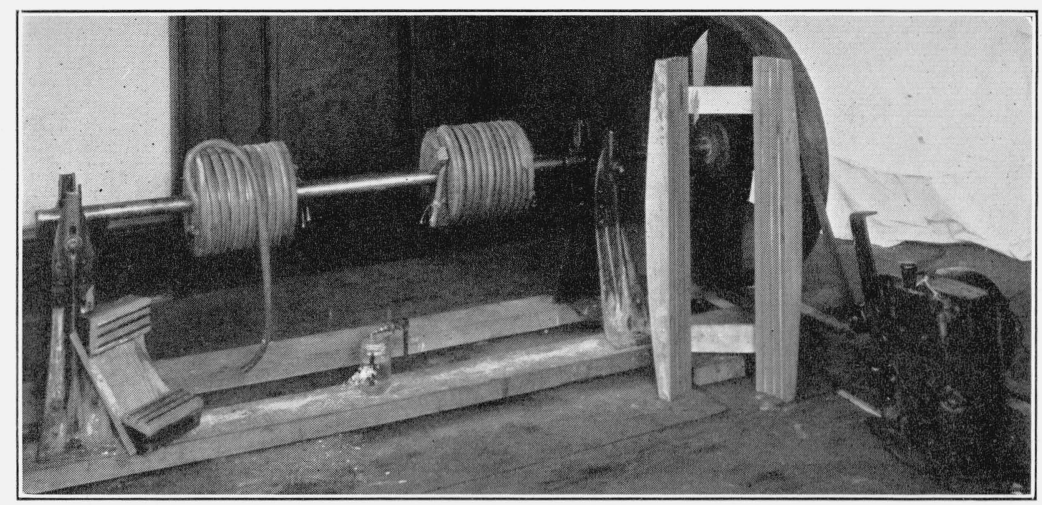

FIGURE 2.-Apparatus used in grinding the form of the quartz inductor, showing pneumatic device for holding the form.

The short and long laps are at the left and right, respectively.

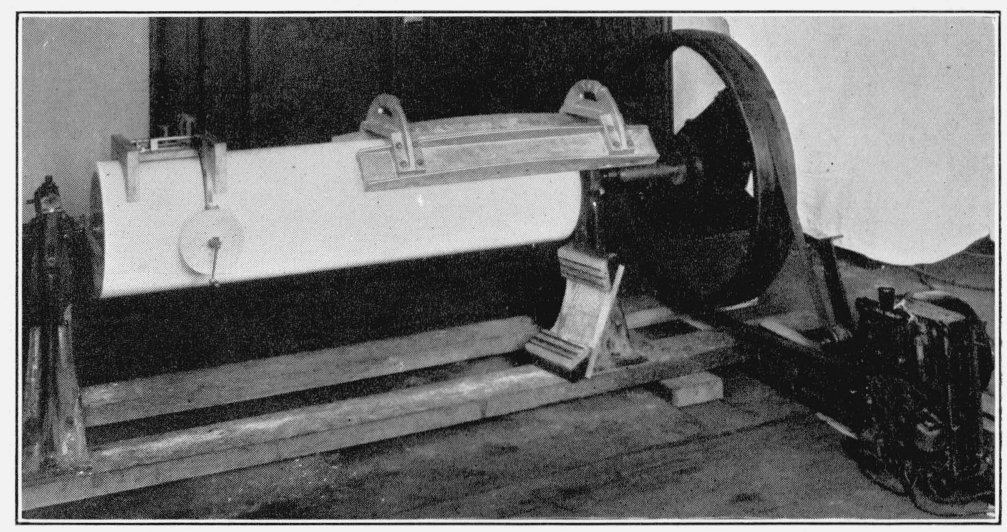

FIGURE 3.-Apparatus used in grinding the form of the quartz inductor.

The long lap rests on one end of the form and the micrometer for measuring the diameter on the other end. The short lap leans against the shaft support at the right. 


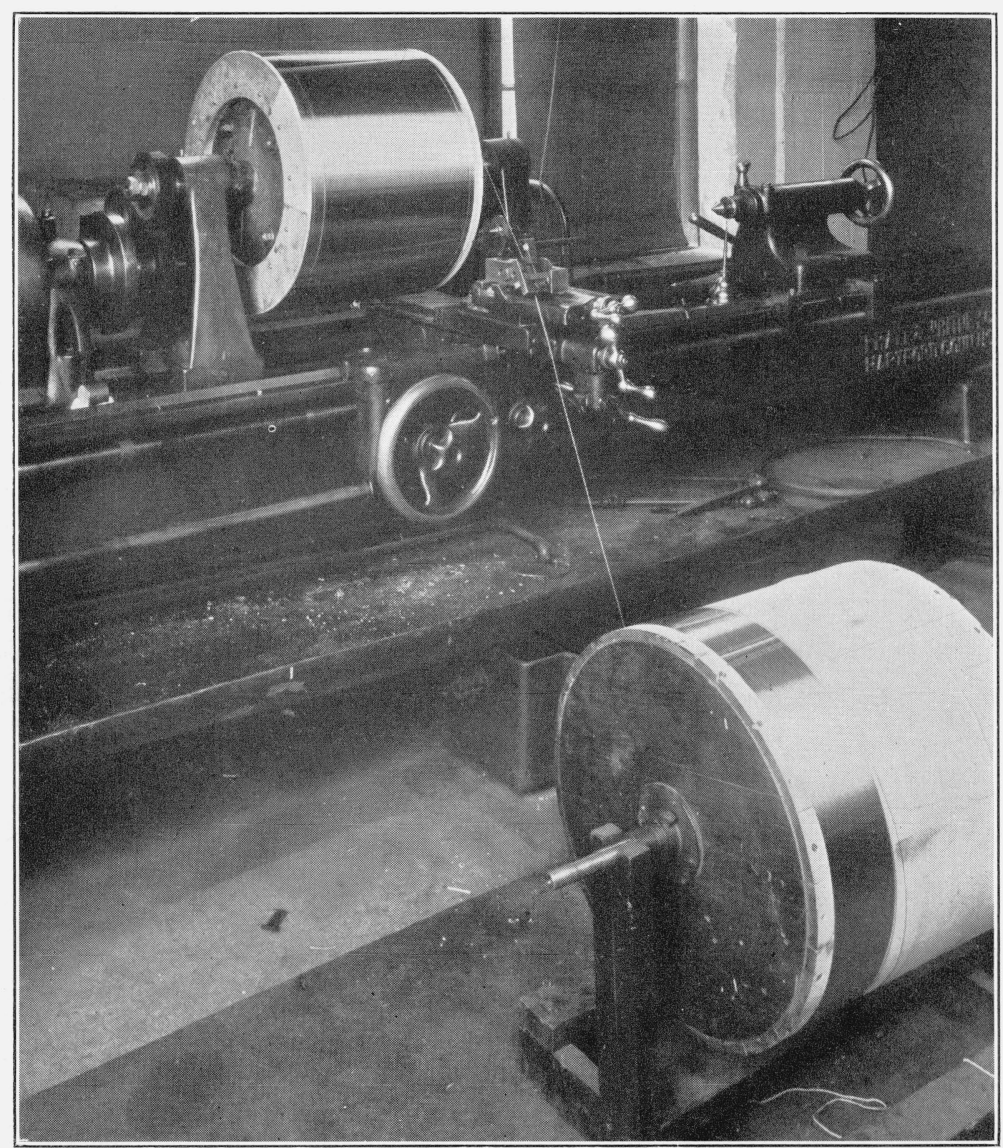

FIGURE 4.-Glass inductor in lathe at completion of winding. 
micron. The crank served to keep the hand of the operator away from the micrometer screw, thus minimizing temperature effects. Instead of the fixed anvil of an ordinary micrometer, a sliding anvil, which cannot be seen in the photograph, was so installed that its motion operated an electrical contact. ${ }^{2}$ This contact was connected in series with a cell and electric buzzer, or other indicating device. The micrometer was so attached to the saddle that the face of the micrometer screw was held by gravity against the cylinder. Advancing the micrometer screw rocked the micrometer about an axis parallel to the axis of the cylinder, thus bringing the anvil into contact with the cylinder. A further advance of the screw pushed the anvil in its slide, opened the electrical contact, and operated the indicator. The micrometer screw and anvil had spherical faces, the radius of curvature of each being about 4 meters. Successive readings repeated to $0.1 \mu$ (micron). The accuracy with which the variation in diameter over the length of the cylinder could be measured was limited by the change in temperature of the micrometer during the measurements. As this change was small over the 15-minute interval required to make a set of measurements, the expansion of the micrometer introduced an uncertainty of less than a micron in measurements of the variations in diameter. The completed cylinder had variations in diameter of approximately this amount.

\section{WINDING OF THE INDUCTORS}

The inductors were wound in a Pratt and Whitney precision lathe. The wire was spaced and its tension maintained by drawing it through a sapphire die attached to the carriage of the lathe, so that the final drawing of the wire and the winding of the inductor occurred simultaneously. The arrangement for winding the inductors and drawing the wire is shown in figure 4, the photograph having been taken at the completion of the winding of the glass inductor.

The wire for the inductors as purchased was no. $18 \mathrm{AWG}$ (diameter $1.02 \mathrm{~mm}$ ) annealed copper wire. It was drawn in the Bureau instrument shop, without further annealing, from the original size to the required size of no. 21 (diameter $0.71 \mathrm{~mm}$ ). Six different dies were required for the necessary reduction in size, the last drawing being made in connection with the winding of the inductors. Each drawing was carried out in the same manner as in the winding of the inductor, except that a wooden drum replaced the form of the inductor.

Before winding the inductors, the cylindrical form was mounted between end plates on a mandrel. After the mandrel was placed in the lathe, the form was adjusted until the axis of the cylinder differed from the axis of the mandrel by less than $20 \mu$. The sapphire die through which the wire was drawn during the winding of the inductors was so mounted on the carriage of the lathe that the wire was drawn through it at a slight angle. Wire drawn in this manner tends to form itself into a coil when the tension is released. The angle of the die was adjusted until the curvature which was taken by the released wire approximately corresponded to the curvature of the cylinder. When the wire was drawn in this way, there was no tendency for the wire to roll about its axis after contact with the form. To aid in

\footnotetext{
- The electrical contact was similar to that used on the micrometer described by one of us. See Moon, An electrically controlled micrometer caliper, J. Opt. Soc. Am. and Rev. Sci. Instr. 11, 453 (1925). $35090-36-2$
} 
maintaining the position of the wire, a thin coating of shellac varnish was applied to the under side of the wire, after it left the die, by means of a hard-rubber roller (not shown in the figure) which pressed lightly against the wire and dipped into a dish of the varnish. The tension on the wire (about $3 \mathrm{~kg}$ ) was sufficient to bring it into in timate contact with the cylindrical form, leaving the shellac as small wedge-shaped filaments on either side of the line of contact between the wire and cylinder.

Various devices were used in fastening the ends of the wires. In the case of the porcelain inductor, the ends were clamped under hardrubber blocks which were attached to the form by bakelite screws. In the cases of the glass and quartz forms, the ends were soldered to small brass rods set in holes drilled in the forms near each end of the winding.

\section{TESTING FOR LEAKAGE BETWEEN TURNS}

The leakage between turns of the porcelain and quartz inductors was tested by measuring the resistance between the helix and a similar winding of fine wire (about $0.15 \mathrm{~mm}$ diameter), which was wound between the turns of the main helix. This fine wire was removed before making measurements of the inductance. The width of the leakage path between the two windings was about half the pitch, and the length of the path was twice the length of each. The length of winding for the porcelain inductor was about $35000 \mathrm{~cm}$ and for the quartz inductor was $90000 \mathrm{~cm}$. Hence, if the leakage is entirely over the surface of the form between the wires, the insulation resistance between the main helix and the winding of fine wire should be, for the porcelain inductor, equal to the surface resistivity of porcelain divided by $1.5 \times 10^{6}$, and for the quartz inductor, equal to the surface resistivity of fused quartz, divided by $3.5 \times 10^{6}$. However, the surface resistivity of both these materials depends so much on the degree of cleanliness of the surface, as well as the relative humidity of the surrounding air, that only an approximate agreement between the measured resistance and the value deduced from published values of the surface resistivity of the material should be expected.

The values for the porcelain inductor were-

\begin{tabular}{|c|c|c|}
\hline \multicolumn{2}{|c|}{ Porcelain inductor } \\
\hline & \multicolumn{2}{|c|}{ Resistance } \\
\cline { 2 - 2 } Humidity & Measured & Computed \\
\cline { 2 - 3 } & & \\
\cline { 2 - 3 } Percent & Ohms & Ohms \\
30 & $1.4 \times 10^{9}$ & $10^{7}$ \\
60 & $2.6 \times 10^{8}$ & $10^{5}$ \\
75 & $0.5 \times 10^{6}$ & $5 \times 10^{3}$ \\
\hline
\end{tabular}

Since the measured insulation resistance was appreciably higher than that computed from published values of the surface resistivity, the leakage was as small as could be expected. It could not produce a measurable effect in the value of the measured inductance. 


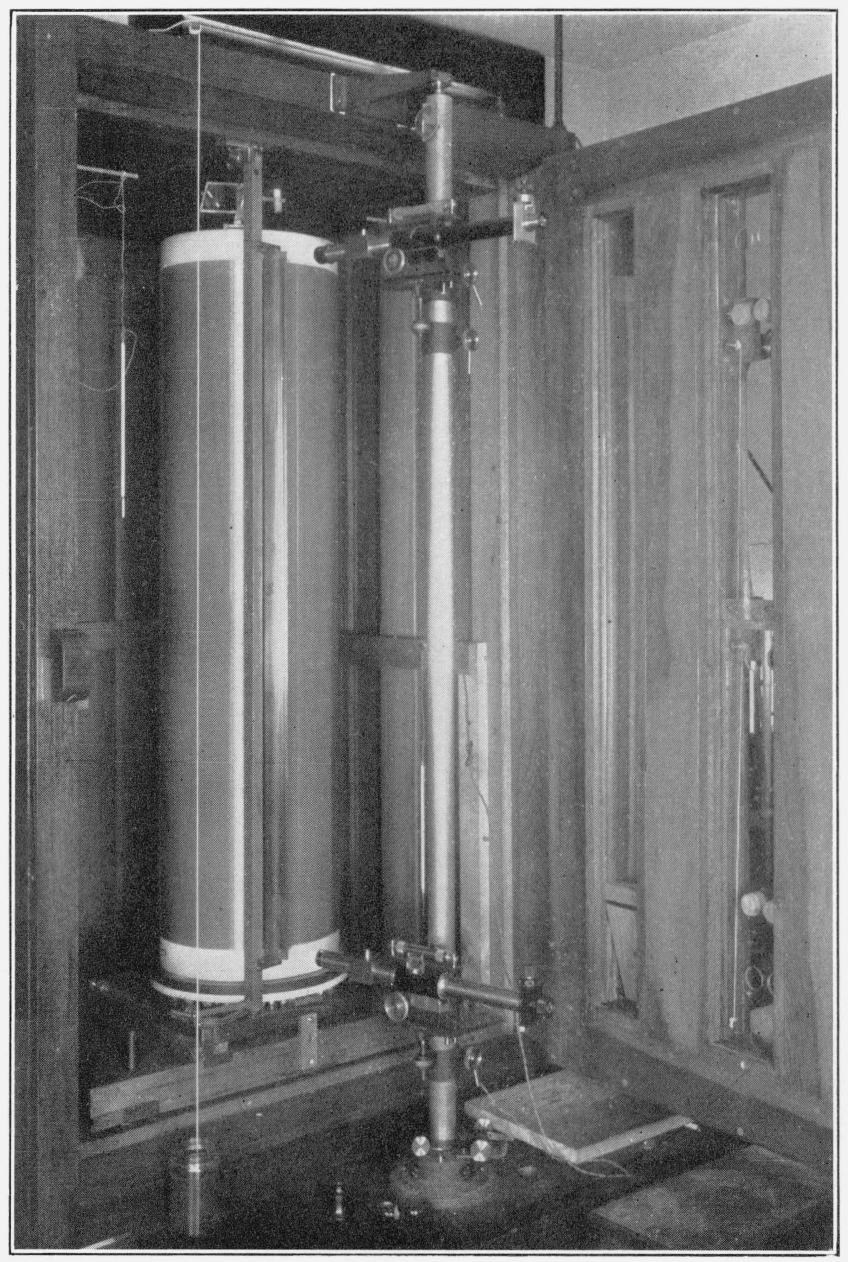

FIGURE 5.-Cathetometer for measuring length of quartz inductor.

The microscopes of the cathetometer are shown pointing at the standard meter. The plumb line at the left was used in adjusting the cathetometer. The door of the cabinet is open to show its interior. 
The helix of fine wire was wound on the quartz inductor while still in the lathe, and a measurement of the resistance using a "megger" gave a value of $1 \mathrm{megohm}$. The relative humidity was not observed, but was probably about 50 percent. The value computed from the published values of the surface resistivity of fused quartz at 50 percent is also $1 \mathrm{megohm}$. In transporting the inductor from the shop to the laboratory, the two helices became short-circuited so that a series of observations of the leakage at several humidities could not be made. However, the single determination showed that the measured inductance was not affected by leakage between turns.

The glass inductor was not investigated for leakage between turns.

\section{METHODS OF MEASURING THE DIMENSIONS}

The geometrical quantities which are used in the computation of the inductance of a helix having an integral number of turns are the pitch of the helix, its mean diameter, and the diameter of the wire with which it is wound. The displacement of each turn from its position in a perfect helix is also required if the effect of irregularities in winding is to be computed. Some of these quantities cannot be directly determined but are deduced from other measurements. All the required quantities were determined from measurements of the distance between turns, the outside diameter of the helix, and the diameter of the wire.

\section{DETERMINATION OF PITCH FROM THE DISTANCE BETWEEN TURNS}

The pitch of each helix was determined from measurements of the distance between turns. This distance was obtained by comparing it with a standard scale, graduated in millimeters, by means of a cathetometer. The coil and the standard scale were mounted in the same constant-temperature chamber, but the cathetometer was outside, requiring that its microscopes be sighted through small holes cut in the glass panels of the door of the constant-temperature chamber. The standard scale was mounted vertically at the same distance from the axis of the cathetometer as the surface of the wires on which measurements were to be made. The cathetometer used for measurements on the porcelain inductor was a commercial instrument with its telescope replaced by a microscope having a filar micrometer eyepiece. For measurements on the quartz and glass inductors, a special cathetometer ${ }^{10}$ was constructed which carried two such microscopes, one for reading near the top of the coil, the other for reading near the bottom. In using the latter instrument, the microscopes were simultaneously sighted at selected wires by two observers, and the micrometer in each eyepiece was read. The cathetometer was then turned so that the microscopes pointed at the scale and readings of each of the micrometers were made on two of the millimeter divisions of the scale. The magnification of the microscopes was such that one division of the micrometer corresponded to about $3 \mu$. The readings were made to tenths of a micrometer division, or $0.3 \mu$, but readings did not repeat with that accuracy. A photograph of the quartz inductor, the standard scale, and the cathetometer is reproduced in figure 5, with the door of the constant-temperature chamber open.

10 For a complete description see paper by Moon, J. Research NBS 14, 363 (1935) RP774. 
When making the measurements on the porcelain inductor, the cross hair of the micrometer eyepiece was set to bisect the space between two turns. More accurate methods were devised for making measurements on the quartz and glass inductors. In one method, a very finegrained flat oilstone was pressed against the winding and slid parallel to the axis, thus producing a small polished spot ${ }^{11}$ on each wire. In figure 6 is reproduced a photomicrograph showing the appearance of these spots in the field of the micrometer eyepiece.

In the second method, a very small block of hardened steel (dimensions 1.5 by 5 by $20 \mathrm{~mm}$ ) was hung from each of the two widely separated wires between which the distance was to be measured. The position of a block with respect to the wire on which it was hung was maintained by small pins which projected from the back of the block. A fiducial line was ruled on the polished face of each block. The distance between the lines on the two blocks was measured by the cathetometer. As the fiducial lines on the two blocks did not occupy exactly the same position relative to the supporting pins, the blocks were interchanged and the distance between the lines measured a second time. The average distance between the lines was the distance between the two wires. This was a very precise method, but so slow in operation that it has been used only to check results by the other method. An enlarged glass model of a block mounted on a helix of heavy wire is shown in figure 7.

A value for the pitch could be obtained from any measurement of a distance between turns. However, the winding was not exactly uniform, so that individual measurements gave different values for the pitch. Two methods were employed in the computation of the inductance from these measurements. In one, a mean pitch was obtained; in the other, a value of the pitch was derived from measurements on the end turns only, and the other measurements were used in obtaining a correction to the inductance as computed from this pitch.

The mean pitch of an inductor was determined by averaging the value obtained from several pairs of turns, the two turns of each pair being near the two ends. The distance between each pair was measured in several axial planes to obtain the average distance between the pair. This distance was divided by the number of turns between the pair to give the average pitch as determined from that pair. This procedure was followed for a number of pairs which were symmetrically located with respect to the ends, and the average of all was taken as the mean pitch of the helix. Since the pitch for any one pair of turns had the same weight as that for any other pair, only a few pairs of turns near the ends were employed because the effect of variations in pitch decreases rapidly as the distance of a pair from the ends increases. This method was used with the porcelain and glass inductors.

In the second method of using the measurements, the pitch was determined from the average distance between the two end turns,

11 This treatment removed a negligible amount of copper. The maximum depth of the portion removed was, for the average spot, about $0.7 \mu$ as computed either from the length of the spot and the radius of the helix or from the width of the spot and the radius of the wire. The effect of the removal of this amount of copper on the computed inductance was negligible.

This treatment gave information concerning the uniformity in diameter of the winding. The depth removed varied as the square of the length (or width) of the spot, so that any variation in diameter was shown by the difference in the size of the spots. In the case of the porcelain inductor, the variation in diameter was so large that this method was not applicable. 


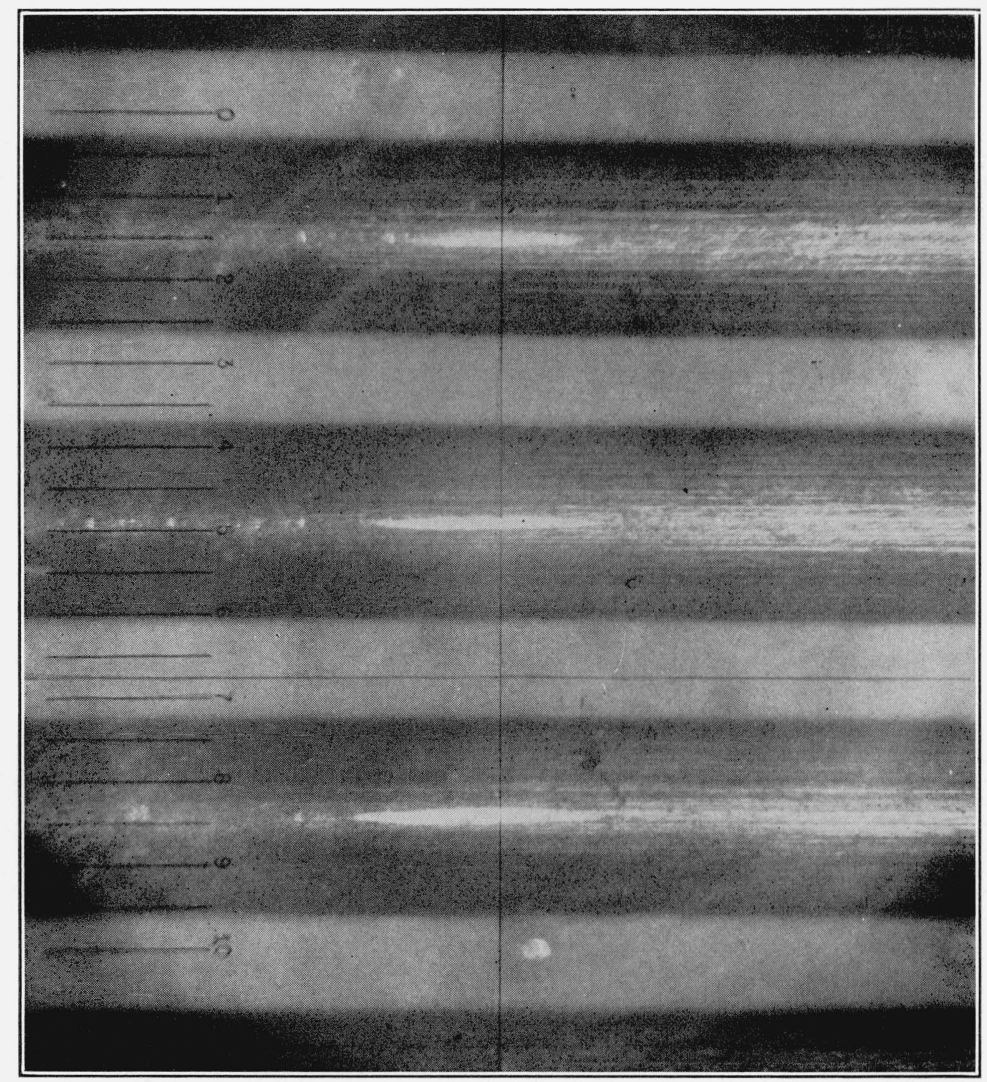

FIGURE 6.-Photomicrograph of "spots" on wires as they appeared in the eyepiece of the cathetometer microscope.

The cross hairs and scale of the filar micrometer are also shown. 


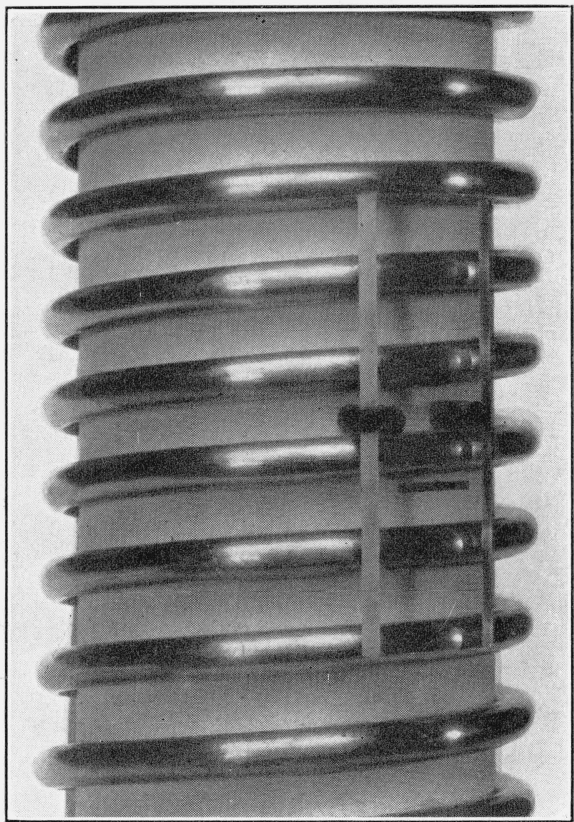

Figure 7.-Transparent model of "block" as used in "block method" of measuring distance between turns.

Two pins project from back of block between wires and are held against the lower wire by gravity. The black strip on the block represents the ruled line which served as a fiducial mark. 
and the average distance from the end turns was obtained for the other turns. The values of the measured distances from the end turns were used to obtain a correction to the inductance as computed by using the pitch determined from the end turns. This method was used with the glass and quartz inductors.

\section{OUTSIDE DIAMETER OF THE HELIX}

The outside diameter of the helix was compared with end standards having spherical ends, by means of a motor-driven micrometer ${ }^{12}$ The screw of the micrometer was turned by an electric motor working through a train of gears in which there was a magnetically-operated clutch that disengaged when the anvil of the micrometer pressed against the object to be measured. A diagram of the micrometer showing the electrical connections and the important mechanical features is given in figure 8 . The micrometer was graduated to

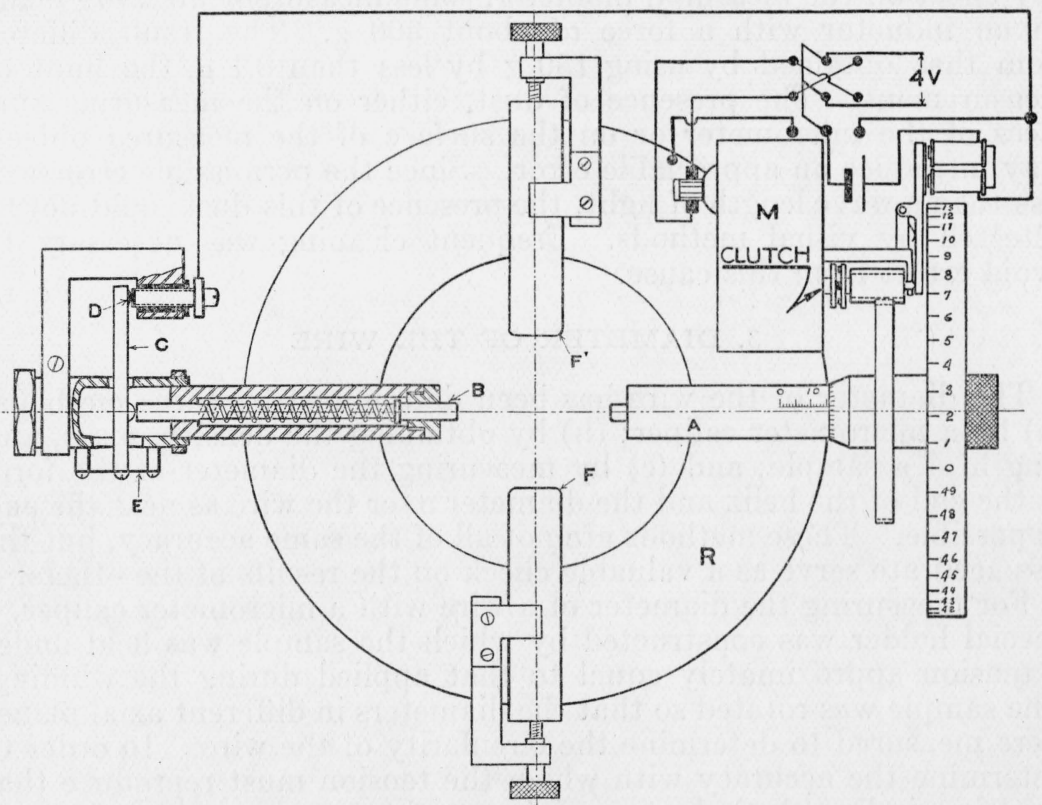

FigURE 8.-Electrically controlled micrometer caliper used to measure the diameter of the inductors.

read directly in microns. The divisions were about $1 \mathrm{~mm}$ apart, so that tenths of microns could be estimated.

The measurements were made inside the constant-temperature chamber. The end standards were mounted on top of the inductor, and the micrometer was suspended, from an elevating screw mounted on top of the chamber, by flexible rods which passed through small holes in the top. Under favorable conditions, successive readings on either the end standards or the inductor did not differ by more than $0.1 \mu$. A photograph showing the micrometer in position to

12 For a more complete description of the micrometer and of the method of calibrating the end standards, see paper by Moon, BS J. Research 10, 249 (1933) RP528. 
measure the diameter of the porcelain inductor is shown in figure 9 . At each elevation of the micrometer the lengths of the suspending rods were adjusted until the reading of the micrometer was a minimum.

End standards of steel and transparent fused quartz have been employed. Quartz was selected because of its small coefficient of expansion. Ali the standards which were used in measuring the diameter had spherical ends, the two ends of each standard being segments of the same sphere. The length of each standard was obtained by comparison with a flat-ended gage, the length of which had been determined in terms of wave lengths of light by the Interferometry Section of this Bureau. The lengths of the flat-ended gages were certified as correct to within $0.03 \mu$. The spherical-ended gages were measured to about $0.1 \mu$ by comparison with the flat-ended gages. ${ }^{13}$

The force required to open the contacts of the micrometer was about $150 \mathrm{~g}$. In order to determine whether this force produced any effect on the measured diameter, some measurements were made on an inductor with a force of about $300 \mathrm{~g}$. The result differed from that obtained by using $150 \mathrm{~g}$ by less than $0.1 \mu$, the limit of measurement. The presence of dust, either on the measuring surfaces of the micrometer or on the surface of the measured object, may introduce an appreciable error. Since the permissible error was less than a wave length of light, the presence of this dust could not be detected by visual methods. Frequent cleaning was necessary to avoid errors from this cause.

\section{DIAMETER OF THE WIRE}

The diameter of the wire has been determined by three methods: (a) by a micrometer caliper; (b) by obtaining the density, mass, and length of a sample; and (c) by measuring the diameter of the form at the end of the helix and the diameter over the wire as near the end as possible. These methods are not all of the same accuracy, but the less accurate serve as a valuable check on the results of the others.

For measuring the diameter of a wire with a micrometer caliper, a special holder was constructed by which the sample was held under a tension approximately equal to that applied during the winding. The sample was rotated so that the diameters in different axial planes were measured to determine the circularity of the wire. In order to determine the accuracy with which the tension must reproduce that used in winding the inductor, a computation was made by a formula used in the theory of elasticity for computing the decrease in diameter of a wire under a given tension. For a tension of $3 \mathrm{~kg}$ (that used in winding) the computed decrease in diameter of a $0.7-\mathrm{mm}$ copper wire is $0.15 \mu$, so that the tension does not need to be known closer than $1 \mathrm{~kg}$ to determine the diameter to $0.1 \mu$. For calibrating the micrometer, gage blocks and small steel balls served as length standards.

The mean diameter of the wire was obtained from the mass, length, and density of samples taken from each end of the glass and quartz inductors. In winding an inductor, it was necessary to wind several extra turns at each end, which were later removed when the permanent fastenings were made. Before removing, the wire was so marked

18 Method of comparison and results given in paper by Moon. See footnote 12. 


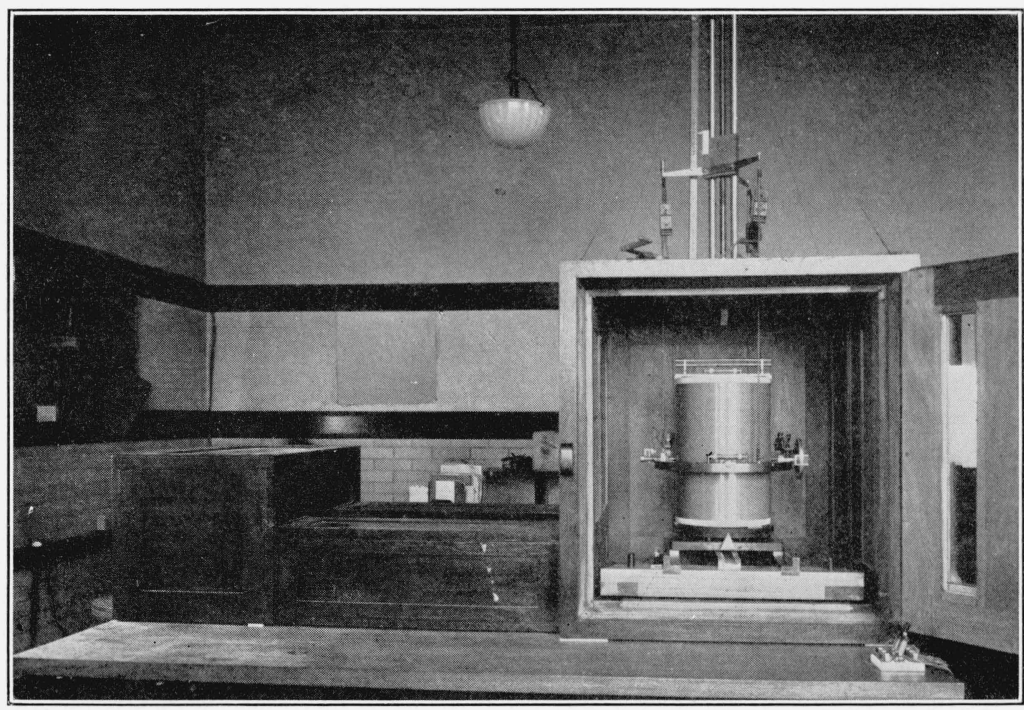

FIGURE 9.-Micrometer caliper and porcelain inductor as mounted for measurement of diameter.

The table, cabinet, and mounting are the same as used when making the electrical measurements on the inductor. All were made entirely of wood and glass, there being no metal of any kind used in their construction. Before making the electrical measurements, the micrometer, end standards, and their metal supports were removed from the vicinity of the inductor. During the electrical measurements, some small pieces of metal were located 2 meters from the inductor at the left of the cabinet. The largest of these was the motor used for driving a wooden fan which circulated the air through the inductor cabinet. A similar motor was brought much closer to the inductor than the location of that just described, without affecting the inductance by a measurable amount. 
that a sample could be prepared, which consisted of a whole number of turns plus a small and easily measured length. The mass and density of a sample were experimentally determined by the Weights and Measures Division of this Bureau. The mean diameter of the wire was computed from the formula:

$$
d=\sqrt{\frac{4 M}{\pi \rho s}}
$$

where $d$ is the diameter of wire; $M$, its mass; $\rho$, its density; and $s$, the length of the sample. All the measured quantities could be determined with an accuracy greater than 1 part in 5000 , so that no one of them introduced an error as great as 1 part in 10000 in the result. This method assumed that the cross section of the wire was circular. If the cross section were not approximately circular, the result by this method would be of little value, since the wire diameter in the radial direction of the inductor is required to obtain the mean diameter of the inductor.

The diameter of the wire is one-half the difference between the overall diameter of the inductor and the diameter of the form. Only at the ends of the inductors have these measurements been made with sufficient accuracy to give a precise value of the wire diameter. Moreover, the accuracy which could be obtained was different with the different inductors. The porcelain inductor was appreciably compressed. The glass inductor had a smooth surface and was only slightly compressed by the winding, so that the necessary accuracy could be obtained. In the case of the quartz inductor, the compression caused by the winding was quite large so that the accuracy was appreciably less than in the case of the glass inductor.

When a wire is wound under tension onto a cylindrical surface, the wire is compressed where it makes contact with the cylinder so that the cross section is not circular. A theoretical investigation ${ }^{14}$ has shown that, with the tension used in winding these inductors, the elastic compression affected the mean diameter by about $0.05 \mu$, which was negligible. The same investigation has shown that the compression of the cylindrical form was practically uniform, the small local indentations under the wires being negligible.

\section{COMPUTATION OF AN INDUCTANCE IN ABSOLUTE UNITS}

The inductance was computed for each helix, for its leads, and for its substitution inductor. The latter consisted in every case of a pair of parallel wires having a resistance equal to the resistance of the helix and its leads. The inductors are shown diagrammatically in figure 10 .

\section{INDUCTANCE OF A HELIX}

The most precise formula for computing the inductance of a helix is the one derived by Snow ${ }^{15}$ as a part of this research. An approxi-

14 Snow. Elastic problem of a wire-wound cylinder. BS J.Research 7, 331 (1931) RP344.

15 The original formula which applies to wire of any cross section is published in BS Sci. Pap. 21, 431 (1926-27) S537; a simplified formula which applies only to round wire is published in BS J. Research 9, 419 (1932) RP479. 
mate formula for a helix of round wire was developed by Rosa ${ }^{16}$ by treating it as a series of parallel turns of wire. Grover ${ }^{17}$ has so extended Rosa's formula, by adding certain correction terms which

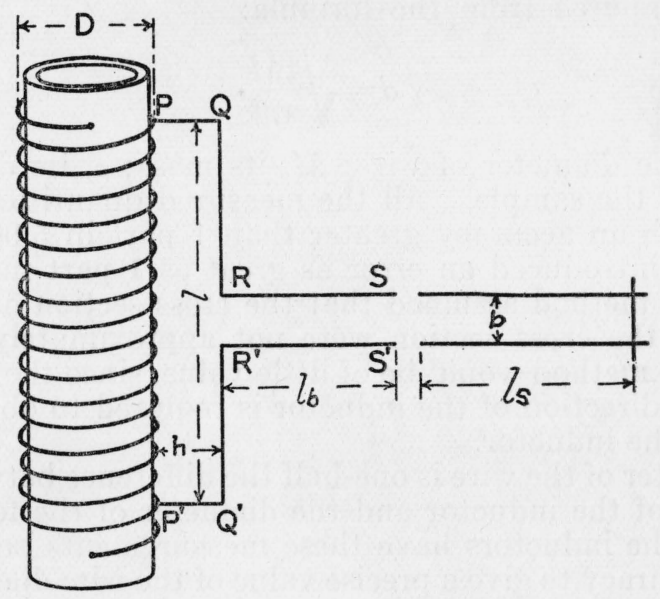

FIGURE 10.-Diagram of helix, with leads, and of substitution inductor consisting of parallel wires of length $l_{\mathrm{s}}$.

were obtained from Snow's formula to make provision for the helicity of the winding, that numerical results by the two formulas differ by less than a part in a million.

\section{(a) SNOW'S FORMULA FOR THE INDUCTANCE OF A HELIX}

Snow's formula involves the following constants:

Measured constants:

$D=$ mean diameter of helix in centimeters.

$g=$ pitch of winding in centimeters.

$N=$ number of turns.

$d=$ diameter of wire in centimeters.

Computed constants:

$l=N g$, the effective length of the helix.

$$
k^{2}=\frac{D^{2}}{D^{2}+l^{2}}=\frac{1}{1+l^{2} / D^{2}} .
$$

$K=$ complete elliptic integral of the first kind to modulus $k$.

$E=$ complete elliptic integral of the second kind to modulus $k$.

The formula for the inductance, $L_{h}$, in millimicrohenrys, ${ }^{18}$ may be written as the sum of six separate terms, so that

$$
L_{h}=L_{0}+L_{1}+L_{2}+L_{3}+L_{4}+L_{5},
$$

${ }_{16}$ Bul. BS 2, 161 (1906) S31.

17 BS J. Research 3, 163 (1929) RP90.

18 The cgs electromagnetic unit of inductance does not have a universally recognized name. Some have called it the "centimeter" and others the "abhenry." The authors prefer the name "millimicrohenry" "pecause it indicates the numerical relationship between the egs unit and the unit of inductance in the "practical" system. 
where

$$
\begin{aligned}
& L_{0}=\frac{4 \pi N^{2} D}{3 k}\left[K-E+\frac{D^{2}}{l^{2}}(E-k)\right] . \\
& L_{1}=\pi N D\left[2 \ln \frac{g}{d}+\frac{1}{3 N} \ln \frac{\pi D}{g}-1.78946\right] \\
& L_{2}=-\frac{2 \pi D}{3 k}\left[K-E-\frac{k^{2} K}{2}\right] \\
& L_{3}=-\frac{2 D}{\pi k}[E-k]\left[2 \pm\left(\frac{\pi d}{2 g}\right)^{2}\right] \\
& L_{4}=-\frac{\pi l}{2}\left[1-\frac{l}{D^{-1}} \sin ^{-1} k\right. \\
& L_{5}=l P .
\end{aligned}
$$

The value of $P$ is computed by one of the following formulas:

$$
P=2.77+\frac{D^{2}}{4 l^{2}}+2 \ln (l / D), \text { when } l \equiv D,
$$

or

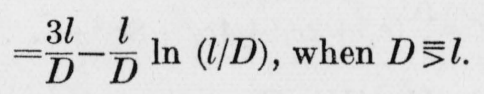

In the above formulas, as elsewhere in this paper, "ln" refers to natural logarithms.

The value of the principal term $L_{0}$ must be computed with the same accuracy as is required in the final result. The second term $L_{1}$ is always less than one percent of the final result, so needs to be computed with only $1 / 100$ of the accuracy required for $L_{0}$. The remaining terms are all small correction terms which can be obtained with sufficient accuracy by performing the numerical multiplications and divisions on a slide rule.

In applying the above formulas to a numerical example, there are three kinds of functions that must either be computed or be taken from tables; viz, logarithms, circular functions, and complete elliptic integrals. For the helices used in this investigation, a five-place logarithm table was sufficient to permit the computation of the inductance to a part in 1000000 . The only circular function needed was the inverse sine, which was computed by the first two or three terms of the series:

$$
\sin ^{-1} k=k+\frac{k^{3}}{6}+\frac{3 k^{5}}{40}+\ldots
$$

The complete elliptic integrals were required with high accuracy. They were sometimes obtained from the tables of Legendre, ${ }^{19}$ but since the interpolation in these tables was difficult, a direct computation was generally made. This was done by the arithmetico-geo-

${ }^{10}$ A photographic reproduction was published by K. Wittwer, Stuttgart in 1931.

$35090-36-3$ 
metric mean series, ${ }^{20}$ which required the computation of three interrelated series as shown in the following tabulation:

$$
\begin{array}{lll}
a_{0}=1 & b_{0}=\sqrt{1-k^{2}} & c_{0}=k \\
a_{1}=\left(a_{0}+b_{0}\right) / 2 & b_{1}=\sqrt{a_{0} b_{0}} & c_{1}=\left(a_{0}-b_{0}\right) / 2 \\
a_{2}=\left(a_{1}+b_{1}\right) / 2 & b_{2}=\sqrt{a_{1} b_{1}} & c_{2}=\left(a_{1}-b_{1}\right) / 2 \\
a_{3}=\left(a_{2}+b_{2}\right) / 2 & b_{3}=\sqrt{a_{2} b_{2}} & c_{3}=\left(a_{2}-b_{2}\right) / 2 \\
\vdots & \vdots & \vdots \\
\vdots & \vdots & \vdots \\
a_{n} & \dot{b}_{n} & c_{n}
\end{array}
$$

The tabulation was continued until $a_{n}$ equaled $b_{n}$, to a part in 10 million, which never required more than three terms. From the values given in the tabulation, the elliptic integrals of the first and second kind and their differences are given by the equations:

$$
\begin{aligned}
K & =\frac{\pi}{2 a_{n}} \\
K-E & =\frac{K}{2}\left(c_{0}^{2}+2 c_{1}^{2}+4 c_{2}^{2}+8 c_{3}^{2}+\ldots\right. \\
E & =K-(K-E)
\end{aligned}
$$

(b) NUMERICAL EXAMPLE ILLUSTRATING SNOW'S FORMULA

The method of computing the inductance of a helix by the formula given above is illustrated in the following computation of the inductance of the quartz inductor.

Measured constants of quartz inductor:

$$
\begin{aligned}
N & =1000 \text { turns } \\
g & =0.1000031 \mathrm{~cm} \\
D & =28.03808 \mathrm{~cm} \\
d & =0.07090 \mathrm{~cm}
\end{aligned}
$$

Computed constants:

$$
\begin{aligned}
l & =100.0031 \mathrm{~cm} \\
l^{2} / D^{2} & =12.721267 \\
k^{2} & =1 /\left(1+l^{2} / D^{2}\right)=0.07287956 \\
k & =0.2699621 \\
\sin ^{-1} k & =k+\frac{k^{3}}{6}+\ldots=0.273 \\
P & =2.77+\frac{D^{2}}{4 l^{2}}+2 \ln (l / D)=5.33 .
\end{aligned}
$$

The arithmetico-geometric mean series for computing the elliptic integrals are:

$$
\begin{array}{lll}
a_{0}=1 & b_{0}=0.9628709 & c_{0}=0.2699621 \\
a_{1}=0.9814355 & b_{1}=0.9812598 & c_{1}=0.0185645 \\
a_{2}=0.9813477 & b_{2}=0.9813476 & c_{2}=0.0000878
\end{array}
$$

${ }^{20}$ For a complete discussion of this method of computing elliptic integrals, see King, On the direct numerical calculation of elliptic functions and integrals. Cambridge Univ. Press (1924). See also Grover, Phil. Mag. [7] 15, 1115 (1933). 
Since $a_{2} \approx b_{2} ; a_{2}=a_{3} \ldots=a_{n}$

$$
\begin{aligned}
K=\pi / 2 a_{n} & =1.6006522 \\
c_{0}^{2} & =0.07287956 \\
2 c_{1}^{2} & =0.00068928 \\
4 c_{2}^{2} & =0.00000003 \\
\left(c_{0}^{2}+2 c_{1}^{2}+4 c_{2}^{2}\right) & =0.07356887
\end{aligned}
$$

$$
\left[-E=\frac{K}{2}\left(c_{0}^{2}+2 c_{1}^{2}+4 c_{2}^{2}\right)=0.05887909\right.
$$

$$
\begin{aligned}
E=K-(K-E) & =1.5417731 \\
E-k & =1.2718110
\end{aligned}
$$

To compute $L_{\circ}$ (eq 2a):

$$
\begin{gathered}
\frac{4 \pi N^{2} D}{3 k}=435.0448 \times 10^{6} \\
K-E=0.05887909 \\
\frac{D^{2}}{l^{2}}(E-k)=0.09997517 \\
K-E+\frac{D^{2}}{l^{2}}(E-k)=0.15885426 \\
L_{0}=\frac{4 \pi N^{2} D}{3 k}\left[K-E+\frac{D^{2}}{l^{2}}(E-k)\right]=+69108723 \text { millimicrohenrys. }
\end{gathered}
$$

To compute $\mathrm{L}_{1}$ (eq $\left.2 \mathrm{~b}\right)$ :

$$
\pi N D=88084
$$

$2 \ln \frac{g}{d}=0.68788$

$$
\frac{1}{3 N} \ln \frac{\pi D}{g}=0.00226
$$

$\left[2 \ln \frac{g}{d}+\frac{1}{3 N} \ln \frac{\pi D}{g}-1.78946\right]=-1.09932$

$L_{1}=\pi N D\left[2 \ln \frac{g}{d}+\frac{1}{3 N} \ln \frac{\pi D}{g}-1.78946\right]=-96834$ millimicrohenrys.

To compute $\mathrm{L}_{2}$ (eq 2c):

$$
\begin{gathered}
\frac{-2 \pi D}{3 k}=-218 \\
K-E=+0.0589 \\
-\frac{k^{2} K}{2}=-0.0583 \\
K-E-\frac{k^{2} K}{2}=+0.0006
\end{gathered}
$$

$L_{2}=\frac{-2 \pi D}{3 k}\left[K-E-\frac{k^{2} K}{2}\right]=-0.1$ millimicrohenry. 
To compute $L_{3}$ (eq $\left.2 \mathrm{~d}\right)$ :

$$
\begin{gathered}
\frac{-2 D}{\pi k}=-66 \\
{[E-k]=1.27} \\
{\left[2 \pm\left(\frac{\pi d}{2 g}\right)^{2}\right]=2 \pm 1.28} \\
L_{3}=\frac{-2 D}{\pi k}[E-k]\left[2 \pm\left(\frac{\pi d}{2 g}\right)^{2}\right]=-168 \pm 107 \text { millimicrohenrys. }
\end{gathered}
$$

To compute $L_{4}$ (eq $2 \mathrm{e}$ ):

$$
\begin{gathered}
\frac{-\pi l}{2}=-157 \\
-\frac{l}{D} \sin ^{-1} k=-0.97 \\
1-\frac{l}{D} \sin ^{-1} k=0.03 \\
L_{4}=\frac{-\pi l}{2}\left[1-\frac{l}{D} \sin ^{-1} k\right]=-5 \text { millimicrohenrys. }
\end{gathered}
$$

To compute $\mathrm{L}_{5}$ (eq $\left.2 \mathrm{f}\right)$ :

$$
L_{5}=l P=100 \times 5.33=533 \text { millimicrohenrys. }
$$

The total inductance $L_{\mathrm{h}}$ (eq 2) is:

$$
\begin{aligned}
L_{h} & =L_{0}+L_{1}+L_{2}+L_{3}+L_{4}+L_{5} \\
& =69012249 \pm 107 \text { millimicrohenrys. }
\end{aligned}
$$

\begin{tabular}{|c|c|c|}
\hline Inductor & \multicolumn{2}{|c|}{ Value of \pm term } \\
\hline $\begin{array}{l}\text { Porcelain } \\
\text { Glass__. } \\
\text { Quartz }\end{array}$ & $\begin{array}{r}\mathrm{m} \mu \mathrm{h} \\
29 \\
14 \\
107\end{array}$ & $\begin{array}{r}\text { ppm } \\
1.3 \\
0.5 \\
1.5\end{array}$ \\
\hline
\end{tabular}

The \pm term shows the difference in inductance that results from two different assumptions concerning the distribution of current in the cross section of the wire. If the current density were uniform over the cross section, the term would be negative; it would be positive if the current density varied inversely as the length of the helical filaments, the so-called natural distribution. Since there is no experimental method for determining the distribution of current, this term remains as an uncertainty in the computed inductance. Values of this term for the inductors used in this investigation are as follows:

\section{EFFECT OF IRREGULARITIES IN PITCH}

The effect of irregularities in pitch was not considered in deriving the preceding formula for the inductance of a helix. Snow ${ }^{21}$ has developed a correction to this formula which takes account of variations in pitch. In deriving this correction, the effect on the computed

\footnotetext{
a1 BS J. Resear ch 6, 777 (1931) R P304.
} 
inductance of a displacement in the axial direction was determined for any one turn and the total effect of all the variations obtained by summing the effects of the individual turns. For an individual turn, the correction produced by the displacement of the turn is equal to the change in the mutual inductances between that turn and the two end turns. In the inductors used in this investigation, irregularities in pitch occurred in a single turn. However, the correction for variation in pitch was applied by determining for each turn the average displacement in the axial direction from the position which it would occupy in a perfect helix.

The change in mutual inductance with respect to the end turns for a given displacement of the $r$ th turn is numerically the same as that of a like displacement of the symmetrical turn as numbered from the opposite end, and the two have the same sign if the displacements are measured from their respective ends. If the actual distance of the $r$ th turn (where $r \geqq n / 2$ ) from the first turn is $D_{(r)}$, the displacement $\delta_{(r)}$ is given by the equation

$$
\delta_{(r)}=D_{(r)}-g(r-1)
$$

For the $r$ th turn from the opposite end, the displacement $\delta^{\prime}{ }_{(r)}$ is given by the same equation if the numbering is from the opposite end. If the numbering is from the first end, the equation is

$$
\delta^{\prime}{ }_{(r)}=D^{\prime}{ }_{(r)}-g(n-r),
$$

where $D^{\prime}{ }_{(r)}$ is the actual distance of the turn numbered $n-r+1$ from the $n$th turn. Then the correction $\delta L$ is given by the formula

$$
\delta L=\frac{4 \pi D}{g} \sum_{r=2}^{n / 2}\left[\psi_{(r-1)}-\psi_{(n-r)}\right]\left[\delta_{(r)}+\delta^{\prime}{ }_{(r)}\right]
$$

The function $\psi_{(r)}$ is the elliptic integral function in the expression for the mutual inductance of two circles at a distance $r$ apart. The exact expression of this function is

$$
\psi_{(r)}=\frac{2}{k}(K-E)-k K
$$

where $K$ and $E$ are complete elliptic integrals of the first and second kinds, respectively, to modulus $k$, and

$$
k=\frac{D}{\sqrt{D^{2}+g^{2} r^{2}}}
$$

$D=$ the diameter of the helix.

$g=$ the pitch of the helix.

$r=$ an integer, less than half the number of turns.

The number of values of $\psi_{(r)}$ that must be computed is one less than half the number of turns on the coil, and an equal number is required for $\psi_{(n-r)}$. For long inductors, the values of $\psi_{(n-r)}$ are so small that they may be neglected except for a few hundred turns near the center of the coil. To simplify the computation of these values, the following formulas may be used, each one only in the range indicated. 


$$
\begin{array}{ll}
\psi_{(r)}=\ln D / g-0.614-\ln (r-1) & \text { Range } 2 \leqq r \leqq \frac{D}{7 g} \\
\psi_{(r)}=\ln D / g-0.614-\ln (r-1)+\frac{5.6 g}{D}(r-1) & \text { Range } \frac{D}{7 g}<r<\frac{D}{2 g}(13) \\
\psi_{(r)}=\frac{0.120 D^{2}}{g^{2} r^{2}} & \text { Range } \frac{D}{2 g}<r<\frac{2 D}{g}
\end{array}
$$

If $r>\frac{2 D}{g}$, the value of $\psi_{(r)}$ is so small that it can be neglected. Equation 12 was obtained by expanding the elliptic integrals of eq 11 ; eq 3 by applying an empirically determined correction to eq 12 ; while eq 14 is entirely empirical. For the inductors used in this investigation, the uncertainty in the measured values of $\delta_{(\tau)}$ introduced a larger uncertainty in $\delta L$ than that caused by the approximations introduced in computing $\psi_{(r)}$ by eq 12,13 , and 14 .

\section{INDUCTANCE OF LEADS AND SUBSTITUTION INDUCTOR}

The inductance of the leads to the helix was computed and added to the computed inductance of the helix to obtain the total inductance up to the point of connection to the outside circuit. Figure 10, page 14, is a diagram showing the position occupied by the two leads. They were symmetrically placed with respect to the two ends of the helix. In the diagram the three parts of the upper lead are designated as $\mathrm{PQ}, \mathrm{QR}$, and RS, with the same symbols primed for the parts of the lower lead. The self inductance of each of these parts was computed, but on account of symmetry only three different calculations were necessary. Also, the mutual inductance between each part and every other part, including the helix, was considered. There were, therefore, 21 mutual inductances. The arrangement was such that 12 of them were zero, 5 more were negligible, and 2 were identical, thus leaving only 3 different mutual inductances to be computed.

The total inductance $L$ of the helix and leads may be written:

$$
L=L_{\mathrm{h}}+2 L_{\mathrm{PQ}}+2 L_{\mathrm{QR}}+2 L_{\mathrm{RS}}+2 M_{\mathrm{QQ^{ \prime }}}-2 M_{\mathrm{Bg}}-4 M_{\mathrm{Rh}} \text {. }
$$

$L_{\mathrm{h}}=$ self inductance of helix.

$L_{\mathrm{PQ}}=$ self inductance of $\mathrm{PQ}$ ( or $\left.\mathrm{P}^{\prime} \mathrm{Q}^{\prime}\right)$.

$L_{\mathrm{QR}}=$ self inductance of $\mathrm{QR}$ (or $\mathrm{Q}^{\prime} \mathrm{R}^{\prime}$ ).

$L_{\mathrm{RS}}=$ self inductance of $\mathrm{RS}\left(\right.$ or $\mathrm{R}^{\prime} \mathrm{S}^{\prime}$ ).

$\mathrm{M}_{\mathrm{Q} \mathbf{\prime}^{\prime}}=$ mutual inductance between $\mathrm{QR}$ and $\mathrm{Q}^{\prime} \mathrm{R}^{\prime}$.

$\mathrm{M}_{\mathrm{ss}^{\prime}}=$ mutual inductance between $\mathrm{RS}$ and $\mathrm{R}^{\prime} \mathrm{S}^{\prime}$.

$\mathrm{M}_{\mathrm{Rh}}=$ mutual inductance between helix and $\mathrm{QR}$ (or $\mathrm{Q}^{\prime} \mathrm{R}^{\prime}$ ).

A formula for computing $L_{\mathrm{b}}$ has already been given. The three self inductances $L_{\mathrm{PQ}}, L_{\mathrm{QR}}$, and $L_{\mathrm{RS}}$ can all be computed by the formula for the inductance of a straight wire. A different formula is required for each of the mutual inductances. Formulas which are sufficiently accurate for the needs of this research are given below. ${ }^{22}$ In these

${ }^{22}$ Equations 16 and 17 are simplifications of more general formulas given by Rosa and Grover, Bul. BS 8, (1912) S169. Equation 18 is given in Cir. BS 74 [ed. 2] (1924). Equation 20 is a modification of Snow's eq 21 in BS J. Research 9, 426 (1932) RP479. 
formulas the logarithms are expressed as natural logarithms, abbreviated $\ln$.

The self inductance $L_{\mathrm{w}}$, in millimicrohenrys, of a straight wire of length $l_{\mathrm{w}}$ and diameter $d$ is

$$
L_{\mathrm{w}}=2 l_{\mathrm{w}}\left[\ln \frac{l_{\mathrm{w}}}{d}+0.636\right] .
$$

The mutual inductance $M_{\mathfrak{q}}$, in millimicrohenrys, between two parallel wires, each having a length $l_{\mathrm{q}}$ and a diameter $d$, the distance between them being $b$, is

$$
M_{\mathrm{q}}=2 l_{\mathrm{q}}\left[\ln \frac{l_{\mathrm{q}}}{b}-0.307+\frac{b}{l_{\mathrm{q}}}\right] .
$$

This equation should not be used if $b<5 d$.

The mutual inductance $M_{8}$, in millimicrohenrys, between two wires lying in the same line, each having a length $l_{B}$, the distance between their adjacent ends being $z$, is

$$
M_{\mathrm{B}}=\left(2 l_{\mathrm{B}}+z\right) \ln \left(2 l_{\mathrm{B}}+z\right)+z \ln z-2\left(l_{\mathrm{B}}+z\right) \ln \left(l_{\mathrm{B}}+z\right)
$$

If $z$ is zero, this equation becomes

$$
M_{\mathrm{s}}=2 l_{\mathrm{s}} \ln 2=1.39 l_{\mathrm{s}} .
$$

The mutual inductance $M_{\mathrm{rh}}$, in millimicrohenrys, between a helix of length $l$ and diameter $D$, and a wire of length $(l-b / 2)$, which is parallel to the axis of the helix and at a distance of $h+D / 2$ from the axis, and which has one end in the end plane of the helix and the other end at a distance of $b / 2$ from the central plane, is

$$
M_{\mathrm{Rh}}=(l-b) P / 2-0.638(D+h)(E / k-1)
$$

In this equation, $k, E$, and $P$ have the same meaning as in the formula for computing the inductance of a helix.

\section{EFFECT OF AN ERROR IN THE MEASURED DIMENSIONS}

The effect of an error in each of the measured dimensions can be computed from a formula which is obtained by differentiating the inductance formula with respect to each of the measured quantities. In order to transform eq 2 into a form suitable for differentiation, the mean diameter $D$ has been replaced by the difference between the outside diameter $D^{\prime}$, and the diameter of the wire $d$. Substituting in eq 2, differentiating, dividing by $L_{\mathrm{h}}$, and neglecting second-order terms

where

$$
\frac{\delta L_{\mathrm{n}}}{L_{\mathrm{h}}}=\frac{3}{y} \frac{\delta D^{\prime}}{D^{\prime}}+\left(1-\frac{3}{y}\right) \frac{\delta l}{l}-\left(\frac{3 d}{y D}+\frac{2 \pi N D}{L_{\mathrm{h}}}\right) \frac{\delta d}{d}
$$

$$
y=1+\frac{l^{2}}{D^{2}}\left(\frac{K-E}{E-k}\right)
$$

In addition to the quantities given in eq 21 , it is desirable to estimate the effect on the inductance of an error in placing the leads which are intended to be attached in an axial plane. For this pur- 
pose, eq $2 \mathrm{a}$ for the inductance can be transformed so that $L_{0}$ is a function of $D, g$, and $s$, where $s$ is the total length of wire on the inductor, by substituting the relations

Varying $s$ only,

$$
N=s / \pi D
$$$$
\text { and } l=s g / \pi D \text {. }
$$

$$
\frac{\delta L}{L}=\left(3-\frac{3}{y}\right) \frac{\delta s}{s} \text { approximately. }
$$

This treatment is not strictly correct, since it assumes a variation in $N$, whereas eq 2a was derived on the assumption that $N$ is an integer. However, when $N$ is very near an integer, the coefficients o the terms that would have to be added to make eq 2 applicable to a coil with $N$ variable are probably small. Hence eq 22 is satisfactory for estimating the effect of an error in attaching the leads.

The values of the coefficients of the differentials for the three inductors are given in table 1. This table also includes, for each of the quantities, the variation from the true value that will introduce an error of a part in a million in the computed inductance.

\begin{tabular}{|c|c|c|c|c|c|c|c|c|c|c|c|c|}
\hline \multirow{2}{*}{$\begin{array}{l}\text { Designation of } \\
\text { inductor }\end{array}$} & \multirow{2}{*}{$\begin{array}{l}\text { Num- } \\
\text { ber of } \\
\text { turns } \\
N\end{array}$} & \multirow{2}{*}{$\begin{array}{l}\text { Out- } \\
\text { side di- } \\
\text { ameter } \\
D^{\prime}\end{array}$} & \multirow{2}{*}{$\begin{array}{c}\text { Effec- } \\
\text { tive } \\
\text { length } \\
l\end{array}$} & \multirow{2}{*}{$\begin{array}{c}\text { Diame- } \\
\text { ter of } \\
\text { wire } \\
d\end{array}$} & \multirow{2}{*}{\multicolumn{2}{|c|}{$\begin{array}{c}\text { Length } \\
\text { of wire } \\
s\end{array}$}} & \multicolumn{5}{|c|}{$\begin{array}{c}\text { Approximate values of computed } \\
\text { constants - }\end{array}$} & \multirow{2}{*}{$\begin{array}{l}\text { Approxi- } \\
\text { mate } \\
\text { value of } \\
\text { induct- } \\
\text { ance } \\
L\end{array}$} \\
\hline & & & & & & & $k$ & $K$ & & $E$ & $y$ & \\
\hline $\begin{array}{l}\text { Porcelain } \\
\text { Glass_... } \\
\text { Quartz.......... }\end{array}$ & $\begin{array}{r}383 \\
263 \\
1000\end{array}$ & $\begin{array}{l}\text { cm } \\
29.09 \\
46.31 \\
28.11\end{array}$ & $\begin{array}{r}\text { cm } \\
40.9 \\
26.3 \\
100.0\end{array}$ & $\begin{array}{l}\mathrm{cm} \\
0.071 \\
0.071 \\
0.071\end{array}$ & \multicolumn{2}{|c|}{$\begin{array}{l}\mathrm{cm} \\
34920 \\
38210 \\
88090\end{array}$} & $\begin{array}{l}0.579 \\
0.872 \\
0.270\end{array}$ & $\begin{array}{l}\text { 1. } 735 \\
\text { 2. } 175 \\
\text { 1. } 600\end{array}$ & & $\begin{array}{l}430 \\
205 \\
542\end{array}$ & $\begin{array}{l}1.710 \\
1.921 \\
1.589\end{array}$ & $\begin{array}{l}\mathrm{mh} \\
22.59 \\
30.86 \\
69.01\end{array}$ \\
\hline & \multicolumn{5}{|c|}{ Coefficients in eq 21 and 22 of - } & \multicolumn{7}{|c|}{$\begin{array}{c}\text { Change in each constant which changes } L \text { by } \\
\text { a part in a million }\end{array}$} \\
\hline & $\frac{\delta 8}{s}$ & $\frac{\delta D^{\prime}}{D^{\prime}}$ & $\frac{\delta l}{l}$ & $\frac{\delta c}{d}$ & & & $\begin{array}{l}\text { ngth of } \\
\text { ire on } \\
\text { helix }\end{array}$ & $\begin{array}{l}\text { Outsid } \\
\text { diamet }\end{array}$ & & $\begin{aligned} \text { Eff } \\
\text { le }\end{aligned}$ & $\begin{array}{l}\text { etive } \\
\text { agth }\end{array}$ & $\begin{array}{l}\text { Diameter } \\
\text { of wire }\end{array}$ \\
\hline $\begin{array}{l}\text { Porcelain.... } \\
\text { Glass... } \\
\text { Quartz....... }\end{array}$ & $\begin{array}{l}\text { 1. } 26 \\
\text { 1. } 45 \\
1.12\end{array}$ & $\begin{array}{l}1.75 \\
1.56 \\
1.89\end{array}$ & $\begin{array}{l}-0.75 \\
-0.56 \\
-0.89\end{array}$ & $\begin{array}{l}-0 \\
-0 \\
-0\end{array}$ & $\begin{array}{l}.0074 \\
0094 \\
0073\end{array}$ & & $\begin{array}{l}\mathrm{mm} \\
0.28 \\
0.26 \\
0.79\end{array}$ & $\begin{array}{l}\mu \\
0 . \\
0 . \\
0 .\end{array}$ & & & $\begin{array}{l}\mu^{\mu} \\
0.54 \\
0.46 \\
1.13\end{array}$ & $\begin{array}{l}\mu .1 \\
0.08 \\
0.1\end{array}$ \\
\hline
\end{tabular}

TABLE 1.-Allowable error in the constants of the inductors

\section{EFFECT OF THE PERMEABILITY OF THE FORM}

In the derivation of the formula for the inductance of a helix, the assumption was made that the surrounding mediums had unit permeability. The principal medium was air, which has a permeability of only 3 parts in 10 million greater than that of a vacuum and thus influenced the inductance by a negligible amount. On the other hand, the permeability of any material suitable for a form on which to wind a helix may be 10 or more parts in a million different from that of a vacuum, so that its influence has to be considered. Two different methods have been employed for deriving a correction 
for the permeability of the form. These will be designated as the integration method and the reluctance method.

By the integration method, the correction, $\Delta L$, to the inductance of a helix is

where

$$
\Delta L=\pi \kappa t l(D-t)\left[H_{\mathrm{x}}{ }^{2}+H_{\mathrm{r}}{ }^{2}\right]
$$

$H_{\mathrm{x}}$ and $H_{\mathrm{r}}=$ the axial and radial components, respectively, of the magnetic intensity at a point which is distant from the outer surface by one-half the radial depth of the form and which is distant from one end by one-fourth its length.

$D=$ outside diameter of the form.

$t=$ thickness of the form.

$l=$ length of form.

$\kappa=$ volume susceptibility of the material of the form.

The values of $H_{\mathrm{x}}$ and $H_{\mathrm{r}}$ are given by the equations:

$$
\begin{aligned}
H_{\mathbf{x}} & =\frac{2 N}{l}\left\{\pi+\frac{D+2 t}{D}\left[k_{1}{ }^{\prime} K\left(k_{1}\right)+k_{2}{ }^{\prime} K\left(k_{2}\right)\right]\right. \\
- & \left.\frac{t}{D}\left[\left(k_{1}{ }^{\prime}+\frac{1}{k_{1}{ }^{\prime}}\right) E\left(k_{1}\right)+\left(k_{2}{ }^{\prime}+\frac{1}{k_{2}{ }^{\prime}}\right) E\left(k_{2}\right)\right]\right\} \\
H_{\mathrm{r}}= & \frac{2 N}{l} \sqrt{\frac{D}{D-t}}\left\{\frac{2}{k_{3}}\left[K\left(k_{3}\right)-E\left(k_{3}\right)\right]-k_{3} K\left(k_{3}\right)\right. \\
& \left.-\frac{2}{k_{4}}\left[K\left(k_{4}\right)-E\left(k_{4}\right)\right]+k_{4} K\left(k_{4}\right)\right\},
\end{aligned}
$$

where $K$ and $E$ are the complete elliptic integrals of the first and second kind, respectively, to the indicated moduli.

$$
\begin{aligned}
k_{1}^{2} & =\frac{16 D^{2}}{16 D^{2}+l^{2}} \\
k_{2}^{2} & =\frac{16 D^{2}}{16 D^{2}+9 l^{2}} \\
k_{3}^{2} & =\frac{16 D(D-t)}{4(2 D-t)^{2}+l^{2}} \\
k_{4}^{2} & =\frac{16 D(D-t)}{4(2 D-t)^{2}+9 l^{2}} \\
k_{1}^{\prime} & =\sqrt{1-k_{1}^{2}} \\
k_{2}^{\prime} & =\sqrt{1-k_{2}^{2}}
\end{aligned}
$$

Equation 23 was obtained as follows. Let $H$ denote the magnetic field at any point in space when there is unit current flowing through the solenoid and when there is no magnetic body within its field. The total electrokinetic energy $T$ and the inductance $L$ of the coil are related by the equation

so that

$$
T=1 / 2 L
$$

$$
2 T=L=\frac{1}{4 \pi} \iint_{\infty} \int H^{2} d v
$$


When there is a body present with volume susceptibility $\kappa$ then

where

$$
2 T^{\prime}=L^{\prime}=2 T+\iint_{\text {body }}(M \cdot H) d v
$$

where

$M$ is the magnetic polarization in the body.

$$
M=\kappa\left(H+H^{\prime}\right)
$$

$H^{\prime}$ is the field due to the magnetization in the body.

Hence

$$
\Delta L=L^{\prime}-L=\iint_{\text {body }} \int_{\kappa}\left(H, H+H^{\prime}\right) d v .
$$

Since $\kappa$ is small, $H^{\prime}$ is small compared to $H$ so that

$$
\Delta L=\iint_{\text {body }} \int_{k} \kappa H^{2} d v .
$$

In the present case, where the body is a cylindrical shell of outer diameter $D$, thickness $t$, and length $l$, this becomes

where

$$
\Delta L=4 \pi \kappa \int_{0}^{l / 2} d x \int_{\frac{D}{2}-t}^{D / 2} r H^{2}(x, r) d r,
$$

$x$ is the axial distance from the center of the solenoid,

$r$ is the radial distance from the axis, and

$H(x, r)$ is the value of $H$ at any point having coordinates $x, r$. When $t$ is small compared to $D / 2$, the value of $H(x, r)$ is, at any section, approximately the value at the midpoint of the shell so that

$$
\Delta L=2 \pi \kappa t(D-t) \int_{0}^{l / 2} H^{2}\left(x, \frac{D-t}{2}\right) d x .
$$

By actually plotting $H^{2}\left(x, \frac{D-t}{2}\right)$ as a function of $x$, it is found that when $t$ is small, $H_{r}{ }^{2}$ increases as $x$ goes from zero to $l / 2$ in a manner that partially compensates for the simultaneous decrease in $H_{x}{ }^{2}$ so that a straight line may be drawn which coincides with the curve at $x=l / 4$ and which does not have a materially different ordinate at any point. Integrating under this straight line instead of the curve introduces an error of about 3 percent. The integration, assuming a straight line, gives

which is equivalent to eq 23 .

$$
\Delta L=\pi \kappa t l(D-t) H^{2}\left(\frac{l}{4}, \frac{D-t}{2}\right)
$$

Equation 25 for the radial component of the magnetic field of a current sheet has previously been published. ${ }^{23}$ Equation 24 for the axial component was found from the approximation

$$
H_{x}\left(\frac{l}{4}, \frac{D}{2}-\frac{t}{2}\right)=H_{x}\left(\frac{l}{4}, \frac{D}{2}\right)-\frac{t}{2} \frac{\delta}{\delta r}\left[H_{x}\left(\frac{l}{4}, \frac{D}{2}\right)\right] .
$$

${ }^{23}$ BS J. Reserch 6, 777 (1931) RP304. The value of $\mathrm{H}_{r}$ is given by eq 8 on p. 780 . 
This equation reduces when $t=0$ to the known value of $H_{x}\left(\frac{l}{4}, \frac{D}{2}\right)$ just inside the windings.

The formula for the reluctance method was developed from a consideration of the effect of the permeability on the reluctance of the magnetic circuit of a helix. For any electric circuit in which all the lines of magnetic induction pass through every turn of the circuit, the inductance, $L_{\mu}$, is related to the reluctance, $R$, of the magnetic circuit by the equation

$$
L_{\mu}=\frac{4 \pi N^{2}}{\Re},
$$

where $N$ is the total number of turns through which the lines of magnetic induction pass. Furthermore, in a uniform medium in which the magnetic intensity is constant, the reluctance is given by the formula

$$
a=\frac{l}{\mu S},
$$

where $\mu$ is the permeability of the medium, $l$ is the length of the specimen in the direction of the magnetic intensity, and $S$ is the cross section of the specimen. Equation 29 may be directly applied to that portion of the magnetic circuit of a helix which lies within the helix since the magnetic intensity in this region may, as a first approximation, be considered uniform and having the same direction as the axis. When the magnetic circuit of this region consists of two parallel paths having permeabilities, $\mu$ and unity, and cross sections, $S_{\mu}$ and $S_{v}$, the reluctance, $Q_{\mathrm{h}}$, is

$$
a_{\mathrm{h}}=\frac{l}{S_{\mathrm{v}}+\mu S_{\mu}}
$$

The reluctance $R_{x}$ of the portion outside the helix is a constant which is added to the reluctance within the helix. If $L_{\mu}$ is the inductance of an actual helix having material which does not have unit permeability within it, and $L_{v}$ the inductance of a theoretical helix of the same dimensions in which all permeabilities are unity,

$$
L_{\mu}=\frac{4 \pi N^{2}}{\Omega_{\mathrm{h}}+\Omega_{\mathrm{x}}} \text { and } L_{\mathrm{v}}=\frac{4 \pi N^{2}}{\Omega_{\mathrm{v}}+\Omega_{\mathrm{x}}}
$$

where $R_{v}$ is the reluctance within the helix when this region has unit permeability. Eliminating $\mathfrak{R}_{\mathbf{x}}$, and rearranging,

$$
\Delta L=L_{\mu}-L_{\mathrm{v}}=\frac{L_{\mu} L_{\mathrm{v}} l}{4 \pi N^{2}} \frac{(\mu-1) S_{\mu}}{\left(S_{\mu}+S_{\mathrm{v}}\right)^{2}+(\mu-1) S_{\mu}\left(S_{\mu}+S_{\mathrm{v}}\right)} \cdot
$$

Since $(\mu-1)$ is small, the term in the denominator containing this quantity is negligible. Also, $\mu-1=4 \pi \kappa$, where $\kappa$ is the volume susceptibility of the material of the form. In the second member of the equation, $L_{v}$ may be substituted for $L_{\mu}$, since only a correction term is being evaluated. Inserting the pitch $g$ from the relationship $l=N g$,

$$
\Delta L=L_{\mu}-L_{\mathrm{v}}=\frac{\kappa g L^{2} S_{\mu}}{N S^{2}}
$$

The data required in computing the correction for the permeability of the forms for the different inductors are given in table 2, as well as the results obtained by the two formulas. 
TABLE 2.-Correction for permeability of forms

\begin{tabular}{|c|c|c|c|c|c|}
\hline Designation of inductor & $\underset{N}{\text { Number of }}$ & $\underset{g}{\text { Pitch }}$ & $\begin{array}{c}\text { Total cross } \\
\text { section } \\
S\end{array}$ & $\begin{array}{c}\text { Cross sec- } \\
\text { tion of } \\
\text { form } \\
S_{\mu}\end{array}$ & $\begin{array}{l}\text { Computed } \\
\text { induct- } \\
\text { ance }\end{array}$ \\
\hline $\begin{array}{l}\text { Porcelain } \\
\text { Glass_._. } \\
\text { Quartz. }\end{array}$ & $\begin{array}{r}383 \\
263 \\
1000\end{array}$ & $\begin{array}{l}\text { cm } \\
0.107 \\
0.100 \\
0.100\end{array}$ & $\begin{array}{r}\mathrm{cm}^{2} \\
661 \\
1678 \\
617\end{array}$ & $\begin{array}{r}\mathrm{cm}^{2} \\
205 \\
912 \\
200\end{array}$ & $\begin{array}{l}\mathrm{mh} \\
22.59 \\
30.86 \\
69.01\end{array}$ \\
\hline & \multirow{2}{*}{\multicolumn{2}{|c|}{$\begin{array}{l}\text { Volume susceptibility } \\
\text { of form }{ }^{1}\end{array}$}} & \multicolumn{3}{|c|}{$\frac{\Delta L}{L}$} \\
\hline & & & $\begin{array}{l}\text { Reluctance } \\
\text { method }\end{array}$ & $\begin{array}{l}\text { Integration } \\
\text { method }\end{array}$ & $\begin{array}{l}\text { Correction } \\
\text { actually } \\
\text { applied }\end{array}$ \\
\hline $\begin{array}{l}\text { Porcelain } \\
\text { Glass_- } \\
\text { Quartz }\end{array}$ & \multicolumn{2}{|r|}{$\begin{array}{l}+1.24 \times 10^{-6} \\
-0.86 \\
-0.76\end{array}$} & $\begin{array}{l}\text { ppm } \\
+3.7 \\
-3.3 \\
-2.8\end{array}$ & $\begin{array}{r}\text { ppm } \\
+3.5 \\
-4.3 \\
-3.1\end{array}$ & ppm $\begin{array}{r}+4 \\
-4 \\
-3\end{array}$ \\
\hline
\end{tabular}

1 The values given were obtained by Dr. Posnjak, Geophysical Laboratory of the Carnegie Institution of Washington, from sam ples furnished by the authors. The porcelain was from a sample cast and burned at the same time as the form. The glass was a sample of Pyrex glass similar to that in the form. The quartz sample was actually cut from the form.

\section{MEASUREMENT OF AN INDUCTANCE IN NBS INTER- NATIONAL ELECTRICAL UNITS}

The inductance of each of the inductors was measured in terms of the NBS international ohm and the mean solar second, giving the value in NBS international henrys. The experimental arrangement for measuring the inductance required an intermediary capacitance which was used successively in two different bridges. The first bridge was Wien's adaptation, for use with alternating current, of Maxwell's bridge for measuring an inductance in terms of capacitance and resistance; the second was a Maxwell capacitance bridge in which the capacitance was measured in terms of resistance and time. These two bridges, with the intermediary capacitors arranged to be switched from one bridge to the other, are shown in figure 11. In addition to these two bridges, a Wheatstone bridge was used for comparing resistances.

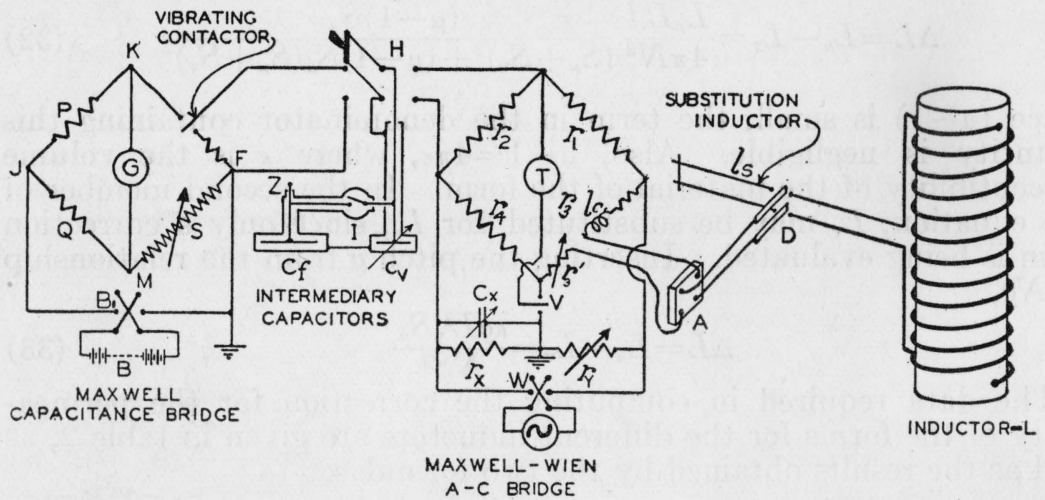

FIGURE 11.-Arrangement of the bridges used in measuring an inductance in terms of resistance and time. 
The following procedure was employed in making a determination. The switch $\mathrm{H}$ was closed to the right to connect the intermediary capacitors to the a-c bridge. With the switch D closed to the left to connect the substitution inductor $l_{\mathrm{s}}$ to the bridge, and with the shielded switch I open, an observer made a group of four balances of the a-c bridge corresponding to the four possible combinations of the positions of the reversing switches $A$ and $W$. Immediately thereafter another observer made a duplicate group of balances. Each balance was made by adjusting the resistance $r_{3}^{\prime}$ and the capacitance $C_{\mathrm{v}}$ of the bridge, and alternately the resistance $r_{\mathrm{y}}$ and capacitance $C_{\mathbf{x}}$ of the Wagner ground. The average of the eight readings of the capacitor was taken as the reading which gave the capacitance $C_{\mathrm{v}}$ required to balance the bridge when the substitution inductor was connected. The substitution inductor was then replaced by the inductor $\mathrm{L}$, by closing $\mathrm{D}$ to the right, the capacitor $\mathrm{C}_{\mathrm{f}}$ was connected by closing the switch I, and eight bridge balances were obtained similar to those for the substitution inductor. After completing the observations with the a-c bridge, the capacitances were immediately measured in a Maxwell bridge by one observer, and the resistances in a Wheatstone bridge by another observer. To connect the capacitors to the Maxwell bridge, the switch $\mathrm{H}$ was closed to the left. With the capacitors $\mathrm{C}_{t}$ and $\mathrm{C}_{\mathrm{v}}$ connected, and $\mathrm{C}_{\mathrm{v}}$ set at some division very near the average reading which had been found when balancing against the inductor in the a-c bridge, two (or more) balances were made of the Maxwell bridge corresponding to the two positions of the battery switch $B_{1}$. Each balance was accomplished by adjusting the resistance $\mathrm{S}$, with the contactor in the $\mathrm{KF}$ arm operated at a known rate by a precision alternating current from the standard-frequency generator of this Bureau. Balances were also made for two additional settings of $C_{v}$, differing from the first setting by five divisions, plus and minus, respectively, corresponding to capacitance differences of about $3 \mu \mu \mathrm{f}$ from the average. The switch I was then opened to disconnect the capacitor $\mathrm{C}_{\mathrm{t}}$, the capacitor $\mathrm{C}_{\mathrm{v}}$ set at a reading near that obtained in the a-c bridge when measuring the substitution inductor, and a group of observations made similar to those obtained when $\mathrm{C}_{t}$ was connected. At the same time, a second observer compared the resistances $r_{1}$ and $r_{4}$ with the standards of this Bureau. When the measurements with the Maxwell bridge were completed, the resistances of that bridge were indirectly compared with the same standards by a method which will be described later. The data obtained by this procedure are used to obtain the value of the inductance in international henrys.

\section{MAXWELL-WIEN ALTERNATING-CURRENT BRIDGE}

The alternating-current bridge, as shown diagrammatically in figure 11, had four arms in the bridge proper and, in addition, a Wagner ground. Two of the arms consisted of the noninductive resistances $r_{1}$ and $r_{4}$, a third arm was a similar resistance, $r_{2}$, shunted by the capacitances $C_{t}$ and $C_{v}$, and the fourth arm, having a total resistance $r_{3}$, contained the inductance to be measured, an auxiliary inductance, $l_{\mathrm{a}}$, and a variable resistance $r_{3}{ }^{\prime}$. The Wagner ground 
approximately duplicated arms $\mathbf{r}_{1}$ and $\mathbf{r}_{2}$. The procedure for balancing the bridge and adjusting the Wagner ground has already been described.

A set of observations on the a-c bridge consisted, as already stated, in making four readings of $\mathrm{C}_{\mathrm{v}}$ with the helix and the capacitor $\mathrm{C}_{t}$ connected in the bridge, and a like number with the substitution inductor connected and the capacitor $\mathrm{C}_{\mathrm{t}}$ disconnected. The four readings with the helix in the measuring circuit were made by reversing $\mathrm{W}$ for each of the two positions of $\mathrm{A}$. The reversal of $\mathrm{W}$ eliminated the effect of electromotive forces induced in any part of the bridge by currents of the measuring frequency which existed in outside circuits; the reversal of A eliminated the effect of the mutual inductance between the helix (or substitution inductor) and the remainder of the bridge. The average value of the capacitance for the four bridge balances when measuring the helix $\mathrm{L}$ was the major capacitance required and hence was designated as $\mathbf{C}$. The average value of the four readings required to balance the bridge when measuring the substitution inductor $l_{\mathrm{s}}$ was the minor capacitance required and hence was designated as $c$.

\section{(a) BRIDGE RESISTORS}

The important characteristics of a resistor for use in the a-c bridge are that its effective inductance is small and that its a-c resistance is

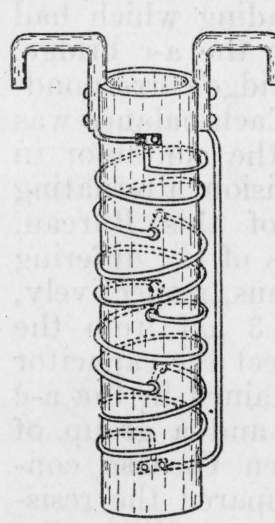
the same as its $\mathrm{d}-\mathrm{c}$ resistance. The first condition is fulfilled by many of the windings employed for standard resistors. The fulfillment of the second condition requires very special construction. ${ }^{25}$ In this investigation reliance has been placed on coils of bare manganin wire wound on tubes of Pyrex glass. The tube for a resistor was threaded in sections of 12 turns each, the sections having alternately right-handed and lefthanded threads.

Beginning at one end, 12 turns of right-handed screw thread were cut, then starting diametrically opposite to the end of the last thread, 12 turns of left-handed thread were cut. At the end of the right-handed thread, and at the beginning of the left-handed thread, holes were bored through the

Figure 12.-Method tube. In constructing a coil, the first section is of winding a-c re- wound, then the wire passed diametrically through manganin wire on Pyrex-glass tubes.

Sketch shows a coil of 4 the holes in the tube to start the second section, etc. In figure 12 is shown a diagram of the method of winding, illustrated by 4 sections of sections of 2 turns each. Actual coils were wound in 12 sections of 12 turns each glass tube. 2 turns each. The computed inductance of one of these resistors, which had 12 sections of 12 turns each, was about $60 \mu \mathrm{h}$. The terminals were suitable for connecting to mercury cups so that the resistors could be easily inserted or removed from the bridge.

The resistors were completely immersed in oil to keep them at a definite temperature. During the first part of this investigation, the

$25 \mathrm{It}$ was found that the a-c resistance of coils depends on the moisture content of the material used to insulate the wires. Presumably this resulted from the increased dielectric loss in the insulation (porcelain, isolantite, silk, cotton, etc.,) when the moisture content was high. Pyrex glass has low dielectric loss and does not absorb moisture, so was chosen as the material for the form. Grüneisen and Giebe observed the effect of dielectric loss on the a-c resistance, and constructed resistors in which very little solid insulating material was used. (See reference in footnote 7.) 
oil was maintained above room temperature by a thermostatically controlled heating coil and was stirred by a metal propeller, which was directly connected to a small electric motor. However, the temperature coefficients of the resistances in the a-c bridge were so small that a precise regulation of temperature was not necessary, and the sudden variations of current in the heating and stirring circuits produced transient effects in the bridge which were an annoyance to the operator. For this reason, the heating coil was completely removed on April 1, 1933, and the stirring was produced by a wooden propeller, which was connected by a belt to a motor placed about a meter from the bath. This arrangement greatly facilitated the measurements, but did not change the results obtained.

The mercury resistor $r_{3}^{\prime}$, which was used in adjusting the resistance balance, allowed a continuous change in resistance from 0.01 to 0.12 $\mathrm{ohm}$. Its construction is shown in a diagram in figure 13. Two straight glass tubes having a length of about $25 \mathrm{~cm}$ and an internal diameter of about 0.18 and $0.6 \mathrm{~cm}$, respectively, were mounted vertically side by side. The tubes were joined at the bottom and each tube had a large reservoir at the top. The tubes and a portion of the reservoirs were filled with mercury. Copper wires extended from the binding posts of the resistor to points within the mercury in the reservoirs so that current could flow from one binding post to the other through the mercury. Copper wires or tubes were arranged so that they could be lowered into the mercury. The resistivity of copper is only $1 / 50$ of that of mercury, so that nearly all of the current in the length occupied by the copper flowed through it. The total change in resistance, when the slider of the major scale (which indicated the position of the smaller wire) was moved from top to bottom, was about $0.1 \mathrm{ohm}$, and for a like movement of the slider of the vernier scale was $0.01 \mathrm{ohm}$.

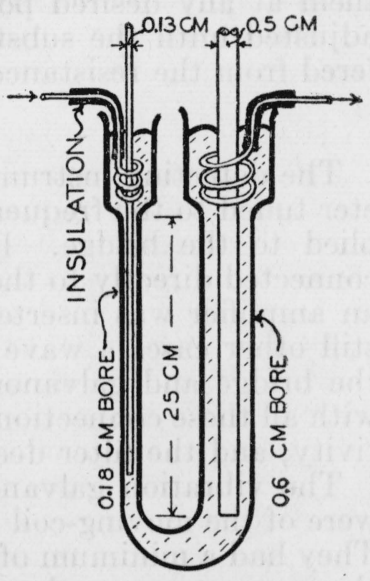
the slider of the vernier scale was 0.01 ohm. Adjustments could be made to about $1 / 4 \mathrm{~mm}$ of the vernier scale, which corresponded to about 10 microhms. The computed change in the inductance of this resistor corresponding to a maximum change in resistance was about $25 \mathrm{~m} \mu \mathrm{h}$. Since the change in resistance was always less than one-half of the maximum possible change, no correction was required for the change in inductance of this resistor as the maximum possible change in inductance was less than one-millionth of that of any of the helices measured.

\section{(b) CAPACITORS}

The capacitor $\mathrm{C}_{\mathrm{f}}$ was a group of air capacitors of fixed value consisting of 20 units, each having a nominal value of $0.01 \mu f$, and two units of $0.03 \mu \mathrm{f}$ each. The units were connected by shielded leads to a central switch I, which operated within the shield. The solid insulation for each unit of the capacitor was three fused-quartz pillars, each about a centimeter in diameter and $3 \mathrm{~cm}$ long. The insulation of the leads to the central switch was amber and fused quartz. The 
effect of the solid insulation on the measured capacitance was so small that it could not be detected by very careful measurements.

The variable capacitor $\mathrm{C}_{\mathrm{v}}$ was a modified commercial instrument, by means of which readings could be made closer than $0.1 \mu \mu \mathrm{f}$.

\section{(c) AUXILIARY AND SUBSTITUTION INDUCTORS}

An auxiliary inductor $l_{\mathrm{a}}$ was inserted in the inductance arm of the a-c bridge to insure that the bridge could be balanced when measuring the substitution inductor $l_{8}$. The several inductors which were used as $\mathrm{l}_{\mathrm{a}}$ had values between 0.1 and $0.5 \mathrm{mh}$, depending upon the requirements of the bridge from time to time, and were in the form of small toroids. This form was chosen so that the mutual inductance between $\mathrm{L}$ and $\mathrm{l}_{\mathrm{a}}$ would be small.

The substitution inductor $l_{\mathrm{a}}$ consisted of two parallel wires, $1 \mathrm{~cm}$ apart, with an adjustable clamp carrying a small wire for bridging them at any desired point. The position of the bridging wire was adjusted until the substitution inductor had a resistance which differed from the resistance of the inductor by less than $0.05 \mathrm{ohm}$.

\section{(d) DETECTORS}

The detecting instrument $T$ was in all cases a vibration galvanometer tuned to the frequency of the alternating current which was supplied to the bridge. In some experiments the galvanometer was connected directly to the bridge as shown in figure 11; in other cases an amplifier was inserted between the bridge and galvanometer; in still other cases a wave filter and amplifier were connected between the bridge and galvanometer. The results obtained were the same with all these connections; however, the amplifier increased the sensitivity, and the filter decreased the difficulty of making adjustments.

The vibration galvanometers, for frequencies of $100 \mathrm{c} / \mathrm{s}$ and less, were of the moving-coil type, especially constructed for this research. They had a minimum of damping so that the sensitivity was high and the resonance very sharp. The magnets were of tungsten steel, with soft-iron pole pieces. The coils contained about 100 turns of enameled copper wire (diameter 0.04 or $0.08 \mathrm{~mm}$ ). In each instrument, the coil hung from a bifilar suspension, and a single wire extended from the bottom of the coil to a stretched spring attached to the lower binding post. The vibration galvanometer used for $1000 \mathrm{c} / \mathrm{s}$ was a moving-magnet instrument of the Wien type.

The amplifier used in this research was loaned by the American Transformer Co. It was a two-tube amplifier with resistance coupling between tubes, and had both an input and an output transformer so that the impedance of the amplifier was matched with the apparatus to which it was connected. The magnetic shielding of the transformers was nearly perfect and the entire amplifier, including batteries, was electrostatically shielded.

The wave filter was of the electromechanical type of band-pass filter, especially constructed by the Bell Telephone Laboratories, Inc., and loaned for this work. The insertion loss was about 2 decibels between 22 and $27 \mathrm{c} / \mathrm{s}$, but increased so rapidly for frequencies above or below these limits that at 20 and $29 \mathrm{c} / \mathrm{s}$ it was 20 decibels. Stated differently, at any frequency between 22 and $27 \mathrm{c} / \mathrm{s} 63$ percent of the power input would be transmitted to the power-output circuit, while at either 20 or $29 \mathrm{c} / \mathrm{s}$ only 1 percent would be transmitted. At 
$60 \mathrm{c} / \mathrm{s}$, the extrapolated curve indicates 200 decibels, so that only $10^{-20}$ of the input power was transmitted.

\section{(e) BRIDGE EQUATIONS}

The equations for the Maxwell-Wien a-c bridge were developed for the general case of sinusoidal currents with the bridge balanced at every instant. Each of the resistors was assumed to have a residual inductance, so that the impedances of the resistors were represented as $r_{1}+j \omega l_{1}, r_{2}+j \omega l_{2}$, etc. The impedance $c_{2}$ of the capacitor in parallel with $r_{2}$ was $-j / \omega c_{2}$, so that the impedance $z_{2}$ of the arm which contained the capacitance was given by the equation

$$
z_{2}=\frac{r_{2}+j \omega l_{2}}{1-\omega^{2} l_{2} c_{2}+j \omega r_{2} c_{2}}
$$

The impedance $z_{3}$ of the arm containing the inductance was represented as

$$
z_{3}=r_{3}+j \omega l_{3},
$$

where $r_{3}$ and $l_{3}$ were the total resistance and inductance, respectively, of this arm. Since, in a balanced bridge

$$
\begin{aligned}
z_{1} z_{4} & =z_{2} z_{3} \\
\left(r_{1}+j \omega l_{1}\right)\left(r_{4}+j \omega l_{4}\right) & =\frac{\left(r_{2}+j \omega l_{2}\right)\left(r_{3}+j \omega l_{3}\right)}{1-\omega^{2} l_{2} c_{2}+j \omega c_{2} r_{2}}
\end{aligned}
$$

An equation for the inductance was obtained from the imaginary part of this equation. Solving

$$
l_{3}=c_{2} r_{1} r_{4}+\frac{\left(r_{1} l_{4}+r_{4} l_{1}-r_{3} l_{2}\right)}{r_{2}}-\frac{\omega^{2} c_{2}\left(r_{1} l_{2} l_{4}+r_{4} l_{1} l_{2}+r_{2} l_{1} l_{4}\right)}{r_{2}}
$$

When the helix was in the bridge, $c_{2}=C, l_{3}=L+l_{\mathrm{a}}$, and $r_{3}=r_{3}^{\prime \prime}+\bar{r}_{3}{ }^{\prime}$ where $L$ was the inductance of the helix and $l_{\mathrm{a}}$ was the remaining inductance in that arm. When the substitution inductor was in the bridge, $c_{2}=c, l_{3}=l_{\mathrm{a}}+l_{\mathrm{a}}$, and $r_{3}=r_{3}^{\prime \prime}+\overline{\bar{r}}_{3}{ }^{\prime}$, it being assumed that $l_{\mathrm{a}}$ was not affected by this change in $r_{3}$. Substituting the two values of $l_{3}$ (and corresponding values of $c_{2}$ and $r_{3}$ ) in eq 38, and subtracting the resulting equations, the following was obtained:

$$
L-l_{\mathrm{s}}=(C-c) r_{1} r_{4}-\frac{\left(\bar{r}_{3}^{\prime}-\overline{\bar{r}}_{3}^{\prime}\right) l_{2}}{r_{2}}-\frac{\omega^{2}(C-c)}{r_{2}}\left(r_{1} l_{2} l_{4}+r_{4} l_{1} l_{2}+r_{2} l_{1} l_{4}\right)
$$

With the low frequencies used in this investigation, the term in $\omega^{2}$ is negligible. The value of $l_{2}$ was of the order of $60 \mu \mathrm{h}, \bar{r}_{3}{ }^{\prime}-\overline{\bar{r}}_{3}{ }^{\prime}$ about $0.05 \mathrm{ohm}$, and $r_{2}$ at least $500 \mathrm{ohms}$. Hence, $\frac{\left(\bar{r}_{3}{ }^{\prime}-\overline{\bar{r}}_{3}{ }^{\prime}\right) l_{2}}{r_{2}}$ was never greater than $6 \mathrm{~m} \mu \mathrm{h}$, which was a negligible quantity. 
In the derivation of eq 39 the assumption was made that the helix had only inductance and resistance. A more complete formula was obtained by assuming that the helix was electrically equivalent to an inductance $L$, in series with a resistance $R$, the two being shunted by a small capacitance $K$. Then the effective inductance $L^{\prime}$, is given by the equation

$$
\begin{aligned}
L^{\prime} & =\frac{L-K R^{2}-\omega^{2} K L^{2}}{1-\omega^{2} K\left(2 L-K R^{2}\right)+\omega^{4} K^{2} L^{2}} \\
& =L\left(1-\frac{K R^{2}}{L}\right)\left(1+\omega^{2} K L\right) \text { approximately }
\end{aligned}
$$

The value of $K$ was certainly less than $20 \mu \mu$ for each of the inductors. Using this value, the term $K R^{2} / L$ was less than $4 \times 10^{-7}$ for each of the inductors and hence was negligible. The term in $\omega^{2} K L$ had, for the largest inductance, a value of less than $10^{-6}$ when the frequency was less than $125 \mathrm{c} / \mathrm{s}$. Hence, for frequencies less than $125 \mathrm{c} / \mathrm{s}$, the distributed capacitance of the inductors did not influence their measured inductances by an appreciable amount.

\section{(f) ALTERNATING-CURRENT POWER SUPPLY}

The primary requirement of the a-c source of power was that the frequency should remain so constant that the vibration galvanometer would always be at its maximum sensitivity. The commercial supply of Washington was satisfactory for both 25 and $60 \mathrm{c} / \mathrm{s}$. While the work was in progress, the commercial supply of $25 \mathrm{c} / \mathrm{s}$ was discontinued at this Bureau, and an equivalent supply of $24 \mathrm{c} / \mathrm{s}$ was provided to replace it. The source of the $100 \mathrm{c} / \mathrm{s}$ was a small motor-generator set located in the laboratory and controlled by a tuning fork. The source of the $1000 \mathrm{c} / \mathrm{s}$ was a motor-generator set located in the dynamo room and hand controlled by means of a rheostat located in the laboratory, the operator being guided by a frequency meter graduated to read to $1 \mathrm{c} / \mathrm{s}$ in $1000 \mathrm{c} / \mathrm{s}$. With each frequency, the harmonics in the current were so small that they did not produce a measurable deflection of the vibration galvanometer.

\section{(g) EFFECT OF MAGNETIC MATERIAL IN THE NEIGHBORHOOD OF THE INDUCTORS}

Magnetic material in the neighborhood of the inductors produced, in some cases, a small effect on the measured inductance. All the cabinets and tables were carefully explored, using a special coil connected to the a-c bridge, and found to be free from magnetic materials. The magnetic materials in the walls of the room had no effect on the inductance of any of the inductors when they were located in the positions selected for making the electrical measurements. To show that the selected positions were satisfactory, a survey was made of room 212, East Building (R212 E), which was known to have more iron in the south wall than was present in any other wall of the rooms used. For the survey, the glass inductor was selected, since its inductance 
was affected more by outside magnetic materials than either of the other inductors. It was placed at an elevation of $150 \mathrm{~cm}$ from the floor with its axis vertical and its inductance measured at different distances from the side walls. The survey showed that there was one position, which was with the center of the inductor at $50 \mathrm{~cm}$ from the south wall, at which there was an increase of 200 parts in a million in the measured inductance, but there was a large region in the center of the room where the change in the measured inductance was less than a part in a million. The electrical measurements were made with the inductors so near the centers of the rooms that they could have been moved a meter in any horizontal direction without affecting their inductance by a part in a million.

The steel reinforcing rods in the floors and ceilings, and in some cases the nails in the floors, had a measurable effect on the inductance, which depended on the elevation of the inductor in the room. Measurements were made in rooms with two different kinds of reinforcement. In one (R212 E) the reinforcing rods in the floor and ceiling were made from ordinary steel. In the others (R213 E and R214 E) the reinforcing rods in the ceiling were made of ordinary steel, but those in the floor were of an alloy steel containing about 12 percent of manganese. This manganese steel is practically nonmagnetic, having a permeability of about 1.2 . The reinforcing rods were about $25 \mathrm{~cm}$ below the floor, and $5 \mathrm{~cm}$ above the ceiling. In all rooms, iron nails were used in the floor.

Soon after the investigation was started, the porcelain inductor was measured with two cast-iron plates, $46 \mathrm{~cm}$ in diameter and $1.5 \mathrm{~cm}$ thick, placed under it on the floor. At that time the effect of these plates was not measurable if the inductor were on a table $80 \mathrm{~cm}$ high, so it was concluded that the steel reinforcing rods did not affect the measured inductance. Later, when the bridge sensitivity had been increased, the effect of the reinforcing rods was suspected because the results by the glass and quartz inductors did not agree. The effect was first definitely established when measurements were made with the axis of the glass inductor changed from a vertical to a horizontal position, resulting in a decrease in inductance of about 10 parts in a million. To determine if this change in inductance could be explained by the effect of the reinforcing rods, they were simulated by a large sheet of iron ( 240 by 60 by $0.08 \mathrm{~cm}$ ) which was placed in two positions relative to the inductor. When the sheet was $120 \mathrm{~cm}$ from the inductor and was placed so that a perpendicular erected at its center passed through the center of the inductor, with the longest dimension of the sheet in the direction of the axis, the inductance was increased by about 7 parts in a million. When the sheet was at the same distance from the center and the axis of the inductor perpendicular to the center of the sheet, the increase was about 14 parts in a million. Hence the difference in inductance between the horizontal and vertical positions could be qualitatively explained by the steel reinforcing rods.

As a further study of the effect of the reinforcing rods and of the nails of the floor, measurements were made on all three inductors, with their axes vertical, at different elevations in a room having 
manganese steel reinforcement in the floor (either R213 E or R214 E). The results of these measurements are plotted in figure 14 . The

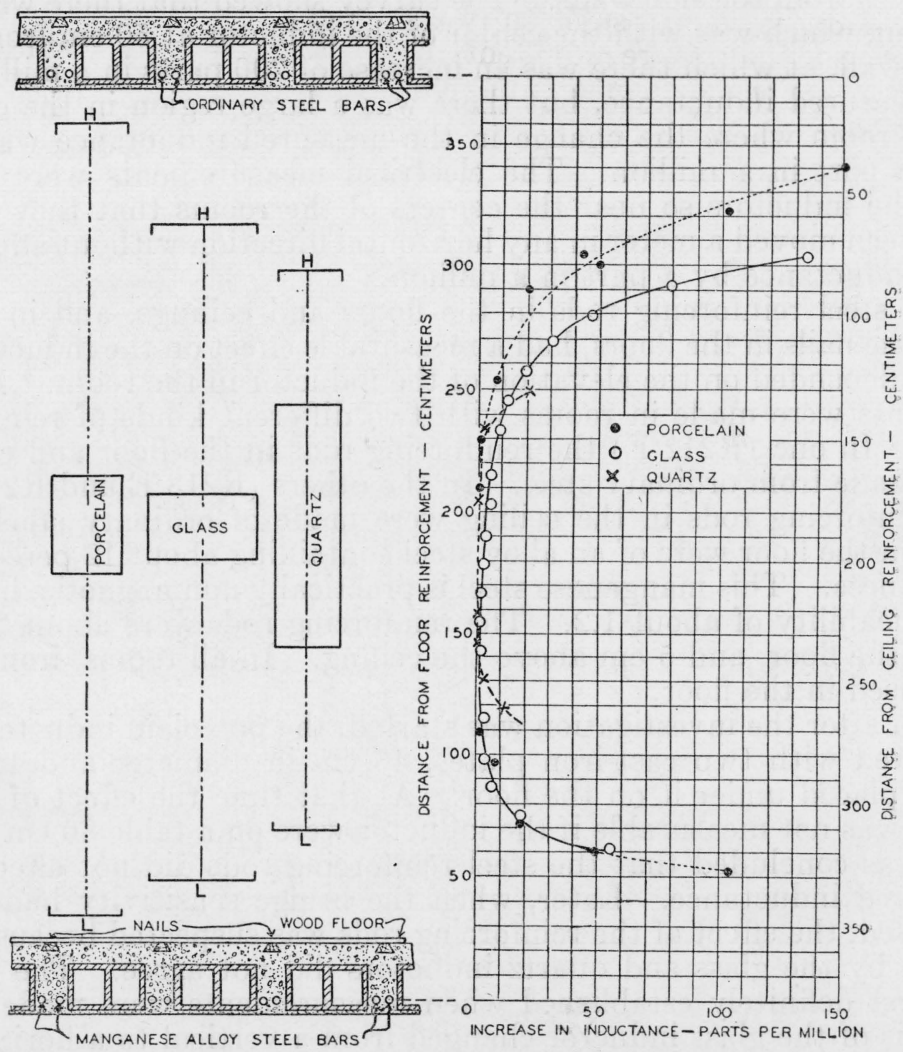

FIGURE 14.-Effect of the reinforcement of the building on the inductance of each of the three inductors at various distances from the reinforcement in a room having manganese-steel reinforcement in the floor.

Measurements on the glass inductor were made in R213 E; on the quartz and porcelain inductors, in R214 E. The extreme positions of the ends of the windings are represented by $H$ and $L$. The axes of all the coils were vertical.

porcelain inductor was measured through the greatest range of clevation, but its temperature was not controlled, so that the individual points do not all lie on the smooth curve which has been drawn. The glass inductor was also measured at a wide range of elevations, but the measurements on the quartz inductor extended only through a range that would clearly indicate the effects from both floor and ceiling.

All the curves are asymmetrical with respect to the plane midway between the reinforcement of the floor and ceiling. The curves of the porcelain and glass inductors have a much greater curvature for the lower part than for the upper part. This is qualitatively explained by assuming that the increase in inductance shown on the lower part of the curves results solely from the nails in the floor. The effect of these nails falls off more rapidly with distance than the effect of 
the steel reinforcing rods, giving this greater curvature. Also, the amount of magnetic material in the fioor is much less than in the ceiling so that, at a given distance from the floor, the effect is much less than at the same distance from the ceiling. The curve of the quartz inductor is not sufficiently extended at the ends to make this difference in curvature apparent, but there is a long distance (60 $\mathrm{cm}$ ) in which the change in inductance is less than 2 parts in a million and this distance is asymmetric with respect to the midplanes. Hence, the upper parts of the curves were judged to be influenced by the ceiling rods only.

To determine whether the observed increase in inductance, when the inductors were near the floor, resulted solely from the nails in the floor, an exploring coil was used consisting of 350 turns of wire in a square section, the mean diameter being $22 \mathrm{~cm}$; and having an inductance of about $55 \mathrm{mh}$. This coil was attached to the bridge by a long pair of twisted leads. When it was moved along the floor, at a distance of $5 \mathrm{~cm}$ above the floor, definite lines were found at $40-\mathrm{cm}$ intervals where the inductance was $700 \mathrm{parts}$ in a million larger than at intermediate positions, but at a height of $27 \mathrm{~cm}$ from the floor no maximum or minimum effect could be observed. These lines might have resulted either from the reinforcing rods or from rows of nails such as exist in the floor since the wooden strips into which the nails were driven were directly above the reinforcing rods. The exploring coil was then mounted so that it could be moved along the ceiling below this floor, where it was brought within 12 $\mathrm{cm}$ of the reinforcing rods of manganese steel, but at a distance of about $32 \mathrm{~cm}$ from the nails of the floor above. The change in inductance as the coil was moved along the ceiling was less than the accuracy of measurement ( 1 or 2 parts in a million), thus showing that the rods were nonmagnetic. When the coil was moved along at the same distance beneath a ceiling reinforced with ordinary steel rods, variations of inductance of 2000 parts in a million were found.

To further insure that the observed effects near the floors having manganese-steel reinforcement resulted from the nails only, strips were prepared in which were set nails that were similar in size and spacing to those used in the floor. When these strips were placed on the floor, underneath the quartz inductor, the center of which was $160 \mathrm{~cm}$ from the floor, there was no measurable effect on the inductance. When the strips were raised so that the nails were about $85 \mathrm{~cm}$ from the center of this inductor, the observed increase in inductance was 24 parts in a million. This same increase would have been obtained if the inductor had been at the same distance from the nails of the floor, as can be seen by extrapolating the curve for this inductor in figure 14 .

The above measurements demonstrate that the increase in inductance shown in the lower part of the curves in figure 14 resulted entirely from the nails in the floor. The effect of these nails decreased rapidly as the inductors were elevated. Hence the upper parts of the curves were employed to determine the effect of the steel reinforcing rods. 


\section{MAXWELL CAPACITANCE BRIDGE}

The capacitance used in the alternating-current bridge was measured in terms of resistance and time by means of the Maxwell bridge for the aboslute measurement of capacitance. This bridge has recently been described ${ }^{26}$ so that only the basic principles and recent modifications will be considered.

A diagram of the bridge is contained in figure 11. The capacitors were connected to the Maxwell bridge by closing switch $\mathrm{H}$ to the left. With the contactor in the KF arm vibrating and the battery switch closed, the capacitance was charged and discharged, a part of the charging current passing through the galvanometer in the direction, say, from $\mathrm{M}$ to $\mathrm{K}$. However, there was a continuous current flowing through the galvanometer from $\mathrm{K}$ to $\mathrm{M}$. The bridge was balanced by adjusting the resistance $S$ until the integral value of these two currents was zero. If the number of charges and discharges per second be represented by $n$ and the resistances of the arms by $P, Q, S, G$, and $B$, as shown on the diagram, the equation for the capacitance $C$ is

where

$$
C=\frac{Q F}{n P S}
$$

$$
F=1-\frac{Q^{2}}{(Q+P+G)(S+Q+B)}-\frac{Q G}{S(Q+P+G)}-\frac{Q B}{P(S+Q+B)}
$$

(a) CORRECTION FACTOR

The correction factor $F$ can be made to approach unity by making $Q, G$, and $B$ small, and either $P$ or $S$ large. In practice, $P$ was generally made equal to $Q$ so that $S$ was the only large resistance. In a typical experiment, $P=Q=100 \mathrm{ohms}, S=40000 \mathrm{ohms}, G=10 \mathrm{ohms}$, and $B=1 \mathrm{ohm}$. Substituting these values:

$$
F=1-(1188+119+25) 10^{-6}=0.998668 .
$$

An uncertainty in the value of $F$ resulted from uncertainties in the values of $G$ and $B$. The equation for computing the effect of these uncertainties on the value of $F$ was obtained by differentiating eq 43 with respect to $G$ and $B$. By assuming that $S$ is so large that $S+Q+B \approx S$ and that terms with $S^{2}$ in the denominator can be neglected, the differential becomes

$$
\delta F=-\frac{Q P}{S(Q+P+G)^{2}} \delta G-\frac{Q}{P S} \delta B
$$

Then, if $P=Q$ and $Q+P+G$ approximates $2 Q$,

$$
\delta F=-(\delta G / 4+\delta B) / S .
$$

But when $P=Q, C=F / n S$. Since for this purpose $F$ may be taken as unity,

$$
\delta F=-n C(\delta G / 4+\delta B) .
$$

${ }^{26}$ Curtis and Moon, Absolute measurement of capacitance ty Maxwell's method. BS Sci. Pap. 22, 487 (1927) S564; also Yoneda and Yamaguchi, Absolute measurement of capacity by Maxwell's bridge method. Researches of Electrotechnical Laboratory, Tokyo, no, 355 (1933). 
In the most unfavorable arrangement in this experimental work, $n C=25 \times 10^{-6}$, so that $(\delta G / 4+\delta B)$ must not be greater than 0.04 ohm if $\delta F$ is to be less than $10^{-6}$. Allowing one-half of the permissible error for the galvanometer, and the same for the battery, the uncertainty in $G$ must be less than $0.08 \mathrm{ohm}$ and in $B$ less than 0.02 ohm. Two galvanometers have been used; one had 5 about ohms resistance, and the other about $10 \mathrm{ohms}$. Both had copper coils and suspensions so that the allowable variation in resistance was not exceeded when the temperature was kept constant within $\pm 1^{\circ} \mathrm{C}$. In order to keep the uncertainty in $B$ below $0.02 \mathrm{ohm}$, a lead storage battery of large size was employed. The total battery resistance, including the battery connections, as well as the resistance of the electrolyte, was less than $0.02 \mathrm{ohm}$. The resistance of the copper leads from the bridge to the battery was about $0.5 \mathrm{ohm}$, so that a temperature change of $10^{\circ} \mathrm{C}$ produced a change of only a part in a million in $F$.

\section{(b) CALIBRATION OF THE BRIDGE}

The calibration of the Maxwell bridge was accomplished by converting it into a Wheatstone bridge by substituting ${ }^{27}$ for the contactor and capacitor a calibrating resistor $R_{\mathrm{c}}$ having an accurately known resistance approximately equal to $P S / Q$. The bridge was balanced by adjusting $S$, care being exercised to avoid making any changes in the large-valued dials. The value of $S$ in NBS international ohms, when the bridge was balanced with $R_{\mathrm{c}}$ in the place of the capacitance, was represented as $S_{\mathrm{c}}$, while the reading of $S$ under the same condition was represented as $S_{\mathrm{c}}{ }^{\prime}$. The corresponding values, when the capacitance was measured, were $S$ and $S^{\prime}$. Subtracting $\frac{P S}{Q}$ from each member of the Wheatstone-bridge equation; viz

$$
R_{\mathrm{c}}=\frac{P S_{\mathrm{o}}}{Q}
$$

there resulted the equation

$$
R_{\mathrm{c}}-\frac{P S}{Q}=\frac{\left(S_{\mathrm{c}}-S\right) P}{Q}
$$

Since $S_{\mathrm{c}}-S$ is small, the nominal values of $P$ and $Q$ were sufficiently accurate for use in this equation. Also, the difference in the readings of $\mathrm{S}$ was substituted for the difference in its values. Substituting and rearranging

$$
\frac{P S}{Q}=R_{\mathrm{c}}-\frac{P S_{\mathrm{c}}^{\prime}}{Q}+\frac{P S^{\prime}}{Q}=\Delta+\frac{P S^{\prime}}{Q}
$$

where

$$
\Delta=R_{\mathrm{c}}-\frac{P S_{\mathrm{o}}^{\prime}}{Q}
$$

${ }^{27}$ Suggested by Rosa and Grover. Bul. BS 1, 153 (1905) S10. 
Substituting in the equation for the capacitance

$$
C=\frac{F}{n} \frac{1}{\frac{P S^{\prime}}{Q}+\Delta}
$$

where $P$ and $Q$ were the nominal values of the ratio arms, and $S^{\prime \prime}$ was the reading of $\mathrm{S}$ when the capacitance was measured.

In this investigation, the most commonly used values of $R_{c}$ were $40000 \mathrm{ohms}$ and $100000 \mathrm{ohms}$. The calibrating resistor of 40000 ohms consisted of twenty 2000 -ohm coils that could readily be connected either in parallel or in series by a convenient switching device. These coils were so adjusted that the maximum difference in resistance of any coil from the mean of all the coils was less than 0.1 percent of the mean value, so that the resistance when connected in series was equal to 400 times the resistance when connected in parallel, with an error of less than a part in a million.

In every measurement of a capacitance of $0.25 \mu \mathrm{f}$ this resistor with the coils in series was used for the calibration of the Maxwell bridge. Immediately thereafter the coils were connected in parallel, and the parallel resistance of $100 \mathrm{ohms}$ was compared with a $100-\mathrm{ohm}$ standard. Two calibrating resistors of $100000 \mathrm{ohms}$ were available, each having 10 coils of $10000 \mathrm{ohms}$ each. The coils of each resistor could be connected either in parallel or in series.

In every determination of a capacitance of $0.1 \mu \mathrm{f}$ one or both of these resistors were used to calibrate the Maxwell bridge. The insulation of the coils of one of these resistors was better than that of the other, but when both were used, no difference in result was obtained, so that the insulation of the poorer resistor was sufficiently high.

\section{(c) GALVANOMETERS}

Two special galvanometers were constructed, having cobalt-steel magnets of such form ${ }^{28}$ that the current in the coil produced a minimum effect on the magnetic flux of the magnet. One galvanometer had a 10-ohm coil which was wound on a wooden form. The other had a 5-ohm coil wound on a form made of silk thread impregnated with shellac. The constants of the galvanometers are given in table 3 .

TABLE 3.-Constants of the galvanometers used in the Maxwell bridge

\begin{tabular}{l|r|r}
\hline \multicolumn{1}{c}{ Constant } & \multicolumn{2}{c}{ Galvanometer } \\
\cline { 2 - 3 } & BS no. 35000 & BS no. 39538 \\
\hline $\begin{array}{l}\text { Resistance at } 25^{\circ} \text { C. } \\
\text { External critical-damping resistance }\end{array}$ & 9.31 & $\begin{array}{r}5.53 \\
140 \pm 10 \\
10\end{array}$ \\
\hline
\end{tabular}

(d) APPARATUS FOR CHARGING AND DISCHARGING THE CAPACITORS

The apparatus for charging and discharging the capacitors had its frequency controlled by a tuning fork. In the earlier work, the frequency of the tuning fork was determined during the course of each

${ }^{28}$ For method of construction see p. 509 and 510 of paper by Curtis and Moon. BS Sci. Pap. 22, 487 (1927). 
measurement by comparison with a pendulum ${ }^{29}$ which was at the same time compared with the standard pendulum clock of this Bureau. Later there was installed at this Bureau a standardfrequency generator ${ }^{30}$ which was controlled by a piezoelectric oscillator from which could be obtained an alternating current having a frequency which never varied from $100 \mathrm{c} / \mathrm{s}$ by as much as a part in a million. This frequency was used to drive a tuning fork which had a free period that was very nearly 0.01 second. As the fork was forced to vibrate at exactly the impressed frequency, no calibration was necessary. The use of the standard frequency greatly reduced the labor of making a determination.

During the earlier work the capacitor was charged and discharged through mercury cups $^{31}$ by means of platinum wires attached to the prongs of the tuning fork. When using these mercury contacts, there was sometimes a slight unsteadiness of the galvanometer. These mercury contacts were more difficult to maintain than those developed later.

A Burgess vacuum contactor and a modification of it, developed during this investigation, have been employed in some of the later determinations. Two of the modified contactors mounted for operation by a tuning fork are shown in figure 15. Each of these consisted of an evacuated glass tube with two tungsten wires of different lengths sealed in one end, and with the opposite end closed by a reen-

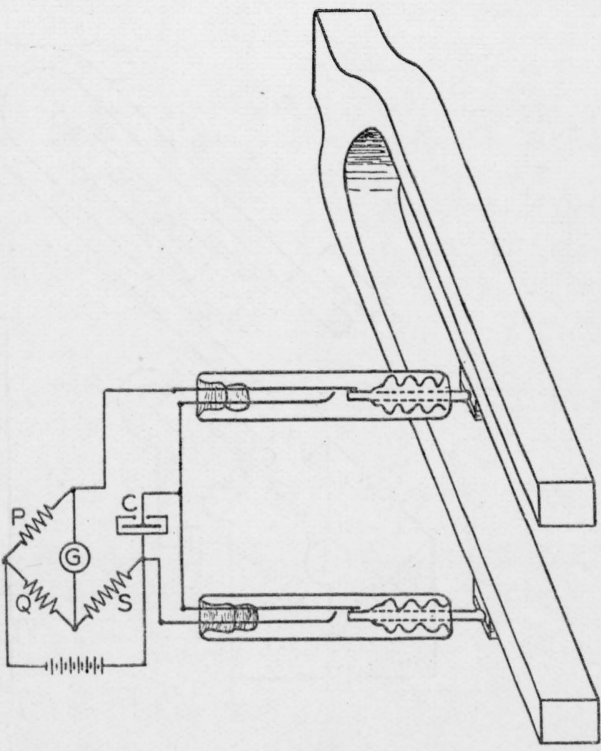

FIGURE 15.-Vacuum contactors mounted on tuning fork, with connections to Maxwell bridge.

trant glass bellows through which extended a glass stem that projected beyond the end of the tube. The inner end of the glass stem pressed against the longer tungsten wire, and normally prevented the wires from touching. The elasticity of the glass bellows was such that a slight upward pressure on the outer end of the glass stem would cause the inner end to move downward, thus permitting the longer tungsten wire to move downward and make contact with the shorter wire. In the figure, the glass stems of both tubes are shown holding the contacts open, which was their normal position when the tuning fork, to which the glass rods were attached, was at rest. When the fork vibrated, the contact in each tube was closed

${ }^{29}$ For a description of the method see Moon, A precision method of calibrating a tuning fork by comparison with a pendulum. BS J. Research 4, 213 (1930) RP144.

${ }^{30}$ For description of a similar generator see Marrison, Bell System Tech. J. 8, 493 (1929), or Proc. IRE 17 , 1103 (1929). The actual generator has been described by Hall, Heaton, and Lapham, J. Research NBS 14, 85 (1935) RP759.

${ }_{31}$ Curtis and Moon, page 522 of reference in footnote 28. 
once during a period, but only one of them at any instant. Hence, one contactor was used to charge the capacitor, the other to discharge it. As the vacuum in the tube was very high, a very slight opening of a contact was sufficient to break the circuit.

An inertia type of contactor has been successfully used for some determinations. In figure 16 is shown a diagram of this contactor attached to a tuning fork and connected into the bridge. In this figure there is also shown a detail drawing of the contactor. A tungsten reed was attached to a small post set in a hard-rubber base, and a mass of a few grams was fastened to the free end. Two other small posts, each carrying an adjustable platinum contact, were

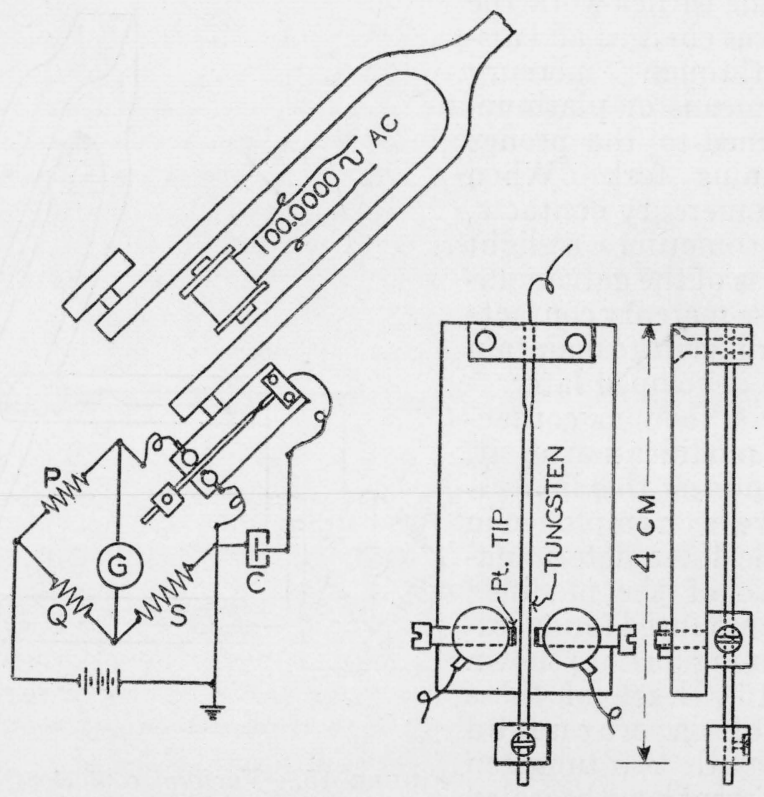

FIGURE 16.-Inertia type of contactor mounted on prong of tuning fork, with connections to Maxwell bridge.

At the right is an enlarged drawing of the contactor.

attached to the base, one on each side of the reed. When the base was mounted on the prong of a vibrating tuning fork, the inertia of the mass caused the wire to vibrate between the two contacts. The posts were connected to the capacitor and bridge by flexible wires.

The use of the vacuum and inertia types of contactors greatly improved the operation of the Maxwell bridge. There was no unsteadiness of the galvanometer, so that the accuracy of setting depended only on its sensitivity. Moreover, higher voltages could be used than were feasible with mercury contacts. As a result, in the recent determinations, the sensitivity permitted bridge settings to be made to about a part in a million.

In order to obtain a correct value of the capacitance, it was necessary that the charging contacts be closed long enough to permit the capacitor to become charged within one-millionth of the charge that would have accumulated if the contact had been closed for a long 
time. The longest time required was when measuring the $0.25-\mu \mathrm{f}$ capacitor. With the bridge constants used, this time ${ }^{32}$ was 0.0002 second, which was about one-fourth of the time that the contact was normally closed. Likewise, it was necessary that the discharging contact be closed sufficiently long so that the charge which remained was less than one-millionth of the total charge. The resistance in the discharge circuit was generally $10 \mathrm{ohms}$, so that for the $0.25-\mu \mathrm{f}$ capacitor, the computed time required for discharge was about 0.00004 second. The actual time the contact was closed was always much larger than this. Occasional tests were made to insure that the time of charging and the time of discharging were sufficiently long.

Another condition for the correct determination of the capacitance was that the charging contact should remain closed for one-half of the period of the charging and discharging apparatus so that the velocity of the galvanometer coil ${ }^{33}$ would be zero when the contact was broken. When measuring the $0.25-\mu \mathrm{f}$ capacitance an error of 0.1 of a period introduced an error of a part in a million in the capacitance. Difficulty was experienced in adjusting the contact to open within this limit at the correct instant. Hence, for the larger capacitor, incorrect timing of the opening of the charging contact might have introduced an error of one or two parts in a million.

\section{(e) CAPACITORS}

The capacitors have already been described on page 29 in connection with the Maxwell-Wien bridge. There were only a few small pieces of solid dielectric in these capacitors, and these pieces were made from materials (fused quartz and amber) which have small dielectric absorption. However, it seemed desirable to determine whether absorption in these capacitors produced an appreciable effect on the measured capacitance. Some measurements made at 60 charges and discharges per second (see table 21) gave results which agreed within experimental error with those obtained at 100 charges and discharges per second. These results indicated that the absorption was negligible.

\section{(f) ACCURACY OF THE CAPACITANCE MEASUREMENTS BY THE MAXWELL BRIDGE}

The accuracy of the capacitance measurements by the Maxwell bridge was determined from measurements of the same capacitance difference with two independent bridges which were placed in different rooms and were connected to the capacitors at different terminals. One bridge, shown diagrammatically in figure 15, was located in the same room (R213 E) as the large air capacitor and was designated as the bridge with vacuum contactors. One or the other of the two galvanometers, which have been described on page 38, was used. The ratio coils ( $\mathrm{P}$ and $\mathrm{Q}$ ) of this bridge were wound bifilarly of manganin wire on brass tubes. The $\mathrm{S}$ arm consisted of a 7 -dial resistance box, with dial steps from 0.1 to $100000 \mathrm{ohms}$. The important coils for this bridge were those having 10000 - and 1000 -ohms resistance. These were Curtis coils ${ }^{34}$ wound with constantan wire on porcelain forms.

\footnotetext{
${ }^{32}$ The formula for computing this time is given on page 498 of the paper by Curtis and Moon. BS Sci. Pap. 22, 487 (1927).

${ }^{33}$ For a more complete discussion see p. 499 et seq. of the paper by Curtis and Moon. The permissible error in timing has been computed by eq 55 of that paper. Reference in footnote 32.

34 Bul. BS 8, 495 (1912) S177.
} 
The second bridge, shown diagrammatically in figure 16, was in the same room (R212 E) as the inductor and the a-c bridge, and was designated as the bridge with inertia contactors. That one of the two special galvanometers which was not at the moment being used in the first bridge was employed. The ratio coils were sealed standards having low inductance. The $\mathrm{S}$ arm consisted of two boxes in series, one having three 100000 -ohm coils and five dials from 10000 to 1 $\mathrm{ohm}$, the other having three dials with steps of $0.1,0.01$, and 0.001 ohm. The $10000-o h m$ coils were Curtis coils wound with manganin wire on porcelain forms. The $1000-\mathrm{ohm}$ coils were made of five sections, each bifilarly wound of manganin wire, the entire coil being on a single brass tube.

The consistency of the results by the two bridges is shown by the values given in table 4 . Some of the results in this table were obtained when measuring the glass inductor and others when measuring the quartz inductor. The average difference between the results by the two bridges was, for each of the capacitors, about a part in a million. The average difference without regard to sign was 3 times as large with the $0.1 \mu \mathrm{f}$ as with the $0.25 \mu \mathrm{f}$, probably because the two bridges had greater sensitivity when measuring the larger capacitance.

TABLE 4.-Difference in the measured value of the capacitance when a capacitor was measured in two different Maxwell bridges

Data taken in connection with measurements on the glass and quartz inductors.

\begin{tabular}{|c|c|c|c|}
\hline \multicolumn{2}{|l|}{ Measured value, 0.1 microfarad } & \multicolumn{2}{|l|}{ Measured value, 0.25 microfarad } \\
\hline Date & $\begin{array}{c}\text { Value on } \\
\text { bridge with } \\
\text { inertia con- } \\
\text { tacts minus } \\
\text { that with } \\
\text { vacuum } \\
\text { contacts }\end{array}$ & Date & $\begin{array}{l}\text { Value on } \\
\text { bridge with } \\
\text { inertia con- } \\
\text { tacts minus } \\
\text { that with } \\
\text { vacuum } \\
\text { contacts }\end{array}$ \\
\hline $\begin{array}{l}\text { Nov. } 5 \\
\text { Nov. } 6 \\
\text { Nov. } 7 \\
\text { Nov. } 8 \text {. } \\
\text { Dec. } 14 \\
\text { Jan. } 5 \\
\text { Jan. } 7934 \\
\text { Jan. } 15 \\
\text { Jan. } 21 \\
\text { Jan. } 22 \\
\text { Jan. } 24 \\
\text { Mar. } 7 \\
\text { Mar. } 11\end{array}$ & $\begin{array}{r}\text { ppm } \\
+7 \\
-2 \\
-6 \\
+3 \\
-7 \\
\\
-5 \\
+6 \\
+4 \\
+13 \\
-6 \\
-3 \\
-5 \\
-6\end{array}$ & $\begin{array}{l}\text { Nov. } 15 \\
\text { Nov. } 16 \\
\text { Nov. } 20 \\
\text { Nov. } 24 \\
\text { Dec. } 36 \\
\text { Dec. } 5 \\
\text { Dec. } 6 \\
\text { Dec. } 7 \\
\text { Dec. } 12 \\
\text { Dec. } 19 \\
\text { Dec. } 31 \\
\text { Jan. } 2 \\
\text { Jan. } 31 \\
\text { Feb. } 7 \\
\text { Feb. } 8 \\
\text { Feb. } 18 \\
\text { Feb. } 28 \\
\text { Mar. } 2 \\
\text { Mar. } 4\end{array}$ & $\begin{array}{r}\text { ppm } \\
+6 \\
0 \\
-2 \\
-5 \\
-2 \\
-2 \\
-4 \\
-3 \\
0 \\
+1 \\
0 \\
+2 \\
\\
-2 \\
-4 \\
-2 \\
0 \\
-2 \\
0 \\
-1 \\
0\end{array}$ \\
\hline $\begin{array}{l}\text { A verage } \\
\text { A verage without regard to sign... }\end{array}$ & $\begin{array}{r}-0.7 \\
5.6\end{array}$ & 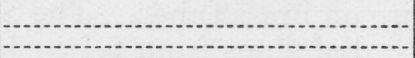 & $\begin{array}{r}-1.0 \\
1.9\end{array}$ \\
\hline
\end{tabular}

\section{RESISTANCE COMPARISONS}

All resistances have been measured in terms of the international ohm as maintained at the National Bureau of Standards. This unit was established by a technical committee of the International 
Committee on Electrical Units and Standards which met at Washington in 1910. The unit has been maintained at this Bureau by assuming that, for a particular period (which on the average has been about 6 months) the mean value of a group of 10 standards each having a nominal value of $1 \mathrm{ohm}$ has remained constant. At the end of every period, a comparison was made of the values of about 20 coils of this denomination and a selection made of the 10 coils which appeared to have changed the least in the preceding 6 months. The mean value of this group was assumed to be the same at the end of the period as at the beginning and established the NBS international ohm for the following period. While it would appear that any particular standard would have only 1 chance in 2 of being selected at each intercomparison, as a matter of fact there are 7 standards which have been among the 10 selected at every intercomparison since 1910. The values of a number of 10-, 100-, and 1000-ohm standard coils were determined by reference to the 1-ohm group, and these coils were used as standards with which the working resistors of the Maxwell-Wien a-c bridge and the Maxwell capacitance bridge were daily compared.

The $d-c$ comparison of the working resistors with the standards was made by a substitution method using a Wheatstone bridge. The standards were maintained at constant temperature in a special oil bath. In this bath was a stand having copper connecting bars in which were mercury cups so arranged that the standards could be connected in the series-parallel combinations required to give about the same value of resistance as that of the different working resistors. The connecting bars extended a short distance outside the bath and had mercury cups near the ends. This arrangement afforded an easy means for substituting in the bridge the calibrating resistance required for the Maxwell bridge, and also permitted the extension of the Wheatstone bridge, by means of heavy copper rods, to the bath containing the a-c bridge, so that the coils of this bridge could be compared with the standards without removing them from the oil bath in which they were used.

As an example of the method employed for insuring the reference of all resistances to the same standards, consider the case where the quartz inductor was measured using an intermediary capacitance of $0.25 \mu \mathrm{f}$. The resistances to be measured had values of 1050,262 , and $100 \mathrm{ohms}$ (the calibrating resistor of twenty $2000-\mathrm{ohm}$ coils in parallel). In the oil bath were two 1000 -ohm standards, five 100$\mathrm{ohm}$, one $10-\mathrm{ohm}$, and two $1-\mathrm{ohm}$. The $100-\mathrm{ohm}$ standards were compared with each other, then the two 1000 -ohm standards were compared, and finally the five 100-ohm coils in series were compared with the two 1000-ohm coils in parallel. Two of the 100-ohm standards which had the same relative values from day to day were assumed to have the same values as at the preceding intercomparison with the $1-\mathrm{ohm}$ group used to maintain the ohm, and values of the other 100- and 1000-ohm standards were measured in terms of these. The values of the 10- and 1-ohm standards were determined at infrequent intervals. The values of the $1050-\mathrm{ohm}$ resistance and of the 262-ohm resistance were determined by comparison with seriesparallel combinations of the standards, but the calibrating resistor was compared directly with one of the 100 -ohm standards. 


\section{EVALUATION OF AN INDUCTANCE FROM THE ELECTRICAL MEASUREMENTS}

The value of an inductance in NBS international units is evaluated from the data obtained with the three bridges previously described. A typical set of observations is given in table 5 which consists of three parts corresponding to the three bridges used in making the measurements. In table 5 (a) are given the readings on the a-c bridge (see fig. 11) made by two observers. In the first part are the readings obtained when measuring the substitution inductor (switch I open). Each observer adjusted the bridge for all possible combinations of the positions of the switches $\mathrm{A}$ and $\mathrm{W}$, the different positions being indicated in columns 4 and 5. The readings of the variable resistor $r_{3}^{\prime}$ are recorded in columns 7 and 8 to show the constancy of the bridge resistances. The four readings of the variable capacitor, $\mathrm{C}_{\mathrm{v}}$, as made by each observer, are given in column 9 , and the average in column 10 . The average reading for the two observers is taken as that reading of the variable capacitor required to balance the bridge when measuring the substitution inductor. The second part of table 5 (a) gives a similar set of observations when the quartz inductor was measured.

TABLE 5.-Typical set of electrical measurements

(a) READINGS WITH THE MAXWELL-WIEN ALTERNATING-CURRENT BRIDGEQUARTZ INDUCTOR AT $29.5^{\circ} \mathrm{U}$

$$
\text { Nominal values of bridge arms: }\left\{\begin{array}{l|l}
r_{1}: 262 \mathrm{ohms} & \text { Frequency: } 24 \mathrm{c} / \mathrm{s} . \\
r_{2}: 1050 \mathrm{ohms} . & \text { Impressed voltage: 10 volts. } \\
r_{4}: 10500 \mathrm{ohms} . & \text { Observers: C. M. and C. M. S. } \\
\mathrm{C}_{\mathrm{f}}: 0.25 \mu \mathrm{f} . & \text { Date: February } 16,1935 .
\end{array}\right.
$$

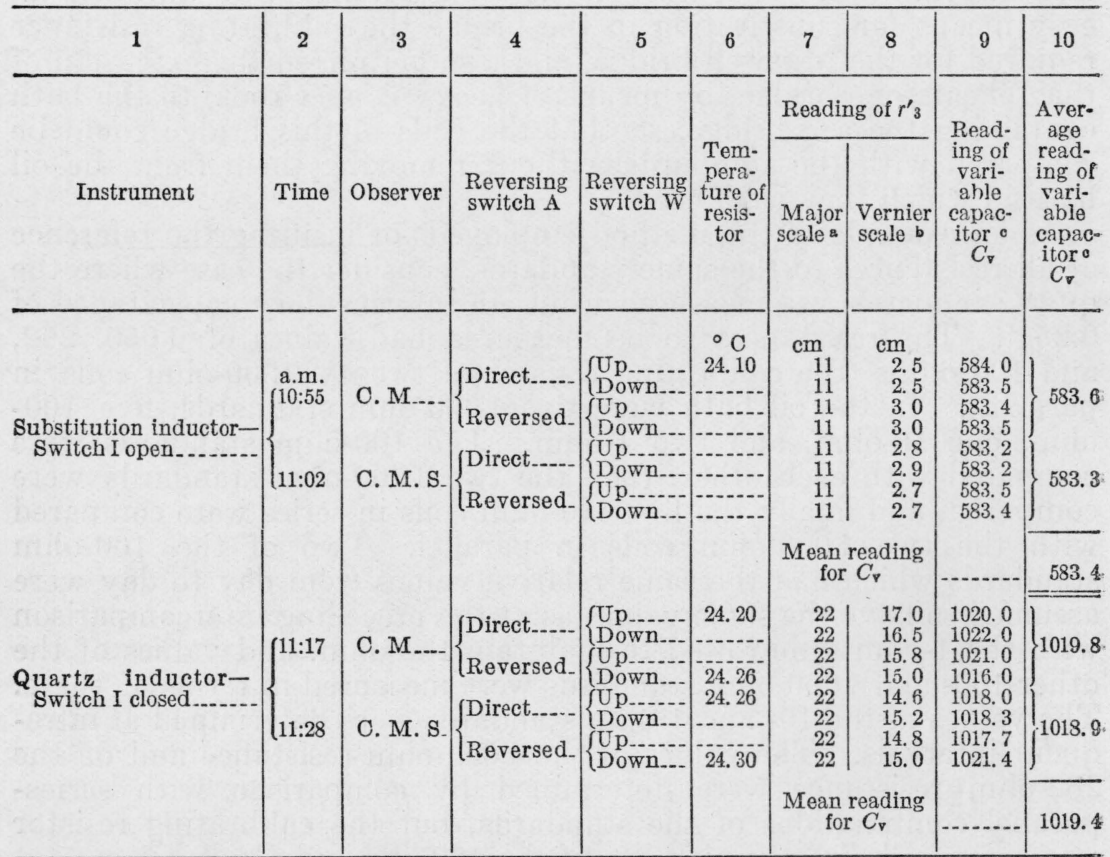

a 1 centimeter of the major scale corresponds to about $0.005 \mathrm{ohm}$.

b 1 centimeter of the vernier scale corresponds to about $0.0005 \mathrm{ohm}$.

- 1 scale division of the variable capacitor corresponds to about $0.6 \mu \mu f$. 
TABLE 5.-Typical set of electrical measurements-Continued

(b) OBSERVATIONS MADE WITH THE MAXWELL BRIDGE TO DETERMINE THE VALUES OF CAPACITANCES USED IN THE A-C BRIDGE

Calibrating resistor $R_{c}: 20$ coils of $2000 \mathrm{ohms}$ each. Variable capacitor: 1 scale division $=0.6 \mu \mu \mathrm{f}$.

Fixed capacitor: $0.25 \mu$ f.

ce: $5.53 \mathrm{ohms}$

Resistance of battery and its leads, B: $0.53 \mathrm{ohms}$.

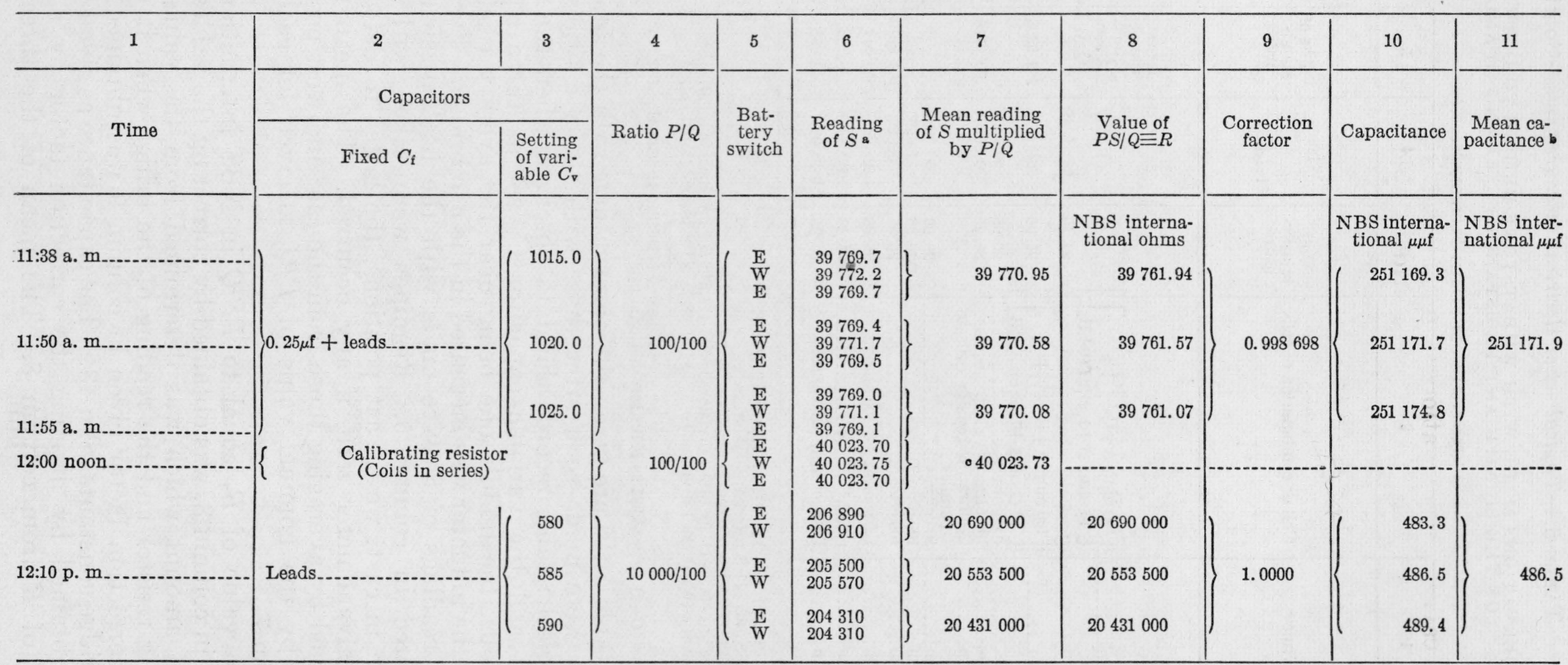

a The resistance box $\mathrm{S}$ had 10 coils in each dial. At any given ratio of $P / Q$ the adjustments of $\mathrm{S}$ were accomplished without changing the 10000 - or 1000 -ohm dials.

- The mean of the three capacitance values at equally spaced settings of the variable was taken as the capacitance at the middle setting.
The calibrating resistor (400 times the value when the coils were in parallel, see table 5 (c)) was 40014.72 NBS international ohms.

the contactors used for charging and discharging capacitors.

Frequency of charge and discharge, $n: 100$ per second.

Impressed voltage: 60 vo'ts.

: February 16, 1935

(1) 
TABLE 5.-Typical set of electrical measurements-Continued

(c) OBSERVATIONS MADE WITH WHEATSTONE BRIDGE TO DETERMINE VALUES OF THE SIGNIFICANT RESISTANCES USED IN 5 (a) AND 5 (b)

[Observer: C. M.; Date: February 16, 1935]

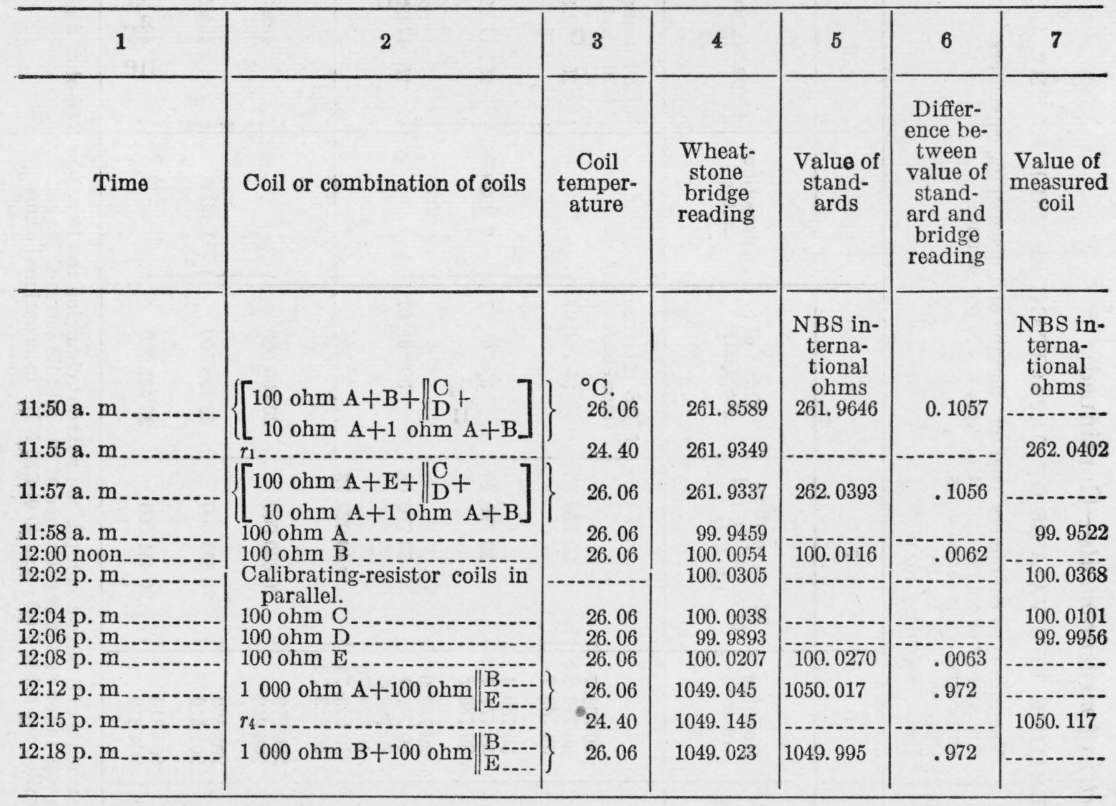

COMPUTATION OF THE INDUCTANCE.

$r_{1}=262.0402$ NBS international ohms.

Value of $C\left(C_{\mathrm{f}}+C_{\mathrm{v}}\right.$ at 1019.4 divisions $)=251171.5$ NBS international $\mu \mu \mathrm{f}$.

Value of $c$ ( $C_{\mathrm{v}}$ at 583.1 divisions) $=485.5 \mathrm{NBS}$ international $\mu \mu \mathrm{f}$.

$C-c=250686.0$ NBS international $\mu \mu f$.

$L-l_{\mathrm{s}}=(C-c) r_{1} r_{4}=68.98199 \mathrm{NBS}$ international $\mathrm{mh}$.

In table 5 (b) are given the observations with the Maxwell bridge, which were made soon after those with the a-c bridge. The first part of the table records the data observed when the switch I was closed and the variable capacitor $\mathrm{C}_{\mathrm{v}}$ set at three equally spaced positions, the middle one being near the average reading obtained when the inductor was measured in the a-c bridge. For each setting, three readings of $\mathrm{S}$ were made with the battery switch closed as indicated in column 5. Readings were taken with the battery switch in east, west, east positions, the latter to detect a drift in the galvanometer zero, if any occurred. The mean reading of S obtained by averaging those from the east and west positions, multiplied by the nominal value of $P / Q$, is given for each position in column 7.

The value of $R$, equal to $P S / Q$ in NBS international ohms, as given in column 8 , was obtained by correcting the values in column 7 by an amount which was determined from the value of the calibrating resistor and the reading of the bridge when it was inserted. The correction factor given in column 9 was obtained by inserting the bridge constants in eq 43 . The capacitance as given in column 10 was obtained by dividing the correction factor by $n$ and by the value of $R$ from column 8 . The mean of the three capacitance 
values is given in column 11. Since the settings of the variable capacitor were made at equally spaced divisions, the mean value gave the capacitance at the middle setting.

In table 5(c) are recorded the measurements of the resistances. The calibrating resistor used in the Maxwell bridge was measured just after it had been used. The resistances of the a-c bridge were measured without removing them from the bath in which they were used. From the data given in the table, the inductance was computed from the values of the resistances and the average values of the capacitances.

To obtain each average capacitance, the average reading of the variable capacitor in the a-c bridge was subtracted from the middle setting of the capacitor when measured in the Maxwell bridge. This difference was multiplied by the value of a scale division for determining the small correction to be subtracted from the capacitance at the middle setting. For example, the average reading of the capacitor when measuring the inductor was 1019.4 divisions. The capacitance value determined in the Maxwell bridge was made at 1020 divisions. By applying the scale calibration of $0.6 \mu \mu \mathrm{f}$ per division to the difference of 0.6 division, a correction of $0.4 \mu \mu \mathrm{f}$ was obtained. Likewise, the average capacitance was determined for the substitution inductance. The difference between these two values of capacitance multiplied by the resistances $r_{1}$ and $r_{4}$ gave the value of $L-l_{B}$ in NBS international henrys.

\section{ACCURACY OF THE ELECTRICAL MEASUREMENTS}

The accuracy of the final value for the inductance depends on the accuracy that could be attained with all three of the bridges. In the Wheatstone bridge, all the connections were so made that the errors introduced never affected the result by more than a few microhms, which was negligible, since all the resistances had values of at least 100 ohms. The substitution method was always used, and standards were so selected that only the low-valued dials of the briage had to be adjusted. Also, the error caused by thermoelectromotive forces was avoided by keeping the galvanometer key closed and reversing the battery connections. The accuracy was ultimately limited by the instability of the standard resistances, which could be depended upon to about a part in a million.

In the Maxwell bridge, the accuracy was limited in part by the sensitivity of the galvanometer. In this investigation, the galvanometers used were of such sensitivity that when $0.25 \mu$ f was being measured with ratio arms $P$ and $Q$ of $100 \mathrm{ohms}$ each, the $S$ arm of $40000 \mathrm{ohms}$ could be set to $0.05 \mathrm{ohm}$. Hence, when measuring this capacitance, the resistance balance could be made to a part in a million. When $0.1 \mu \mathrm{f}$ was being measured, difficulty was experienced in setting the $S$ arm of $100000 \mathrm{ohms}$ to $0.1 \mathrm{ohm}$, but by using the average of several settings, an accuracy approaching a part in a million was obtained. The accuracy may also have been limited by the necessity of assuming, in each measurement, that the integral value of the current through the galvanometer was zero when the deflection was zero. Tests were occasionally made by a 
special arrangement ${ }^{35}$ and the galvanometer as used was always in good adjustment.

The capacitances actually measured in the Maxwell bridge were slightly different from those employed in the a-c bridge because different leads were used for the two bridges. Hence, it was necessary to show that the capacitance difference was the same for the two bridges. The shielded portions of the leads presented no difficulty since they were portions of the capacitors.

The unshielded leads may be considered in four parts; viz: (1) the part connecting the a-c bridge to the switch $\mathrm{H}$ (see fig. 11), for changing the capacitance from one bridge to the other; (2) the part connecting the Maxwell bridge to the same switch; (3) the unshielded part between the switch $\mathrm{H}$ and the switch I which disconnected the fixed capacitor from the variable one; and (4) any unshielded portion beyond the switch I. The first part produced no effect on the capacitance difference, since the value of its total capacitance when measuring the substitution inductance was the same as when measuring the inductance of the helix. In exactly the same manner, the second part, i. e., the capacitance of the leads to the Maxwell bridge, did not affect the capacitance difference. Also, the third part had no effect on the capacitance difference, because in each bridge the potentials of the leads and of surrounding objects were the same when measuring the smaller capacitance as when measuring the larger. However, for the fourth part; viz, for any unshielded portion of the lead beyond the switch I (which occurred in the earlier measurements before the need of a cap to the terminal $\mathrm{Z}$ had been realized), a correction for its capacitance to earth was required. This capacitance to earth was in parallel with the fixed capacitance $C_{t}$ and hence was measured as a part of $\mathrm{C}_{\mathrm{f}}$ in the Maxwell bridge, since in this bridge the terminal $\mathrm{Z}$ was not at earth potential. However, when the fixed capacitance was used in the a-c bridge, the terminal $\mathrm{Z}$ was at earth potential and therefore did not affect the value of the fixed capacitance. Hence, for sets of observations made when such an unshielded portion was present, its capacitance to earth was measured by a double Maxwell bridge ${ }^{36}$ and the value applied as a correction. In using the double bridge, the terminal was disconnected from the condenser at a point within the shield, and connected in the measuring arm of the bridge. The plates and shield were connected together and inserted in the double bridge in place of the guard ring, with the earth as the third terminal.

In the a-c bridge, the accuracy was generally limited by the varying electromotive forces induced in various parts of the bridge, principally in the helix, by the varying magnetic field of the laboratory. The varying magnetic field consisted of two parts; viz, a periodic part and an aperiodic part. The periodic part was mainly caused by electric currents of $60 \mathrm{c} / \mathrm{s}$. These produced a constant deflection of the vibration galvanometer. Many observations were made with this deflection present, the bridge adjustments being made until the beats between the measuring frequency and the $60 \mathrm{c} / \mathrm{s}$ frequency disappeared from the galvanometer deflection. Two methods of minimizing the $60 \mathrm{c} / \mathrm{s}$ deflection were used. In one, the mechanical wave filter already described was inserted between the

3s See page 507 BS. Sci. Pap. 22, 487 (1927). In making the test therein described, the battery was always used in both the direct and reversed positions.

${ }^{86}$ Described in a paper by Rosa and Dorsey, Bul. BS 3, 543 (1907). 
bridge and the galvanometer. This was effective with regard to the periodic currents, but introduced slight aperiodic disturbances caused by the vibration of the building. Another method was to induce in the helix an equal and opposite electromotive force of the same frequency as produced by the periodic magnetic field. For this purpose, two compensating coils were placed two or three meters from the helix with their planes vertical. Both coils were connected to the regular 60 -cycle circuit, one through a resistance, the other through a capacitance. By rotating first one coil and then the other, the galvanometer deflection with the supply switch of the bridge open was reduced to zero.

The disturbance caused by the $60 \mathrm{c} / \mathrm{s}$ magnetic field was not always of such magnitude as to require the use of the mechanical filter or the compensating coils. At the discretion of the observer, measurements were made using the one or the other as seemed necessary and many measurements were made without either. Results made under the three conditions agreed within experimental error. Hence the particular method used has not been indicated in the tabulation of the data.

The aperiodic electromotive forces induced in the inductor by operating relays, sparking motors, and possibly variations of the earth's magnetic field, set the real limit to the accuracy. Their effects could be minified by increasing the voltage on the bridge, but this tended to produce excessive heating. Occasionally the aperiodic disturbances were so pronounced that observations could not be made. Generally the disturbances gave the observer a feeling of uncertainty concerning his final reading, but it was considered that the reading was reliable when the reading of a second observer agreed with it.

A second limitation to the a-c bridge was the difficulty of maintaining the resistance balance for a sufficient time to enable a capacitance reading to be obtained. In order that a capacitance setting could be made to a part in a million, the resistance balance had to be made with much higher accuracy. The change in temperature of the copper wire of the inductor by as much as a ten-thousandth of a degree produced a noticeable change in the resistance balance. As the thermostat controlled the temperature to $0.01^{\circ} \mathrm{C}$. only, an almost continual adjustment of the resistance was required. In the last set of measurements on the quartz inductor, this shifting in resistance was somewhat alleviated by placing over the coil a silk skirt which was suspended from the top of the chamber so that it did not touch the inductor.

\section{OBSERVATIONAL DATA AND RESULTS}

Space is lacking for printing all the observations made in the course of this investigation and, were space available, there is no essential need for doing so. Only such data are presented as will enable the reader to form an independent judgment of the accuracy of the work. The earlier data have not been entirely discarded since they have value in showing the constancy of the results over a period of time. 


\section{PORCELAIN INDUCTOR}

The porcelain inductor was constructed in 1924. Mechanical and electrical measurements have been made on it on several occasions since then. The results do not indicate that any change either in geometrical dimensions or measured inductance has occurred. Hence, all the measurements on any one quantity have been averaged.

\section{(a) MEASUREMENTS OF THE DIMENSIONS OF THE PORCELAIN INDUCTOR}

The dimensions of the porcelain inductor were measured before and after the electrical measurements. The diameter was measured a third time after it was discovered that the end standard which was used to establish this dimension had changed an appreciable amount. The detailed results which follow show that no measurable change in dimensions occurred.

(1) Outside Diameter of Porcelain Inductor.-The data on the outside diameter of the porcelain inductor are given in table 6. In 1924

TABLE 6.-Outside diameter of porcelain inductor measured in equally spaced axial

Steel end standard: 291.

Measurements at $29.5^{\circ} \mathrm{C}$. planes

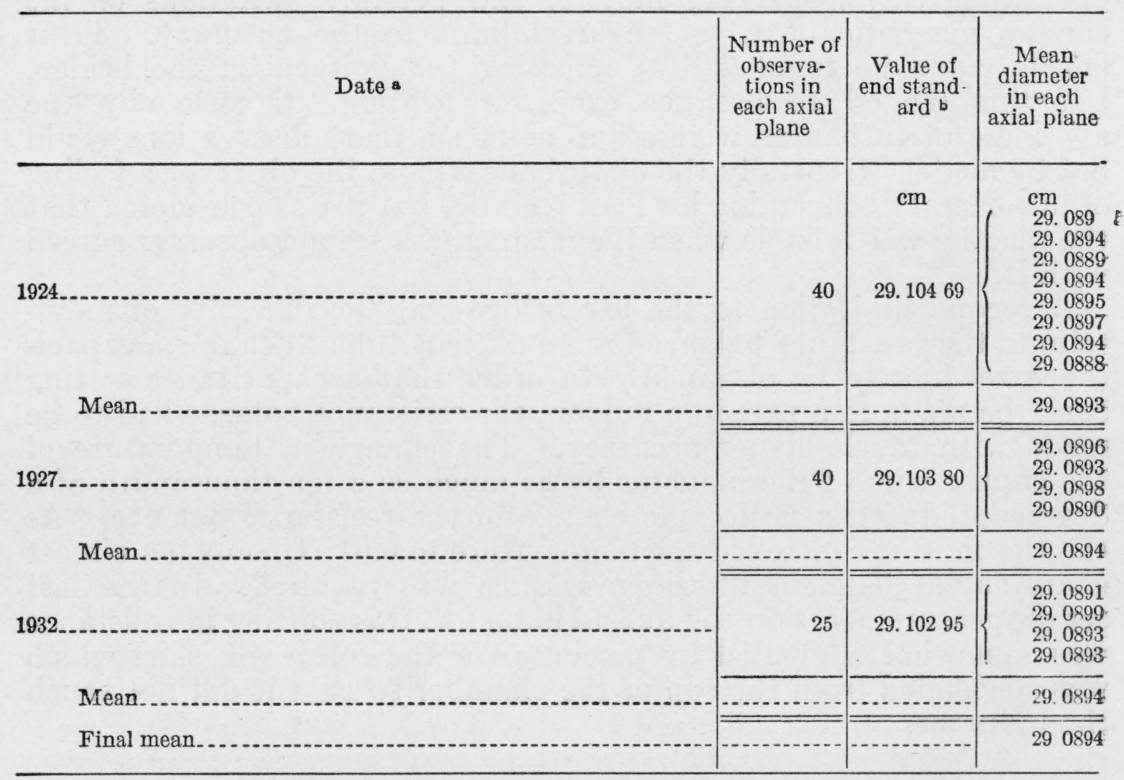

- Measurements were not made in the same axial planes on the different dates.

End standard calibrated by the Gage Section of this Bureau in 1924 and 1932 . Also, an independent calibration was made in 1932 by the method referred to in footnote 13 . The value given for 1927 was so chosen that the mean diameter of the inductor agrees with that obtained in 1932.

measurements were made in eight equally spaced axial planes. In each plane, the diameter was measured for every centimeter of length, so that the set of measurements consisted of observations at 320 different positions on the inductor. In 1927 measurements were made in only four axial planes, but as before, at every centimeter of length in each plane. In 1932 measurements were made in four 
axial planes, at 1 -cm intervals near the ends, and at 2 -cm intervals in the center of the inductor. However, the location of the scale for determining angular positions was different in each set of determinations, so that the three different sets may have been made at different positions on the inductor.

The steel end standard which was used in all the determinations was calibrated in 1924 and again in 1932. During that interval its length had changed $17.4 \mu$ or 59 parts in a million. However, the mean diameter of the coil was the same, within experimental error, at both dates. The 1927 value of the end standard was then assumed to be such that the 1927 measurements gave the same mean diameter as those at the other dates. When the three values of the end standard were plotted as ordinates, with time as abscissa, the resulting curve was similar to the aging curves which have been found by other observers for steel of the kind used in the end standard. This strengthens the assump-

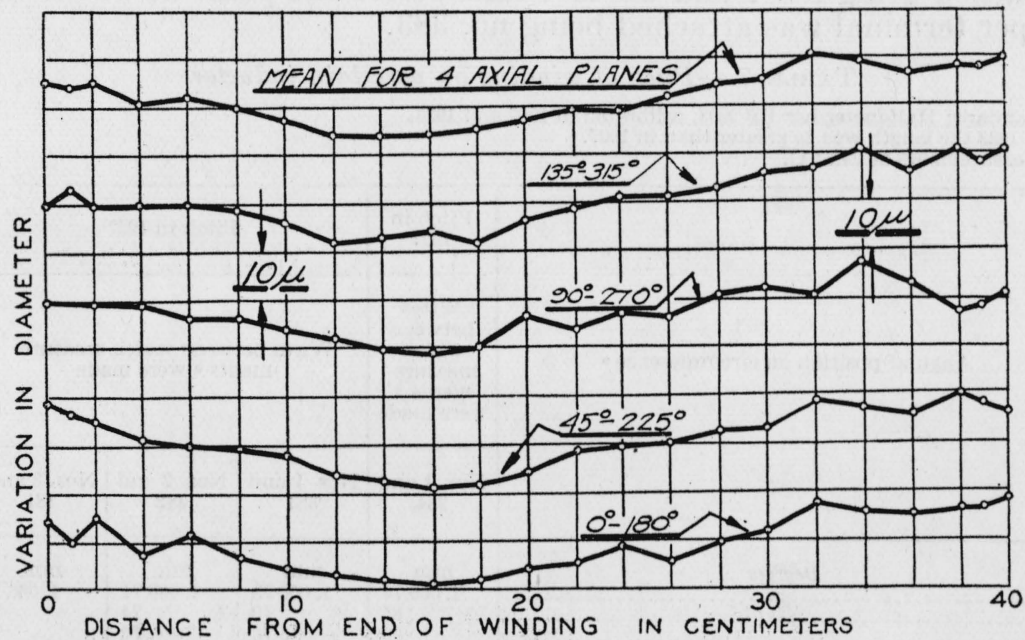

FIGURE 17.-Measured variations in the diameter of the porcelain inductor along four axial planes.

tion that the diameter of the coil did not change between 1924 and 1932.

The variation in the diameter at points in four different axial planes is shown by the data taken in 1932, which are plotted in figure 17 . The curves show that the maximum variation in any axial plane was about $20 \mu$ and the variation in diameter taken from the mean curve was only slightly less. The average diameter obtained in 1932 differed from that of 1924 by $1 \mu$, which would cause a difference of 6 parts in a million in the computed inductance of this inductor.

In addition to the error caused by variations in the measured diameters, the mean diameter may have been affected by a systematic error caused by the variations in diameter from turn to turn. The faces of the anvil and screw of the micrometer covered four or five wires so that the distance measured was from the prominent wire of the group on one side to the prominent wire on the opposite side, resulting in a measured diameter which was larger than that of any single turn. The amount of this error was probably only a few 
microns at most, but might have introduced an error of 10 or more parts in a million in the computed inductance.

(2) Pitch of the Winding on the Porcelain Inductor.-The pitch, as recorded in table 7 , was determined by measuring the distance from a point midway between the wires which were near one end of the inductor, to a similar point at the opposite end, and dividing the measured distance by the number of included turns. The observer set the crosshair of a microscope so that it bisected the space between adjacent wires. To obtain an accuracy of 10 parts in a million, the setting had to be correct to about 1 percent of the space between the wires, or to $4 \mu$ in 350 . This accuracy was approached by averaging the readings of several independent settings at each position.

The 1924 measurements were made before the leads to the inductor were attached. Before the 1927 measurements, the wires were numbered, the first turn above the point at which the lower terminal was attached being no. 1 and the last turn before the point at which the upper terminal was attached being no. 383 .

\section{TABLE 7.-Pitch of winding on porcelain inductor}

Standard: Half-meter bar BS 2983, calibrated in 1907 and 1933.

In 1933 the length was $2 \mu$ greater than in 1907.

Measurements at $29.5^{\circ} \mathrm{C}$.

\begin{tabular}{|c|c|c|c|c|}
\hline \multirow{3}{*}{ Angular position on circumference } & \multirow{2}{*}{$\begin{array}{c}\begin{array}{c}\text { Pitch in } \\
1924\end{array} \\
\begin{array}{c}\text { Wires } \\
\text { between } \\
\text { which } \\
\text { measure- } \\
\text { ments b } \\
\text { were made }\end{array}\end{array}$} & \multicolumn{3}{|c|}{ Pitch in 1927} \\
\hline & & \multicolumn{3}{|c|}{$\begin{array}{l}\text { Wires between which measure- } \\
\text { ments b were made }\end{array}$} \\
\hline & $\begin{array}{c}\text { Nos. } 1 \text { and } \\
384\end{array}$ & $\begin{array}{l}\text { Nos. } 1 \text { and } \\
383\end{array}$ & $\begin{array}{l}\text { Nos. } 2 \text { and } \\
382\end{array}$ & $\begin{array}{l}\text { Nos. } 3 \text { and } \\
381\end{array}$ \\
\hline $\begin{array}{c}\text { Degrees } \\
025\end{array}$ & $\begin{array}{r}\mathrm{mm} \\
1.066 \quad 74 \\
65 \\
66 \\
74 \\
75 \\
72 \\
81 \\
82\end{array}$ & $\begin{array}{r}\operatorname{mm} \\
1.068 \\
70 \\
75 \\
73 \\
75 \\
79 \\
77 \\
76 \\
\end{array}$ & $\begin{array}{r}\mathrm{mm} \\
1.066 \\
74 \\
76 \\
76 \\
77 \\
77 \\
72 \\
71\end{array}$ & $\begin{array}{r}\operatorname{mm} \\
1.06675 \\
79 \\
73 \\
77 \\
78 \\
76 \\
75 \\
76\end{array}$ \\
\hline $\begin{array}{l}\text { Mean } \\
\text { Final mean }\end{array}$ & 1.06674 & \multicolumn{2}{|c|}{$\begin{array}{l}1 . 0 6 6 7 5 \longdiv { 1 . 0 6 6 7 4 } \\
1.06675 \mathrm{~mm}\end{array}$} & 1.06676 \\
\hline
\end{tabular}

- The location of the scale for measuring the angular position was different in 1924 from that in 1927. b The numbers assigned indicate the lower of the two wires bounding the space between which the microscope settings were made.

The maximum variation between the results for the four sets of observations was 20 parts in a million. It was estimated that the error in the pitch might have been of this amount, which would cause an error in the computed inductance of 16 parts in a million. In addition, there was an uncertainty arising from irregularities in the pitch of the winding which was not estimated, since data were not available, and the difficulty of making the necessary observations was so great that the expenditure of the time required to make them was not warranted.

(3) Diameter of Wire on the Porcelain Inductor.-The diameter of the wire was measured by two independent methods which gave 
slightly different results as shown in table 8 . The mean value was considered correct to within a micron. This error might have introduced an error into the value of the computed inductance of 10 parts in a million.

TABLE 8.-Diameler of wire-porcelain inductor

(a) Measurements on samples removed from inductor after winding was completed. Diameter measured in Gage Section of this Bureau

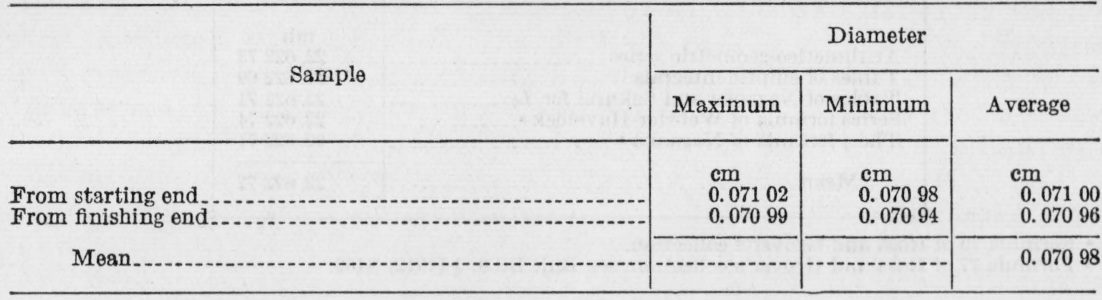

(b) Measurements by difference, at each end, between the over-all diameter and the diameter of the form

\begin{tabular}{c|c}
\hline Position & $\begin{array}{c}\text { Average } \\
\text { diameter of } \\
\text { wire }\end{array}$ \\
\hline Top of inductor & $\mathrm{cm}$ \\
Bottom of inductor. & 0.07081 \\
Mean & 0.07086 \\
\hline
\end{tabular}

Final mean of all measurements.

$0.07091 \mathrm{~cm}$

The above analysis of measured dimensions has shown that the value of the computed inductance might have been in error by more than 20 parts in a million as a result of accidental errors of measurements. There were also systematic errors for which no estimate has been made: viz the variations in pitch and an uncertainty in the measured diameter. The first of these might have introduced a positive or a negative error in the computed inductance, but the second made the computed inductance too large.

\section{(b) COMPUTATION OF THE INDUCTANCE OF THE PORCELAIN INDUCTOR}

The inductance of the porcelain inductor was computed by several different methods, partly as a check on the numerical work and partly as a check on the formulas. For the computations, the following constants were used, some of which are carried to one more significant figure than warranted by the observational data.

\begin{tabular}{|c|c|c|}
\hline Quantity & Symbol & Value \\
\hline $\begin{array}{l}\text { Mean diameter of helix } \\
\text { Diameter of wire } \\
\text { Pitch of winding } \\
\text { Number of turns } \\
\text { Efiective lensth of helix }\end{array}$ & $\begin{array}{l}D \\
d \\
g \\
\stackrel{N}{l} \\
l=N g\end{array}$ & $\begin{array}{c}29.01850 \mathrm{~cm} \\
0.07091 \mathrm{~cm} \\
0.1066750 \mathrm{~cm} \\
383.85652 \mathrm{~cm}\end{array}$ \\
\hline
\end{tabular}


The inductance of a cylindrical current sheet having the above length and diameter is given by the expression for $L_{0}$ in eq $2 \mathrm{a}$. It was computed by the direct use of elliptic integrals and also by series formulas. The results are as follows:

\begin{tabular}{|c|c|}
\hline Method & Results \\
\hline $\begin{array}{l}\text { Arithmetico-geometric series } \\
\text { Tables of elliptic integrals } \\
\text { Tables of Nagaoka and Sakurai for } L_{0} \\
\text { Series formula of Webster-Havelock } \\
\text { The } g \text {-formula of Nagaoka }\end{array}$ & $\begin{array}{c}\mathrm{mh} \\
22.62273 \\
22.62269 \\
22.62271 \\
22.62274 \\
22.62271\end{array}$ \\
\hline Mean & 22.62272 \\
\hline
\end{tabular}

- Formula 79 of Rosa and Grover's collection.

- Formula 77 of Rosa and Grover's collection; see Bul. BS 8, 1 (1912) S169.

The above mean result for the inductance of a current sheet was then corrected to obtain the inductance of a helix of round wire. Two formulas were used with the following results:

\begin{tabular}{|c|c|}
\hline \multicolumn{1}{|c|}{ Formula } & Correction \\
\hline & \\
Snow's & $\begin{array}{c}\mathrm{mh} \\
\mathbf{0} \\
\text { Rosa's. }\end{array}$ \\
\hline
\end{tabular}

The difference in the two corrections produces a difference of 2 parts in a million in the computed inductance. However, Snow's formula has the better theoretical basis, so that the correction obtained by it will be assumed correct. The computed value of the inductance $L_{\mathrm{h}}$ of the porcelain inductor, considering that part of the winding between the points to which the leads were attached, was 22.58904 absolute $\mathrm{mh}$.

The computed inductance of the leads was $0.00078 \mathrm{mh}$, so that $L=22.58982 \mathrm{mh}$. The computed inductance, $l_{\mathrm{s}}$, of the substitution inductor was $0.00039 \mathrm{mh}$. Hence the value of $L-l_{\mathrm{s}}$ was 22.58943 absolute $\mathrm{mh}$. Correcting this value for the permeability of the form by the value in table $2(+4$ parts per million) gave,

$$
L-l_{\mathrm{B}}=22.58952 \text { absolute millihenrys. }
$$

Because of the uncertainties in the measured dimensions, the last figure of the above value has no significance.

(c) ELECTRICAL MEASUREMENTS ON THE PORCELAIN INDUCTOR

Three series of electrical measurements were made. The first two are now considered preliminary and hence are not here reported. The third series was begun in March 1929 and, with an intermission from May 1929 to April 1930, continued through June 1930. Measurements were made at several frequencies but there were few modifications of the bridge. In this series, 110 independent results were obtained. The average value of the measured inductance $L-l_{8}$ was 


\subsection{NBS international millihenrys}

The average deviation from the mean was 13 parts in a million.

Some of the measurements on which the above result was based were made at a height of $110 \mathrm{~cm}$ from the floor in room R213 E, which has nonmagnetic reinforcement in the floor and ordinary steel reinforcement in the ceiling. Others were made in R212 E, which has ordinary steel reinforcement in both the floor and ceiling. With the accuracy of measurement attainable at that time, there was no obobserved difference between the two sets of results, and the two groups were averaged as though made under identical conditions. After the accuracy of measurements had been appreciably increased, some relative measurements were made in R214 $\mathrm{E}$, which has reinforcement similar to that of R213 E. The results are plotted, for comparison, with similar results for the other inductors in figure 14 . However, the effect of the reinforcement on the measured inductance of the porcelain inductor was estimated as less than 2 parts in a million, which would not affect the above result.

\section{GLASS INDUCTOR}

The glass inductor was completed in December 1929. Some measurements were made to determine the irregularities in the pitch of the winding while it was still mounted in the precision lathe. After removing from the lathe, no further measurements were made on it until 1932 .

(a) MEASUREMENTS OF THE DIMENSIONS OF THE GLASS INDUCTOR

The measurements of the dimensions of the glass inductor were made after those on both the other inductors had been completed. Hence, the experience gained on the other inductors was utilized in measuring this one.

(1) Diameter of the Glass Inductor.-The diameter of the form for the glass inductor was measured at a number of positions in several axial planes before it was wound with wire. The diameter of the form after winding has, on two different occasions, been determined at similar positions by measuring the diameter over the winding and subtracting from the result twice the diameter of the wire. The mean result for each axial plane is given in table 9 and is plotted in figure 18 . The measurements on each occasion were made at several equally spaced axial planes, on the first occasion in 6 planes, on the second in 8 planes, and on the third in 4 planes. All angular measurements were made from the same zero position. The measurements made in 1928 were referred to a commercial steel end standard that was not calibrated until 1931. As the length of such a standard usually changes with age, the absolute value of the diameter obtained in 1928 was not known with high precision, but the relative values in the different axial planes were as accurate as those obtained later. Hence the plot in figure 18 gives an indication of the change in shape of the form caused by winding, but does not show the amount of its compression. The average value for 1932 agrees with that for 1933 to a part in 5 million. 


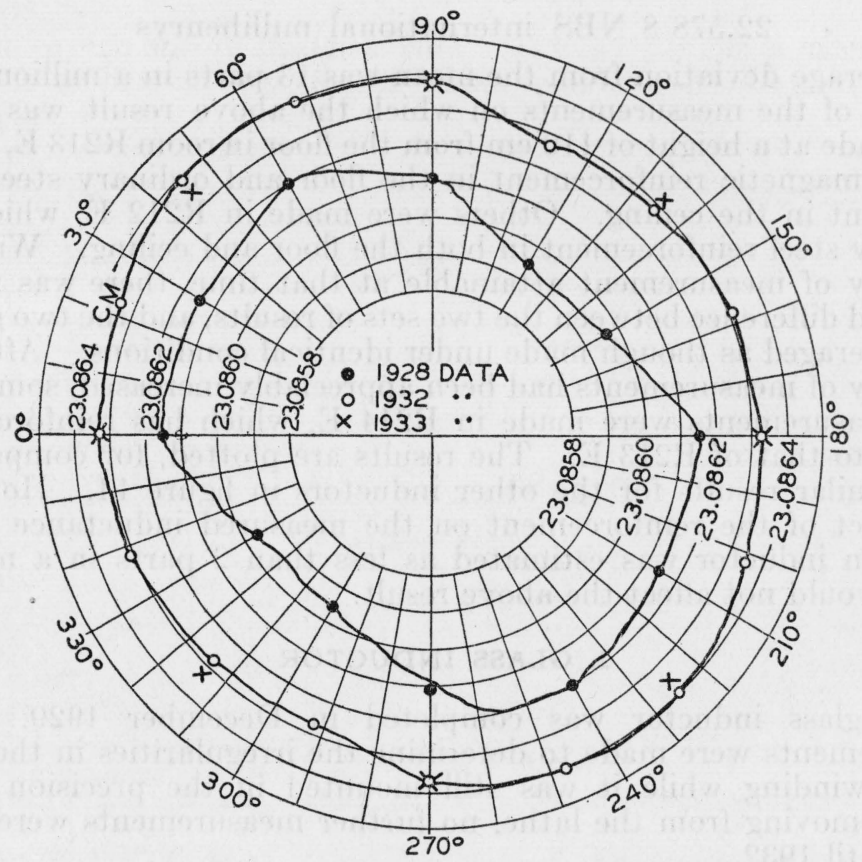

FIgURE 18.-Variations in mean radius of Pyrex-glass form before and after

The curves show the change in shape on winding, but do not show the amount of compression.

\section{TABLE 9.-Diameter of glass form at $29.7^{\circ} \mathrm{C}$}

[Each recorded diameter in the first 2 columns is the average of readings made at 1-cm intervals along its length. The diameters in the third column were obtained from measurements at 2-cm intervals]

\begin{tabular}{|c|c|c|c|c|}
\hline \multirow{3}{*}{$\begin{array}{c}\text { Angular position of axial } \\
\text { planes }\end{array}$} & \multicolumn{3}{|c|}{ Diameter of form } & \multirow{3}{*}{ Remarks } \\
\hline & $\begin{array}{c}\text { Before } \\
\text { winding }\end{array}$ & \multicolumn{2}{|c|}{ After winding } & \\
\hline & 1928 s & 1932 b & 1933 & \\
\hline $\begin{array}{c}\text { Degrees } \\
0\end{array}$ & $\stackrel{\mathrm{cm}}{46.17230}$ & \multirow[t]{2}{*}{$\begin{array}{c}\mathrm{cm} \\
46.17266 \\
46.17267\end{array}$} & \multirow{2}{*}{${ }^{\mathrm{cm}}$} & \multirow{8}{*}{$\begin{array}{l}\text { The diameter after winding was ob- } \\
\text { tained by subtracting twice the diam- } \\
\text { ter of the wire }(0.07074 \mathrm{~cm}) \text { from the } \\
\text { diameter measured over the winding }\end{array}$} \\
\hline 30 & 46.17228 & & & \\
\hline 60 & 46.17240 & 46.17279 & 46.17269 & \\
\hline $\begin{array}{l}67.5 \\
90, \ldots+1 \\
112.5\end{array}$ & 46.17221 & \multirow{2}{*}{$\begin{array}{l}46.17280 \\
46.17275 \\
46.17254\end{array}$} & 46.17275 & \\
\hline $120 \ldots$ & 46.17190 & & - & \\
\hline & 46.17192 & 46.17255 & 46.17263 & \\
\hline 157.5 & (2) & 46.17261 & 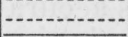 & \\
\hline Mean. - & 46.17217 & 46.17269 & 46.17268 & \\
\hline
\end{tabular}

a The measurements were referred to an uncalibrated steel end standard so that its precise length was not known. The values given show the variations in the diameters, but not their actual values.

$b$ Measurements referred to fused-quartz end standard BS 6827, which was calibrated in 1932 by means of Johansson blocks, the lengths of which were determined both in 1931 and 1932 . 
The form is slightly conical. This is shown by the curves of figure 19 , in which all the readings made in 1933 are plotted to show the

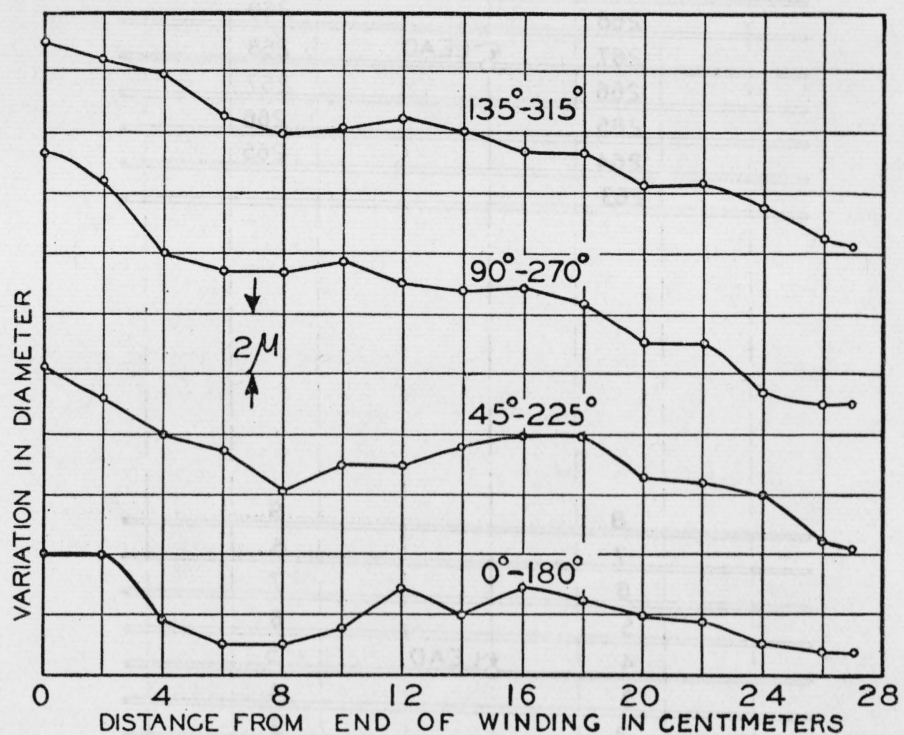

FIGURE 19.-Measured variations in the diameter of the glass inductor along four axial planes.

variation in diameter along four axial planes. The difference in diameter of the two ends is about $6 \mu$, or 13 parts in a million. The mean diameter of the inductor was obtained by adding the diameter of the wire to the average value of the diameter of the form as obtained from the last two columns of table 9. This mean diameter appears to be in error by less than $0.2 \mu$, which would cause an error in the computed inductance of a part in a million.

(2) Pitch of the Winding on the Glass Inductor.-The pitch of the winding on the glass inductor was determined from measurements of the distance from one end turn to the other end turn, from the second turn at one end to the second at the other end, etc., for nine symmetrical turns from each end. The positions of these turns relative to the ends of the winding and the points of attachment of the leads are shown in figure 20 , which also indicates the axial planes in which the measurements were made on each turn. The values of the pitch, as determined from the measured distances, are given in table 10. The measurements for determining the pitch were made in February 1933, before the leads were attached, and extended from turns 2 to 270 . As the winding was slightly more irregular near the ends, the leads were attached at the beginning of the fifth turn and at the end of the 267th turn.

The variations in pitch were measured by two methods when the coil was in the lathe. In each method a comparision was made 


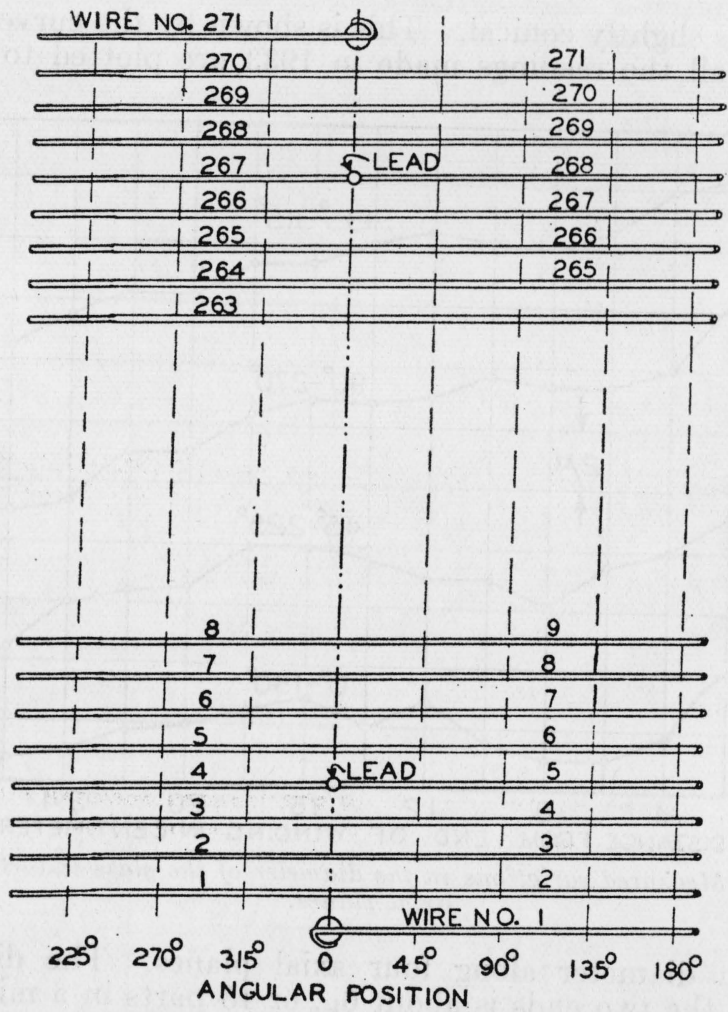

FIGURE 20.-Winding of glass inductor developed in a plane.

\section{TABLE 10.-Pitch of winding on glass inductor}

The distance was measured between the indicated wires in the designated axial planes and the pitch com. puted by dividing the measured distance by the number of turns between the wires.

polished on the wires.

calibrated from 0 to $260 \mathrm{~mm}$ by the Length comparision with the steel half-meter bar BS 2983, which was $10.75 \times 10^{-6}$ per degree centigrade.

Measurements at $29.3^{\circ} \mathrm{C}$.

\begin{tabular}{|c|c|c|c|c|c|c|c|c|c|c|}
\hline \multicolumn{2}{|c|}{ Wire number } & \multicolumn{9}{|c|}{$\begin{array}{l}\text { Pitch in different angular positions. (Computed from the distance between the } \\
\text { designated top and bottom wires.) }\end{array}$} \\
\hline Bottom & Top & $0^{\circ}$ & $45^{\circ}$ & $90^{\circ}$ & $135^{\circ}$ & $180^{\circ}$ & $225^{\circ}$ & $270^{\circ}$ & $315^{\circ}$ & Mean \\
\hline & $\begin{array}{l}267 \\
266 \\
265 \\
264 \\
263\end{array}$ & \begin{tabular}{|c|}
$\mathrm{mm}$ \\
0.999969 \\
1.000081 \\
0.999891 \\
1.000061 \\
1.000028
\end{tabular} & \begin{tabular}{|c|}
$\mathrm{mm}$ \\
1.000042 \\
0.999996 \\
1.000042 \\
1.000133 \\
1.000016
\end{tabular} & \begin{tabular}{|c|}
$\mathrm{mm}$ \\
1.000055 \\
0.999994 \\
1.000027 \\
1.000029 \\
1.000014
\end{tabular} & $\begin{array}{c}\mathrm{mm} \\
1.000038 \\
1.000000 \\
1.000035 \\
1.000019 \\
1.000016\end{array}$ & $\begin{array}{c}\mathrm{mm} \\
1.000046 \\
1.000019 \\
1.000054 \\
1.000047 \\
1.000000\end{array}$ & \begin{tabular}{|c|}
$\mathrm{mm}$ \\
1.000126 \\
1.000038 \\
1.000093 \\
1.000059 \\
0.999992
\end{tabular} & 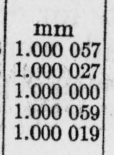 & \begin{tabular}{c|}
$\mathrm{mm}$ \\
1.000046 \\
1.000035 \\
1.000011 \\
1.000010 \\
1.000071
\end{tabular} & \begin{tabular}{l}
\multicolumn{2}{c}{$\mathrm{mm}$} \\
1.000047 \\
1.000024 \\
1.000019 \\
1.000053 \\
1.000020
\end{tabular} \\
\hline & $\begin{array}{l}262 \\
261 \\
260 \\
259\end{array}$ & $\begin{array}{l}1.000040 \\
0.999964 \\
0.999996 \\
0.999976 \\
\end{array}$ & $\begin{array}{l}1.000099 \\
0.999960 \\
1.000004 \\
0.999906 \\
\end{array}$ & $\begin{array}{l}1.000026 \\
0.999940 \\
0.999966 \\
0.999933 \\
\end{array}$ & & 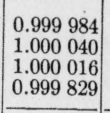 & $\begin{array}{l}1.000040 \\
1.000036 \\
1.000000 \\
0.999968 \\
\end{array}$ & $\begin{array}{l}1.000004 \\
0.999968 \\
0.999948 \\
1.000111 \\
\end{array}$ & & $\begin{array}{l}1.000028 \\
0.999984 \\
0.999996 \\
0.999963\end{array}$ \\
\hline Iear & & 1.000001 & 1.000022 & 0.999998 & 0.999999 & 1.000004 & 1.000039 & 1.000021 & 1.000034 & 0015 \\
\hline
\end{tabular}


between the pitch of the winding and the pitch of the precision screw of the lathe. In the first method a micrometer microscope and a small electric lamp were mounted on the lathe carriage. With the lathe in motion, the image of the lamp filament as reflected from the wire appeared as a line of light in the microscope. The lathe was run continuously, but very slowly, and readings of the micrometer were made four times during a revolution at equally spaced angular positions. In the second method one end of a metal finger pressed

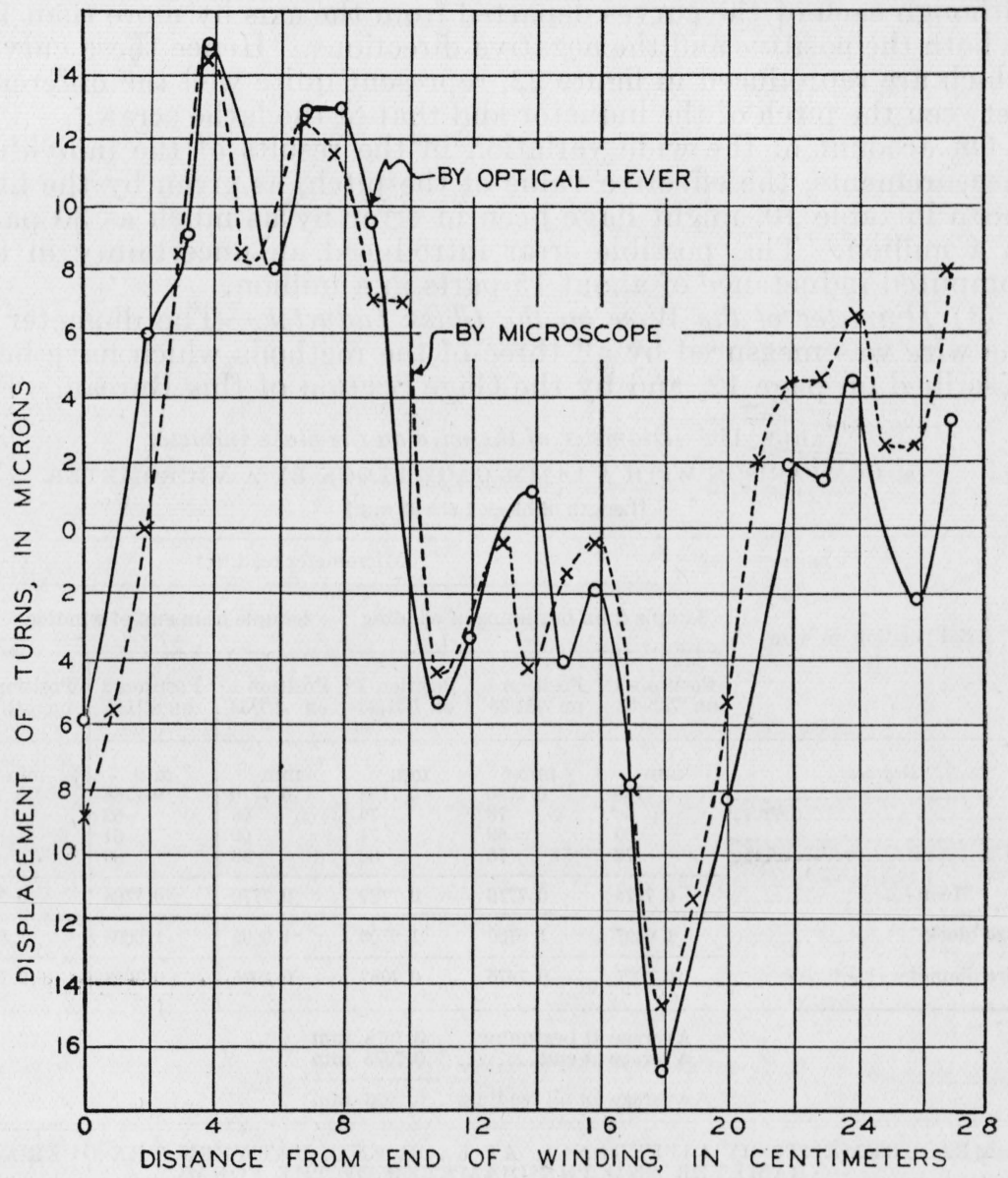

FIGURE 22.-Displacement of turns from nominal position for glass inductor as determined by means of a lathe screw whose pitch is assumed uniform.

lightly against one side of the wire while the other end was hinged to a block that was attached to the lathe carriage. There was a mirror on the face of the finger so that the angular deflections could be read by a lamp and scale. Readings were made at the same positions as with the micrometer microscope. A photograph of the setup is shown in figure 21 with the quartz inductor in the lathe. The metal finger with attached mirror may be seen at the far end of the winding. 
The readings for each angular position and for both sets of data were plotted with wire numbers as abscissas and deflections as ordinates. There was frequently a variation of several microns from one turn to the next so that the curve connecting the points had a jagged appearance. A smooth curve was drawn to represent a mean of the plotted points for each of the eight sets of data. Finally, the curves obtained by the micrometer microscope were combined into a single curve and the curves with the optical lever into another curve. At very few points did these two curves differ by more than 2 or $3 \mu$ although each of the curves departed from the axis by more than $15 \mu$ in both the positive and the negative directions. Hence these curves, which are reproduced in figure 22, represent quite well the difference between the pitch of the inductor and that of the lathe screw.

On account of the wide variation in the results of the individual measurements, the effective value of the pitch, as given by the final mean in table 10 , might have been in error by as much as 30 parts in a million. This possible error introduced an uncertainty in the computed inductance of about 15 parts in a million.

(3) Diameter of the Wire on the Glass Inductor.-The diameter of the wire was measured by all three of the methods which have been described on page 12, and by the Gage Section of this Bureau. The

TABLE 11.-Diameter of the wire on the glass inductor

(a) COMPARISON WITH A 1.6-MM GAGE BLOCK BY A MICROMETER

[Length of block $1.59999 \mathrm{~mm}$ ]

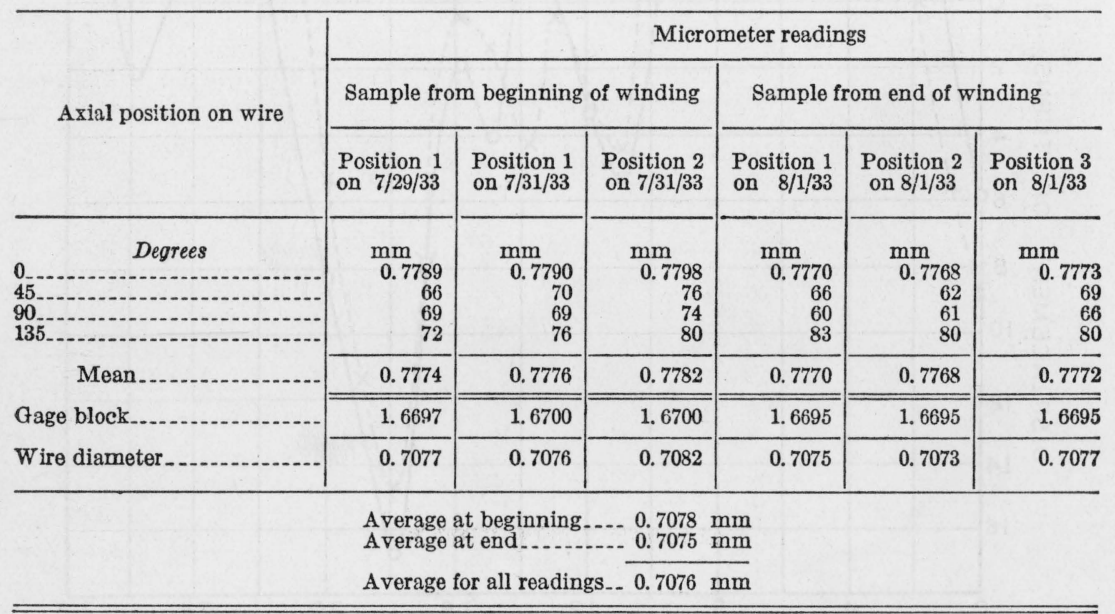

(b) MEASUREMENTS BY DIFFERENCE, AT EACH END, BETWEEN THE OVER-ALL DIAMETER AND THE DIAMETER OF THE FORM

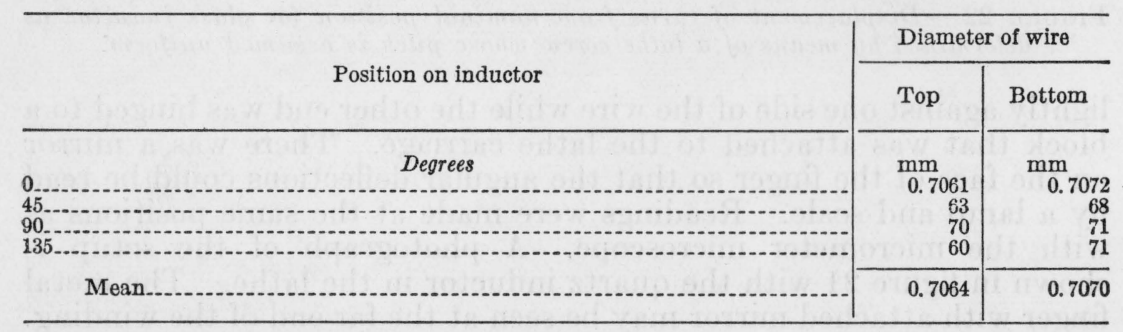

Mean of all, $0.7067 \mathrm{~mm}$ 


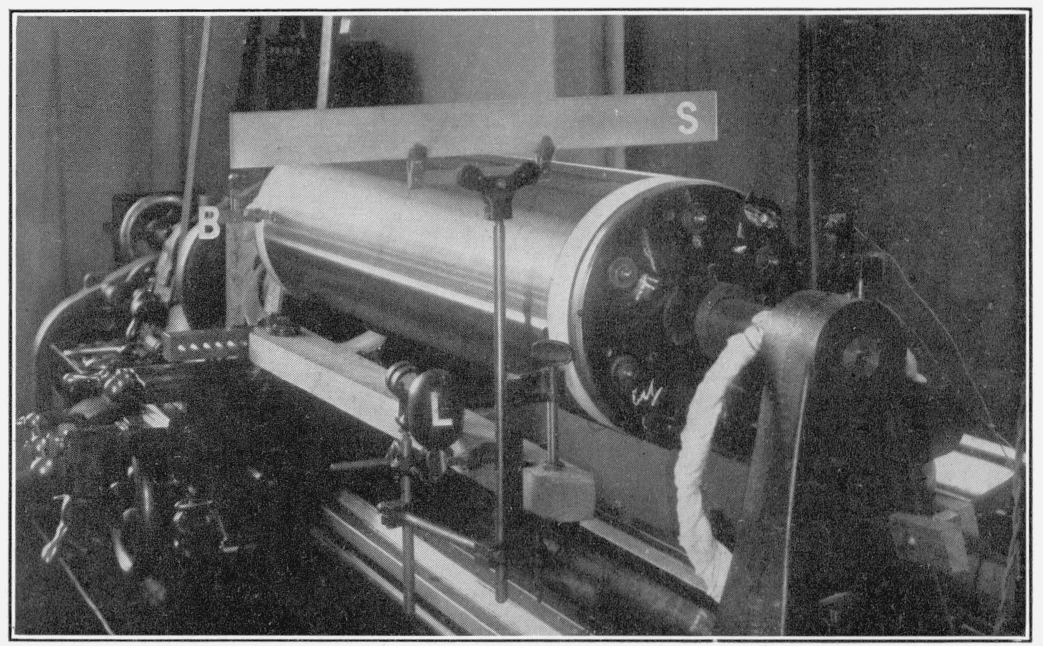

FIGURE 21.-Optical lever used to measure the variations in pitch of the glass and quartz inductors.

The photograph shows the arrangement for measurements on the quartz inductor. One end of a metal finger, which pressed lightly against one side of the wire, was hinged to a block $\mathrm{B}$, that was attached to the lathe carriage. The lamp $L$ and the scale $S$, by which the deflections of a mirror attached to the to the lathe carriage. The $\mathrm{amp} \mathrm{L}$ and the scale $\mathrm{S}$, by which the deflections of a mirror attached to the
finger were read, were also attached to the carriage. The lathe was run continuously and readings made at every quarter of a revolution. 


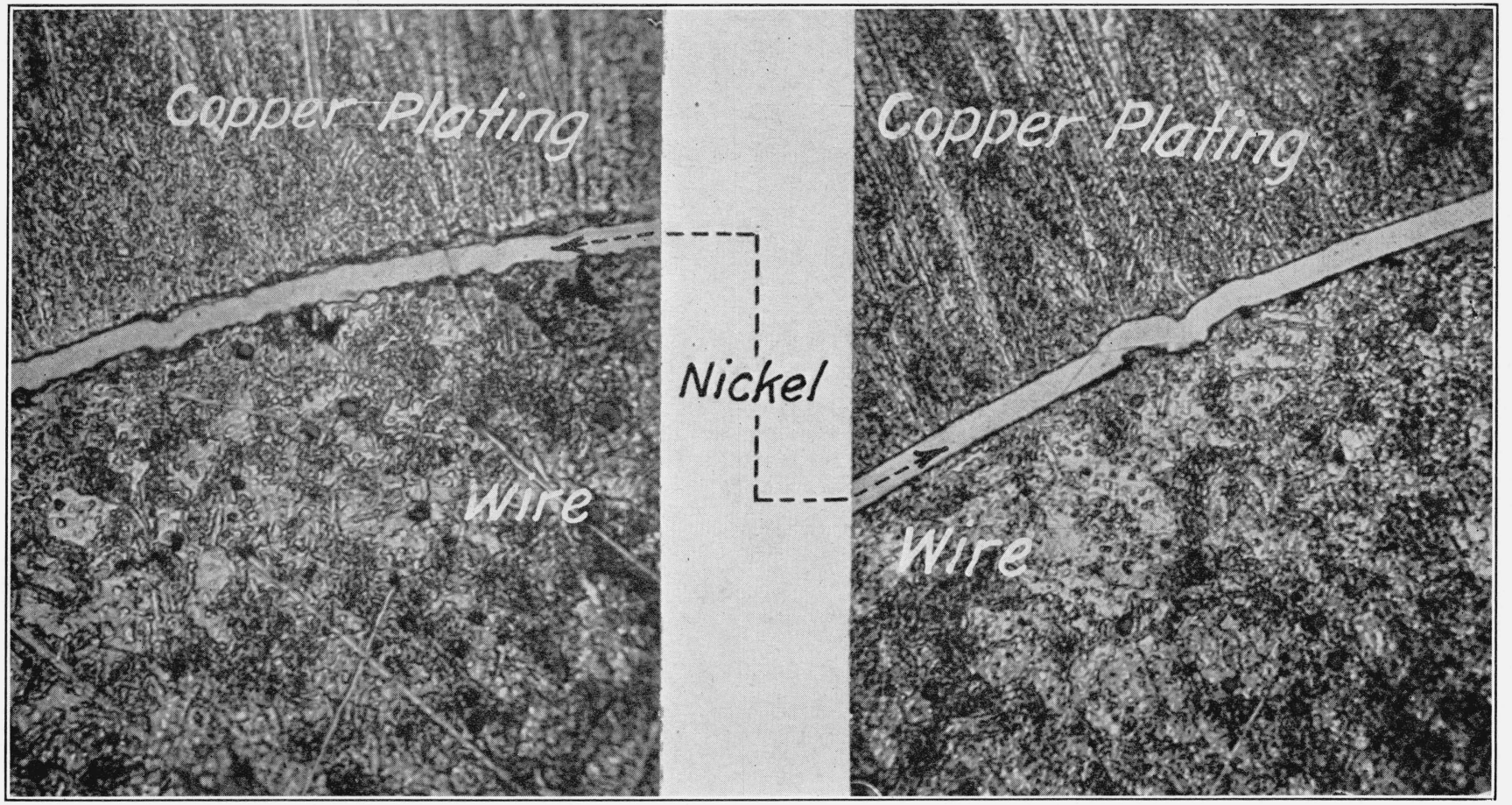

FIGURE 23.-Photomicrographs, with a magnification of 1000, of portions of transverse cross sections of wire used in the glass inductor. Before making a section, the wire was lightly nickel-plated, then heavily copper-plated. 
TABLE 11.-Diameter of the wire on the glass inductor-Continued

(c) COMPUTATION FROM MEASUREMENTS OF LENGTH, MASS, AND DENSITY

\begin{tabular}{|c|c|c|c|c|}
\hline Sample & Length & Mass & Density & $\begin{array}{l}\text { Computed } \\
\text { diameter }\end{array}$ \\
\hline $\begin{array}{l}\text { Beginning of winding } \\
\text { End of winding }\end{array}$ & $\begin{array}{l}\text { cm } \\
\text { 436. } 181 \\
436.103\end{array}$ & $\begin{array}{l}\mathrm{g} \\
15.191 \\
15.170\end{array}$ & $\begin{array}{l}\mathrm{g} / \mathrm{cm}^{3} \\
8.864 \\
8.863\end{array}$ & $\begin{array}{l}\mathrm{mm} \\
0.7073 \\
0.7069\end{array}$ \\
\hline Mean.. & $\ldots$ & $\ldots$ & $\ldots$ & 0.7071 \\
\hline
\end{tabular}

(d) MEASUREMENT BY GAGE SECTION* ON SAMPLES TAKEN FROM BEGINNING AND END OF WINDING

Average minimum diameter... $0.7071 \mathrm{~mm}$

Average maximum diameter.. $0.7092 \mathrm{~mm}$

Mean

"Report states: "No appreciable difference in diameter of the two samples was observed, but there was a slight ellipticity."

(e) SUMMARY OF RESULTS OF (a), (b), (c), AND (d)

\begin{tabular}{|c|c|c|}
\hline Method & Diameter & $\begin{array}{l}\text { Variation } \\
\text { from mean }\end{array}$ \\
\hline $\begin{array}{l}\text { Micrometer-1. } \\
\text { Difference-_. } \\
\text { Density } \\
\text { Gage Section- }\end{array}$ & $\begin{array}{r}\mathrm{mm} \\
0.7076 \\
67 \\
71 \\
82\end{array}$ & $\begin{array}{r}\mu \\
+0.2 \\
-0.7 \\
-0.3 \\
+0.8\end{array}$ \\
\hline Mean.... & 0.7074 & \pm 0.5 \\
\hline
\end{tabular}

results are given in table 11 . The measurements on the diameter of samples by the micrometer and by the methods of the gage section showed that the wire was not exactly round, the difference between the maximum and minimum diameter being about $2 \mu$. The difference between the over-all diameter and the diameter of the form as measured at the ends gave a value for the diameter of the wire which was about a micron smaller than the average of the micrometer readings. This might be interpreted as indicating either that the wire lay on the form with its maximum diameter in the direction of the axis of the helix, or, more probably, that the form was compressed by the winding so that the difference in diameters did not give the true diameter of the wire. The density method gave an average diameter of wire somewhat smaller than that obtained by the micrometer readings. This was explained by the striae on the surface of the wire (see fig. 23) which made the actual cross section somewhat smaller than that obtained by the micrometer measurements. However, the method had the advantage of determining the average diameter over a considerable length (3 turns) of wire.

As each method has some strong and some weak points, it was decided to use the mean of the average values obtained by all of the methods as the diameter of the wire. This value is given in table $11(\mathrm{e})$, together with the variation of the results by each method from the mean of all. The uncertainty $(0.5 \mu)$ in the diameter of the wire introduces an uncertainty of 7 parts in a million in the computed value of the inductance. 
(b) COMPUTATION OF THE INDUCTANCE OF THE GLASS INDUCTOR

In the computation of the inductance of the glass inductor, two methods were followed in correcting for the variations in pitch. In one case the pitch was taken as the mean value, given in table 10 , for the 9 symmetrical turns at each end of the coil and the assumption was made that the mean pitch obtained in this way was the effective pitch. In the other case the pitch was taken as the average value obtained from the measurements between the two end turns as given in the first row of table 10 , and a correction was made for the variations in pitch by Snow's method, using the observations recorded in the curves of figure 22 , without correcting them for possible variations in the pitch of the lathe screw.

The computation of the inductance, using the pitch obtained by the first method, made use of the following constants:

\begin{tabular}{|c|c|c|}
\hline Quantity & Symbol & Value \\
\hline $\begin{array}{l}\text { Mean diameter of helix } \\
\text { Diameter of wire } \\
\text { Pitch of winding- } \\
\text { Number of turns } \\
\text { Effective length of helix }\end{array}$ & $\begin{array}{r}D \\
d \\
g \\
N \\
N=N g\end{array}$ & $\begin{array}{c}46.24342 \mathrm{~cm} \\
0.07074 \mathrm{~cm} \\
0.1000015 \mathrm{~cm} \\
263 \\
26.30039 \mathrm{~cm}\end{array}$ \\
\hline
\end{tabular}

The computation by eq 2 gave the following results:

$$
\begin{aligned}
& L_{0}=+30903112 \text { millimicrohenrys } \\
& L_{1}=-41570 \\
& L_{2}=\quad-16 \\
& L_{3}=\quad-23 \pm 14 \\
& L_{4}=\quad-18 \\
& L_{5}=\quad+53 \\
& L_{\mathrm{h}}=\quad 30861538 \pm 14 \text { millimicrohenrys. }
\end{aligned}
$$

The significance of the \pm term has already been explained (page 18). This computation has been independently checked so that, for the given constants, the result is certainly correct to a part in a million.

The leads to the glass inductor had a diameter of $0.089 \mathrm{~cm}$ and the different parts, as indicated in figure 10, had the following lengths:

$$
\begin{aligned}
\mathrm{PQ} & =\mathrm{P}^{\prime} \mathrm{Q}^{\prime}=1.0 \mathrm{~cm} \\
\mathrm{QR} & =\mathrm{Q}^{\prime} \mathrm{R}^{\prime}=12.65 \mathrm{~cm} \\
\mathrm{RS} & =\mathrm{R}^{\prime} \mathrm{S}^{\prime}=24.2 \mathrm{~cm} \\
\mathrm{RR} & =\mathrm{SS}^{\prime}=1.0 \mathrm{~cm}
\end{aligned}
$$

The total computed inductance, by eq 15 was:

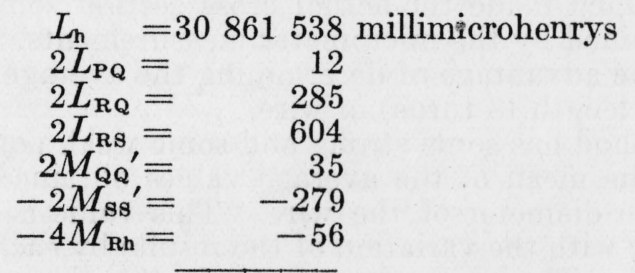

$L=30862139$ millimicrohenrys. 
The substitution inductor consisted of two parallel wires spaced $1 \mathrm{~cm}$ apart and bridged by a gold wire $0.06 \mathrm{~cm}$ in diameter. Each parallel wire consisted of $2 \mathrm{~cm}$ of copper wire $0.09 \mathrm{~cm}$ in diameter, and $17.4 \mathrm{~cm}$ of manganin wire $0.01 \mathrm{~cm}$ in diameter. The computed inductance, $l_{s}$, of the substitution inductor was 426 millimicrohenrys. Hence the value of $\mathrm{L}-l_{s}$ was, by the first method:

$$
L-l_{s}=30.86171 \text { absolute millihenrys. }
$$

In determining the inductance by using the end turns to obtain the pitch and correcting for the variations in pitch, the pitch of the inductor was taken from the first row of table 10 as $0.1000047 \mathrm{~cm}$, all other dimensions being the same as in the first procedure. The decrease in inductance caused by this change in pitch was 18 parts in a million and the correction for variations in pitch was found by Snow ${ }^{37}$ to be an increase of 31 parts in a million. Hence this procedure gave a value of the computed inductance which was 13 parts in a million larger than that obtained by the first procedure, so that, by the second method:

$$
L-l_{s}=30.86211 \text { absolute millihenrys. }
$$

As the data for computing the pitch corrections were not precise, it was estimated that the error in the computed inductance, resulting from an uncertainty in the distance between the end turns and from the correction for the irregularities in winding, may have been in error by 15 parts in a million.

Objection can be raised to each of the above procedures. The first made use of only a few turns at each end, and gave equal weight to every value of the pitch as determined from measurements of the distances between these turns. The second procedure made use of only a few length measurements in determining the pitch, so that observational errors might have been relatively large, and based a correction for variations in pitch upon the comparisons of the winding with a lathe screw, which might have had errors as large as $10 \mu$ per decimeter. Hence the two values were given equal weight, so that

$$
L-l_{\mathrm{s}}=30.86191 \text { absolute millihenrys. }
$$

Correcting this value for the permeability of the form by the value in table $2(-4$ parts per million) gave

$$
L-l_{\mathrm{B}}=30.86179 \text { absolute millihenrys. }
$$

From a consideration of the errors in the measurements of the dimensions, the error in the computed inductance was estimated as less than 20 parts in a million.

\section{(c) ELECTRICAL MEASUREMENTS ON THE GLASS INDUCTOR}

More than 100 electrical determinations of the inductance of the glass inductor were made, all in R212 E, which had ordinary steel reinforcement in both floor and ceiling. Additional relative measurements for obtaining the effect of the reinforcement in the floor and ceiling were made in R213 E and R214 E.

(1) Effect of the Steel Reinforcement of the Building.-A correction for the effect of the reinforcing rods on the inductance, when the axis

${ }^{37}$ The value previously published (see BS. J. Research 6, 777, (1931) RP304) was different from thi value because the dimensions of the inductor had not then been accurately measured. 
of the inductor was vertical, was obtained from curve I of figure 24 , which was plotted from the data used in the upper central part of the curve for the glass inductor in figure 14, and which included, therefore, only those observations in which the inductor was so far removed from the floor that the effect of the nails was negligible. This curve is extrapolated to $300 \mathrm{~cm}$ from the ceiling, at which point it becomes practically horizontal, so that at this distance the effect of the reinforcing rods was considered to be negligible. Hence the zero of the ordinates was arbitrarily drawn through this horizontal part. Curve II was plotted from data similar to those used in curve I, except

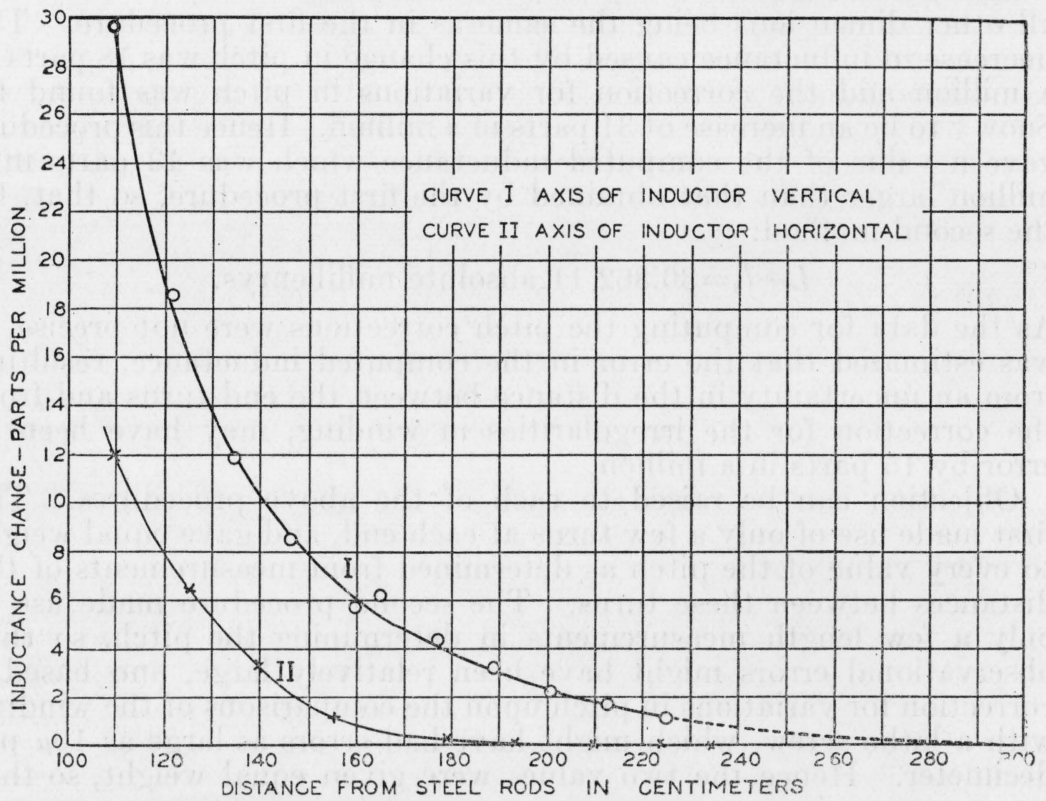

FIGURE 24.-Variation in inductance of glass inductor with distance from horizontal reinforcing rods of ordinary steel

In curve I the axis of the inductor was vertical and perpendicular to the reinforcing rods; in curve II the axis was parallel to the rods.

that the axis of the inductor was horizontal and parallel to the reinforcing rods. The corrections for the steel reinforcing rods on the inductance at different elevations in $\mathrm{R} 212 \mathrm{E}$ have been estimated from these curves and are given in table 12 .

TABLE 12.-Corrections to the inductance of the glass inductor for the effect of steel reinforcing rods

Values are given for 3 different elevations in R212 E, which has steel reinforcing rods in both the floor and ceiling.

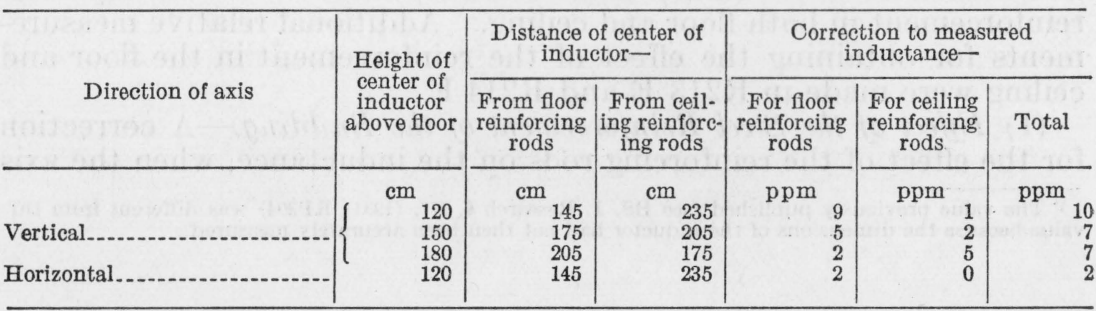


(2) Measured Inductance.-The measurements of the inductance of the glass inductor can be divided into two series, designated as the early series and the later series. In the early series, the terminal $Z$ of the capacitor, shown in figure 11, was unshielded, but a correction, obtained by measurement with a double Maxwell bridge, has been made to each result. During this series, several different types of resistors were used in the $\mathrm{a}-\mathrm{c}$ bridge, some of which were later found to be defective. All results obtained with the defective types have been discarded.

The combinations of resistances and capacitances used in the a-c bridge (see fig. 11) for determining the results tabulated in table 13 were as follows: In one combination, the nominal resistances of $r_{2}$ and $r_{4}$ were $1050 \mathrm{ohms} ; r_{1}$ was $293 \mathrm{ohms}$, and $\mathrm{C}_{\mathrm{f}}, 0.1 \mu \mathrm{f}$. In the second combination the same resistors were used for $r_{2}$ and $r_{4}$, but $r_{1}$ was 117.5 ohms, and $\mathrm{C}_{\mathrm{f}}, 0.25 \mu \mathrm{f}$. In the third combination $r_{2}$ and $\mathrm{r}_{4}$ were 525 ohms, $r_{1}$ was 293 ohms, and $\mathrm{C}_{\mathrm{f}}, 0.2 \mu \mathrm{f}$. During this early series the precision of measurement was increased from time to time, but no marked changes were made at any one time. The average result for each position has been corrected for the effect of the reinforcing rods by the data given in table 12 .

\section{TABLE 13.-Inductance of glass inductor (early series)}

In these measurements, the terminal $\mathrm{Z}$, shown in figure 11, was unshielded. After the series was completed, a measurement of the capacitance of this terminal to earth by the method described on page 48 gave a value of $1.7 \mu \mu \mathrm{f}$. This correction has been made in obtaining the values of inductance given in the table.

All measurements were made in R212 E with the center of the inductor at a height of $120 \mathrm{~cm}$ from the All measurements were made in $\mathrm{R} 212 \mathrm{E}$ with the center of the inductor at a height of $120 \mathrm{~cm}$ from the
floor (145 $\mathrm{cm}$ from reinforcing rods of floor and $235 \mathrm{~cm}$ from those of ceiling). In the absolute-capacitance bridge, the contacts were of tungsten and were operated in a vacuum.

Temperature of inductor: $29.5^{\circ} \mathrm{C}$.

\begin{tabular}{|c|c|c|c|c|c|c|c|c|}
\hline Date & $\begin{array}{c}\text { Fre- } \\
\text { quency }\end{array}$ & Direction of axis & \begin{tabular}{|} 
Nom- \\
inal \\
value of \\
capaci- \\
tance
\end{tabular} & $\begin{array}{l}\text { Num- } \\
\text { ber of } \\
\text { deter- } \\
\text { mina- } \\
\text { tions in } \\
\text { group }\end{array}$ & $\begin{array}{c}\text { A verage } \\
\text { value of } \\
\text { inductance } \\
\text { of group }\end{array}$ & $\begin{array}{l}\text { Induc- } \\
\text { tance cor- } \\
\text { rected for } \\
\text { steel rein- } \\
\text { forcement }\end{array}$ & \begin{tabular}{|} 
Mean de- \\
viation \\
of indi- \\
vidual \\
readings \\
from \\
average \\
of group
\end{tabular} & $\begin{array}{l}\text { Devia- } \\
\text { tion of } \\
\text { average } \\
\text { values } \\
\text { from } \\
\text { weighted } \\
\text { mean }\end{array}$ \\
\hline $\begin{array}{l}1933 \\
\text { Mar. } 18 \text { to } 23 . \\
\text { Mar. } 24 \text { to } 27 \\
\text { Mar. } 28 \text { to } 30 \\
\text { Mar. } 31 \text { and } \\
\text { Apr. } 1 . \\
\text { Apr. } 8 \text { to } 11 \\
\text { Apr. } 11 \text { to } 12 \\
\text { Apr. } 13 \text { to } 15 . . \\
\end{array}$ & $\begin{array}{r}\mathrm{c} / \mathrm{s} \\
25 \\
100 \\
100 \\
25 \\
\\
25 \\
100 \\
100 \\
\end{array}$ & Vertical.. & $\left\{\begin{array}{l}\mu \mathrm{f} \\
0.25 \\
.25 \\
.10 \\
.10 \\
\\
.25 \\
.25 \\
.10 \\
\end{array}\right.$ & $\begin{array}{l}5 \\
5 \\
4 \\
1 \\
\\
4 \\
3 \\
2 \\
\end{array}$ & \begin{tabular}{|r|}
$\begin{array}{c}\text { NBS inter- } \\
\text { national } \\
\text { mh }\end{array}$ \\
30.84852 \\
837 \\
867 \\
908 \\
836 \\
829 \\
891 \\
\end{tabular} & $\begin{array}{c}\begin{array}{c}\text { NBS inter- } \\
\text { national } \\
\text { mh }\end{array} \\
\end{array}$ & $\begin{array}{r} \\
\text { ppm } \\
3 \\
2 \\
4 \\
4 \\
1 \\
1 \\
4 \\
\end{array}$ & $\begin{array}{r}\text { ppm } \\
0 \\
-5 \\
+5 \\
+19 \\
-4 \\
-7 \\
+13 \\
\end{array}$ \\
\hline \multicolumn{5}{|c|}{$\begin{array}{l}\text { Mean, weighted according to number of determinations. } \\
\text { Average deviation of individual values from the mean }\end{array}$} & $\begin{array}{c}30.84851 \\
\end{array}$ & 30.84820 & 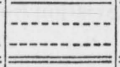 & $\overline{5}$ \\
\hline $\begin{array}{l}\text { May } 1 \text { to } 5 \\
\text { May } 18 \text { to } 25 \\
\text { May } 22 \\
1934 \\
\text { May } 1 \text { to } 4 \\
\text { May } 8 \\
\text { May } 10 \text { to } 11 \\
\text { May } 17 \\
\text { May } 24 \\
\text { May } 24 \text { to June } 1 \\
\end{array}$ & $\begin{array}{l}24 \\
24 \\
24 \\
24 \\
24 \\
24 \\
\end{array}$ & $\begin{array}{l}\text { Horizontal (east. } \\
\text { west). }\end{array}$ & $\begin{array}{l}.25 \\
.10 \\
.20 \\
.10 \\
.25 \\
.10 \\
\end{array}$ & $\begin{array}{l}5 \\
1 \\
3 \\
1 \\
1 \\
3 \\
\end{array}$ & $\begin{array}{r}30.84802 \\
822 \\
815\end{array}$ & 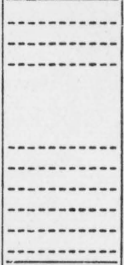 & \begin{tabular}{r}
1 \\
10 \\
\hdashline-15 \\
\end{tabular} & $\begin{array}{r}-7 \\
+5 \\
+12 \\
+16 \\
+2 \\
+4\end{array}$ \\
\hline $\begin{array}{l}\text { Mean, weig } \\
\text { Average der }\end{array}$ & viation & $\begin{array}{l}\text { ordin } \\
\text { Find } \\
\text { Fina }\end{array}$ & etermin & ons. & 30.84831 & $\begin{array}{r}30.84825 \\
30.84822\end{array}$ & 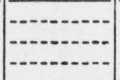 & $-\infty-\frac{1}{7}$ \\
\hline
\end{tabular}




\section{TABLE 14.-Inductance of glass inductor (later series)}

All measurements made at $24 \mathrm{c} / \mathrm{s}$. Fixed capacitance completely shielded. Resistors of a-c bridgebare manganin wire on Pyrex-glass forms. Inductor in R212 E, which has steel reinforcement in both floor and ceiling.

Temperature of inductor: $29.5^{\circ} \mathrm{C}$

\begin{tabular}{|c|c|c|c|c|c|c|c|c|}
\hline Date & Direction of axis & $\begin{array}{c}\text { Height } \\
\text { from } \\
\text { floor }\end{array}$ & $\begin{array}{c}\text { Nomi- } \\
\text { nal } \\
\text { value of } \\
\text { inter- } \\
\text { medi- } \\
\text { ary ca- } \\
\text { paci- } \\
\text { tance }\end{array}$ & $\begin{array}{c}\text { Capaci- } \\
\text { tance by } \\
\text { bridge } \\
\text { with } \\
\text { vacuum } \\
\text { contac- } \\
\text { tors } \\
\text { minus } \\
\text { that by } \\
\text { bridge } \\
\text { with } \\
\text { inertia } \\
\text { contac- } \\
\text { tors }\end{array}$ & $\begin{array}{l}\text { Induct- } \\
\text { ance }\end{array}$ & $\begin{array}{c}\text { Variation } \\
\text { from } \\
\text { mean of } \\
\text { group }\end{array}$ & $\begin{array}{l}\text { Average } \\
\text { induct- } \\
\text { ance cor- } \\
\text { rected for } \\
\text { reinforc- } \\
\text { ing rods. } \\
\text { See table } \\
12\end{array}$ & $\begin{array}{l}\text { Devia- } \\
\text { tion of } \\
\text { aver- } \\
\text { age } \\
\text { values } \\
\text { from } \\
\text { final } \\
\text { aver- } \\
\text { age }\end{array}$ \\
\hline $\begin{array}{l}\quad 1934 \\
\text { Nov. } 5 \\
\text { Nov. } 6 \\
\text { Nov. } 8 \text { (a. m.). } \\
\text { Nov. } 8 \text { (a. m.) } \\
\text { Nov. } 9 \\
\text { Nov. } 14(\mathrm{a} . \mathrm{m} .) \\
\text { Nov. } 14 \text { (p. m.) } \\
\text { Nov. } 15 . . . \\
\text { Nov. } 16 .\end{array}$ & $\left\{\begin{array}{l}\text { Horizontal (east- } \\
\text { west). }\end{array}\right\} \begin{array}{l}\text { Horizontal (east- } \\
\text { west). }\end{array}$ & 120 & $\begin{array}{l}\mu f \\
0.10\end{array}$ & $\left\{\begin{array}{r}\text { ppm } \\
-7 \\
+2 \\
-3 \\
\hdashline-6 \\
0\end{array}\right.$ & \begin{tabular}{|r} 
NBS inter- \\
national \\
mh \\
30.84826 \\
823 \\
808 \\
811 \\
815 \\
808 \\
793 \\
819 \\
834 \\
\end{tabular} & $\begin{array}{r}\mathrm{ppm} \\
+4 \\
+3 \\
-2 \\
-1 \\
0 \\
-2 \\
-7 \\
+1 \\
+6 \\
\end{array}$ & $\begin{array}{c}\begin{array}{c}\text { NBS inter- } \\
\text { national } \\
\text { mh }\end{array} \\
\\
\\
\\
\\
\\
\end{array}$ & \begin{tabular}{|c} 
ppm \\
\\
\\
\\
\\
\\
\\
\\
\end{tabular} \\
\hline $\begin{array}{l}\text { A verage of group } \\
\text { A verage deviation }\end{array}$ & $\cdots$ & $\ldots$ & (n..... & 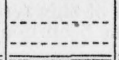 & $\begin{array}{r}30.84815 \\
\end{array}$ & 2.9 & $\begin{array}{r}30.84809 \\
-\end{array}$ & $\begin{array}{r}+1 \\
-1 \\
\end{array}$ \\
\hline $\begin{array}{l}\text { Nov. } 20 \\
\text { Nov. } 24 \\
\text { Nov. } 26\end{array}$ & \}ertical & 120 & .25 & $\begin{array}{l}+2 \\
+5 \\
+2\end{array}$ & $\begin{array}{r}30.84860 \\
40 \\
37 \\
\end{array}$ & $\begin{array}{l}+5 \\
-2 \\
-3\end{array}$ & 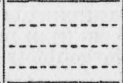 & \begin{tabular}{ll}
$\ldots \ldots$ \\
\hdashline$\ldots \ldots$
\end{tabular} \\
\hline $\begin{array}{l}\text { Average of group } \\
\text { Average deviatio }\end{array}$ & (n) & (n)...... & 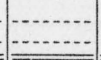 & 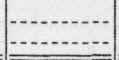 & $\begin{array}{r}30.84846 \\
\hdashline\end{array}$ & 3.3 & $\begin{array}{r}30.84815 \\
\end{array}$ & $\begin{array}{r}+3 \\
-\end{array}$ \\
\hline $\begin{array}{l}\text { Dec. } 3 \text { (a. m.) } \\
\text { Dec. } 3 \text { (p. m.) } \\
\text { Dec. } 5 \ldots\end{array}$ & Vertical. & 150 & .25 & $\begin{array}{r}0 \\
+2 \\
+4 \\
\end{array}$ & $\begin{array}{r}30.84820 \\
18 \\
23 \\
\end{array}$ & $\begin{array}{r}0 \\
-1 \\
+1 \\
\end{array}$ & 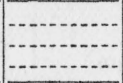 & 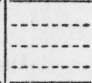 \\
\hline $\begin{array}{l}\text { Average of group } \\
\text { A verage deviatio }\end{array}$ & n- & . & -... & - & $\begin{array}{r}30.84820 \\
\hdashline\end{array}$ & 0.7 & $\begin{array}{r}30.84799 \\
\end{array}$ & $\begin{array}{r}-3 \\
-3 \\
\end{array}$ \\
\hline $\begin{array}{l}\text { Dec. } 6 \\
\text { Dec. } 7 \\
\text { Dec. } 11 \\
\text { Dec. } 12 \\
\text { Dec. } 14\end{array}$ & Vertical & 180 & $\left\{\begin{array}{l}.25 \\
.1\end{array}\right.$ & $\left\{\begin{array}{r}+3 \\
-1 \\
-1 \\
+7\end{array}\right.$ & $\begin{array}{r}30.84816 \\
00 \\
25 \\
41 \\
24 \\
\end{array}$ & $\begin{array}{l}-2 \\
+7 \\
+1 \\
+7 \\
+1 \\
\end{array}$ & $\begin{array}{l} \\
\\
\end{array}$ & 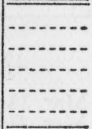 \\
\hline $\begin{array}{l}\text { A verage of group } \\
\text { A verage deviation }\end{array}$ & $\mathrm{n}$ & - & & - & 30.84821 & 3.6 & 30.84800 & -2 \\
\hline Weighted mean & for vertical observ & ations. & $\ldots . .$. & (n...... & 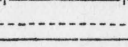 & -. & 30.84805 & $\mid-$. \\
\hline nal average fo & series_................ & & & & & & 30.84807 & \\
\hline
\end{tabular}


The data obtained in the later series of measurements on the glass inductor are given in table 14. In this series, the inductance was determined at three elevations, at one of which the axis was successively horizontal and vertical. All the resistors used in this series were wound with bare manganin wire on Pyrex-glass forms and the capacitor $\mathrm{C}_{\mathrm{f}}$, including the terminal $Z$, was completely shielded. Only the first two combinations of resistances and capacitances used in obtaining the results tabulated in table 13 were employed in the determinations of this series. In all but five of the 20 measurements, the capacitance was measured by two independent Maxwell bridges. Since the average deviation from the mean value of each group of the later series is about 3 parts in a million, and the average deviation of each group from the final mean is 2 parts in a million, the error in the final value of the measured inductance by this series is probably less than 5 parts in a million. All results have been corrected for the effect of the reinforcing rods.

\section{QUARTZ INDUCTOR}

The quartz inductor was superior to either of the other two used in this investigation. Some of the points of superiority were: The material of the form had higher surface resistivity and lower expansivity; the diameter was more uniform; the length was more suitable for precise measurement; and the greater length made the variations in pitch of less importance.

(a) MEASUREMENTS OF THE DIMENSIONS OF THE QUARTZ INDUCTOR

The length and the diameter of the quartz inductor were measured in 1931 and the length was again measured in 1932 . The diameter of the wire was obtained from samples taken from the ends of the inductor at the time of the winding.

(1) Outside Diameter of the Quartz Inductor.-The outside diameter of the quartz inductor was measured at every centimeter of its length in four axial planes, making over 400 observations of this dimension. In each axial plane a set of measurements was first made at each evennumbered centimeter of the length and a few days later a set at each odd-numbered centimeter. The mean result of each set is given in table 15 for the four axial planes. In every axial plane, the average diameter at the odd-numbered centimeters was larger than the average at the even-numbered centimeters by a part in a million. The average deviation of the means for the several axial planes from the mean of all is only 2 parts in a million and is the same for each set. 
The variation in diameter along each axial plane is shown in figure 25 in which are plotted the two sets of readings taken at the odd and the even-numbered centimeters. In the first $5 \mathrm{~cm}$ on each end there was a decrease in diameter of about $4 \mu$ caused by the compression of the tube produced by the winding. The tube was also forced slightly out of round, probably because of the existence of some areas in the wall which were not of full thickness.

\section{TABLE 15.-Outside diameter of the quart $z$ inductor}

Clear fused-quartz end standard BS 1992 was the reference standard for all the measurements. This end standard was calibrated in June 1931 and June 1932 by means of Johansson blocks, the lengths of which were determined in both 1931 and 1932. There was no measurable change in the length of the end standard.

Date of measurement: September 1931.

Measurements at $29.5^{\circ} \mathrm{C}$.

\begin{tabular}{|c|c|c|c|c|}
\hline Axial plane & $\begin{array}{l}\text { Mean of outside } \\
\text { diameter at odd- } \\
\text { numbered centi- } \\
\text { meters along } \\
\text { axis }\end{array}$ & $\begin{array}{c}\text { Deviation } \\
\text { from mean } \\
\text { diameter } \\
\text { of set }\end{array}$ & $\begin{array}{l}\text { Mean of outside } \\
\text { diameter at even- } \\
\text { numbered centi- } \\
\text { meters along } \\
\text { axis }\end{array}$ & $\begin{array}{l}\text { Deviation } \\
\text { from mean } \\
\text { diameter } \\
\text { of set }\end{array}$ \\
\hline $\begin{array}{l}\text { Degrees } \\
0 \text { to } 180 \\
40 \text { to } 225 \\
135 \text { to } 315\end{array}$ & $\begin{array}{r}\mathrm{cm} \\
28.10905 \\
906 \\
891 \\
898\end{array}$ & $\begin{array}{r}\mathrm{ppm} \\
+2 \\
+2 \\
-3 \\
-1\end{array}$ & $\begin{array}{r}\mathrm{cm} \\
28.10903 \\
903 \\
887 \\
895\end{array}$ & $\begin{array}{r}\text { ppm } \\
+2 \\
+2 \\
-3 \\
-1\end{array}$ \\
\hline Mean... & 28.10900 & \pm 2 & 28.10897 & \pm 2 \\
\hline Final & & & 28.10898 & \\
\hline
\end{tabular}

From the above data it was estimated that the mean diameter of $28.10898 \mathrm{~cm}$ was not in error by more than $0.3 \mu$ or a part in a million. This might have introduced an error of 2 parts in a million in the computed inductance.

(2) Pitch of the Quartz Inductor.-The pitch of the quartz inductor was determined from measurements, at eight angular positions, of the distance between the two end turns. The average value of this distance was divided by 999, the number of turns in the distance measured, to obtain the pitch. The values of the pitch, as measured at different positions, are given in table 16 .

The measurements of 1931 were made before the leads were attached. This set of observations was made as a part of a series for locating the best positions for attaching the leads, and hence the readings were not made simultaneously on the two wires as was done in 1932. For this reason, the average of the values of 1932 have been given twice the weight of the average of the values of 1931 in determining the weighted average pitch. 


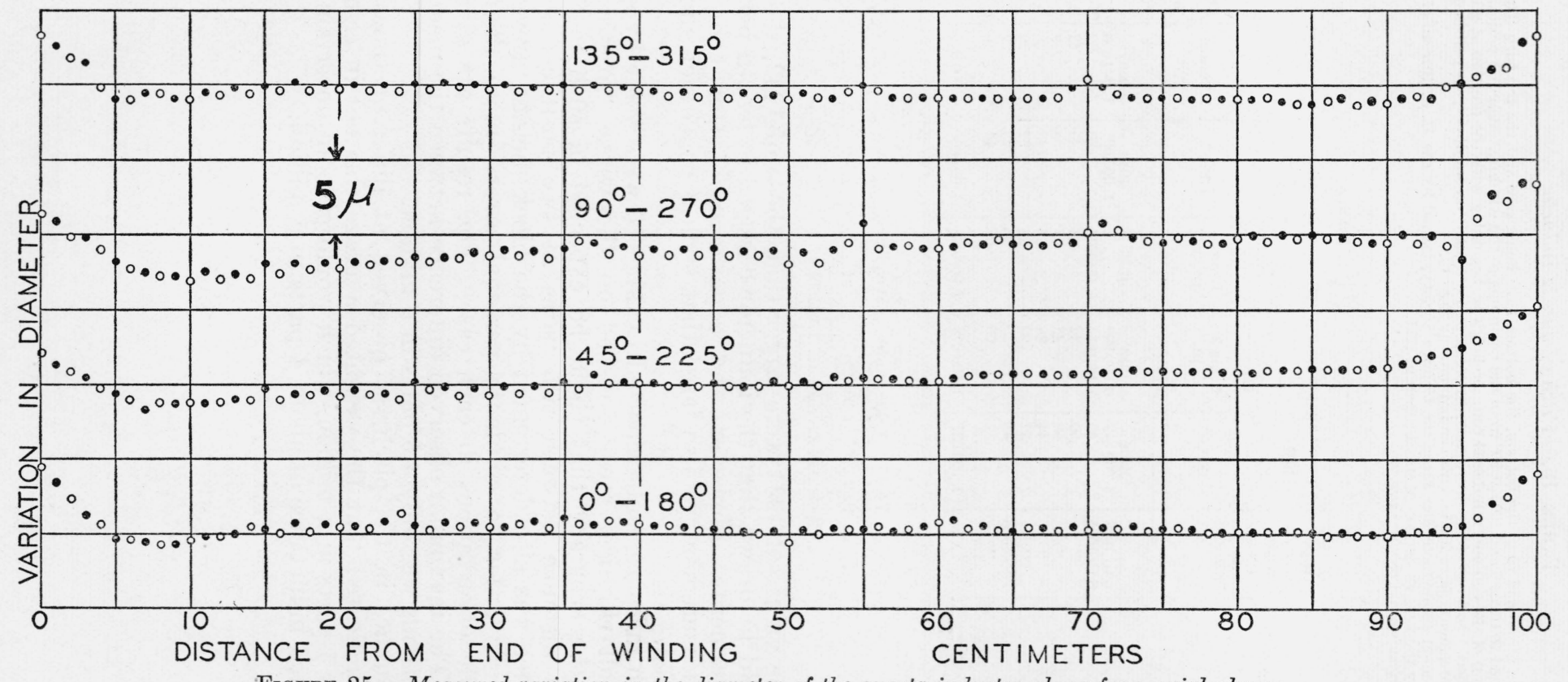

The readings obtained in a set of observations on the even centimeters along its length are indicated by circles; those in a second set on the odd centimeters, by dots. 


\section{TABLE 16.-Pitch of quartz inductor}

The turns were numbered from the bottom, the bottom turn being zero and the top turn 1009. The leads were attached to turns 6 and 1006 at $90^{\circ}$ from the beginning of the winding. Angular positions were marked on the top of the coil and numbered counterclockwise beginning with the position at which the leads were attached. Settings of the micrometer microscope were made on small ellipses polished on the wires. All measurements were made with the inductor at $29.5^{\circ} \mathrm{C}$

Standard of length: Invar meter-bar 354 of the Geneva Society, loaned by the U. S. Bureau of Mines, and calibrated by the Length Section of this Bureau in 1931.

Coefficient of expansion: $1.68 \times 10^{-6}$ per ${ }^{\circ} \mathrm{C}$.

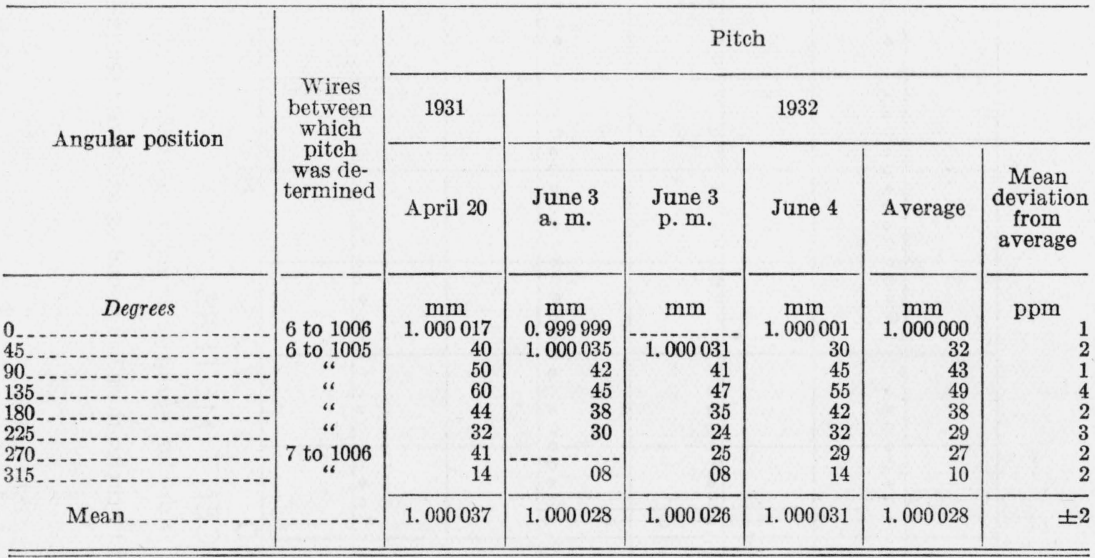

\begin{tabular}{|c|c|c|}
\hline \multicolumn{3}{|c|}{ Weighted Average Pitch } \\
\hline Year & Value $(\mathrm{mm})$ & XX \\
\hline 1931 -..- & 1.000037 & 1 \\
\hline $1932 \ldots$ & 1. 000028 & \\
\hline
\end{tabular}

As all the values of 1931 were larger than those of 1932, the conclusion could be drawn that the inductor changed in length between the measurements. However, the experimental error connected with the measurement was so large that such a conclusion did not seem justified.

The pitch measurements reported in table 16 were made by sighting on small elliptical areas polished on the wires. In order to determine the accuracy that could be expected in such measurements, the distance between two wires at two positions on the circumference was also determined by the block method previously described. In order to eliminate personal errors, more than one person made observations in each case. The results are given in table 17. The maximum observed difference between the means by the two methods was only 1.5 parts in a million.

The difference in the pitch, as observed at different times (see table 16), indicated that the weighted average was not in error by as much as 5 parts in a million, which would give an uncertainty in the computed inductance of about 4 parts in a million. 
TABLE 17.-Comparison of block and ellipse methods of measuring the distance between wires on quartz inductor

\begin{tabular}{|c|c|c|c|}
\hline \multirow{2}{*}{ Method } & \multirow{2}{*}{ Observer } & \multicolumn{2}{|c|}{ Results at- } \\
\hline & & Position 1 & Position 2 \\
\hline Block. & $\begin{array}{l}\mathrm{A} \\
\mathrm{B}\end{array}$ & $\begin{array}{c}\mathrm{cm} \\
99.8993 \\
4\end{array}$ & $\begin{array}{l}\mathrm{cm} \\
100.0006 \\
7\end{array}$ \\
\hline Mean.... & & 99.89935 & 100.00065 \\
\hline Ellipse & $\begin{array}{l}\mathrm{A} \\
\mathrm{B} \\
\mathrm{C} \\
\mathrm{D} \\
\mathrm{E}\end{array}$ & $\begin{array}{r}99.8997 \\
5 \\
2 \\
3 \\
\end{array}$ & $\begin{array}{r}100.0004 \\
6 \\
3 \\
4 \\
8\end{array}$ \\
\hline Mean & . & $99.8994_{2}$ & 100.00050 \\
\hline
\end{tabular}

(3) Irregularities in Winding.- The irregularities in winding were determined by two different methods, one by using the lathe screw, the other by comparison with a graduated meter bar. While the inductor was still mounted in the precision lathe in which it was wound, an optical lever, attached to the lathe carriage, measured the difference between the pitch of the winding and the pitch of the lathe screw as already described for the glass inductor. The second method employed the same cathetometer and calibrated meter bar that were used in determining the pitch. The positions relative to the graduations of the meter bar were determined for 100 wires at each end of the inductor. Measurements were made at $45^{\circ}$ intervals around the circumference for the first 10 turns at each end, then at $180^{\circ}$ intervals for each of the next 90 turns. Between the 100th and the 200th turns, measurements were made on every fifth turn at two positions, while for the remaining 300 turns from each end, measurements were made on every tenth wire at two positions. The displacement of the wires, as observed by both methods, has been plotted in figure 26, which shows the mean curve obtained by the optical lever method and two curves obtained by the cathetometer method for axial positions $180^{\circ}$ apart. The distance from the end wires to each of the next ten wires is given for eight axial positions in table 18. These data have been given to afford the reader information concerning the variations that occur within a single turn. Individual values may be in error by as much as $5 \mu$. The average values in table 18, together with the data obtained by the cathetometer on other turns, were used to compute the correction for the variation in pitch by means of eq 10 . 


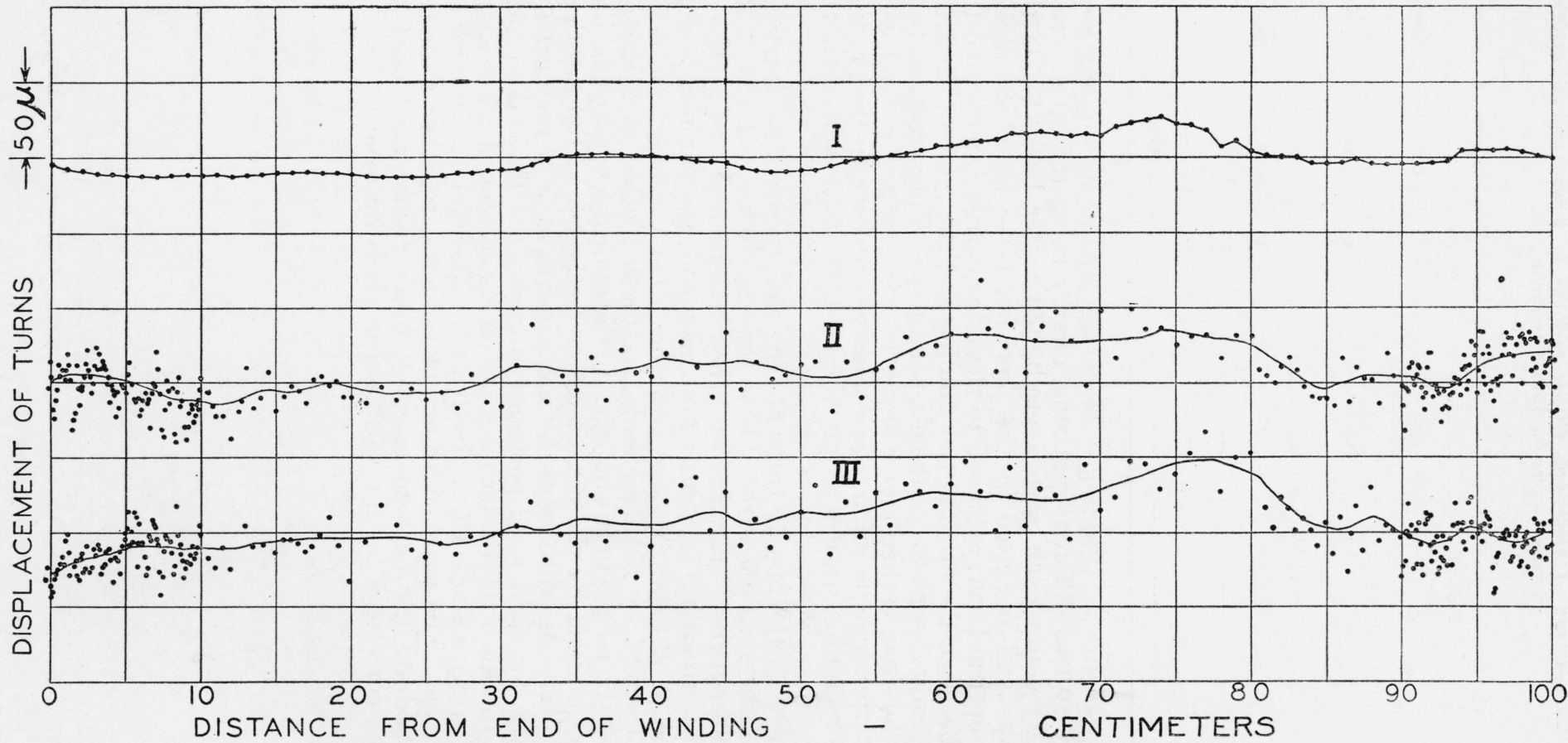

FIGURE 26.-Displacement of turns from nominal position for quartz inductor.

Curve I was obtained by the optical-lever method and represents the mean of the results of four sets of observations taken at $90^{\circ}$ intervals around the inductor. The apparatus for making these measurements is shown in figure 21. Curves II and III were obtained by the cathetometer method and each represents the data of a set of observations taken in one making these measurements is shown in figure 21 . Cur the planes of the two sets being $180^{\circ}$ apart. 
TABLE 18.-Distance from each end turn to each of the next ten turns of the quartz inductor

Data taken in 1931 with the same apparatus as used in the determinations of pitch. See table 16. Measurements at $29.5^{\circ} \mathrm{C}$.

(a) AT UPPER END OF INDUCTOR

[Distance from turn no. 999, in microns]

\begin{tabular}{|c|c|c|c|c|c|c|c|c|c|c|}
\hline $\begin{array}{l}\text { Wire } \\
\text { no. } \\
\downarrow\end{array}$ & $\begin{array}{l}\text { Angular } \\
\text { position }\end{array} \rightarrow$ & $0^{\circ}$ & $45^{\circ}$ & $90^{\circ}$ & $135^{\circ}$ & $180^{\circ}$ & $225^{\circ}$ & $270^{\circ}$ & $315^{\circ}$ & $\begin{array}{l}\text { A ver- } \\
\text { age }\end{array}$ \\
\hline $\begin{array}{l}998- \\
997- \\
996-- \\
995-- \\
994- \\
993- \\
992- \\
991- \\
990 \ldots \\
989 .\end{array}$ & & $\begin{array}{r}986 \\
1966 \\
2984 \\
3963 \\
4997 \\
5974 \\
6978 \\
7981 \\
9003 \\
9979\end{array}$ & $\begin{array}{r}994 \\
1970 \\
2979 \\
3996 \\
4994 \\
5967 \\
6972 \\
7976 \\
8998 \\
9975\end{array}$ & $\begin{array}{l}1011 \\
1979 \\
2996 \\
4005 \\
5002 \\
5988 \\
6976 \\
7988 \\
9016 \\
9993\end{array}$ & $\begin{array}{r}1027 \\
1982 \\
2995 \\
3995 \\
5010 \\
5970 \\
6990 \\
8017 \\
9013 \\
10001\end{array}$ & $\begin{array}{r}1032 \\
1958 \\
2974 \\
3994 \\
5004 \\
5992 \\
6979 \\
7985 \\
9008 \\
10000\end{array}$ & $\begin{array}{l}1021 \\
1975 \\
2966 \\
3984 \\
4991 \\
5978 \\
6973 \\
7959 \\
8988 \\
9984\end{array}$ & $\begin{array}{l}1020 \\
1986 \\
2983 \\
3996 \\
4991 \\
5990 \\
6982 \\
7975 \\
8991 \\
9997\end{array}$ & $\begin{array}{l}1011 \\
1884 \\
2968 \\
3980 \\
4981 \\
5984 \\
6970 \\
7971 \\
8976 \\
9989\end{array}$ & $\begin{array}{l}1012 \\
1975 \\
2981 \\
3989 \\
4996 \\
5980 \\
6978 \\
7982 \\
8999 \\
9999\end{array}$ \\
\hline
\end{tabular}

(b) AT LOWER END OF INDUCTOR

[Distance from turn no. 1 , in microns]

\begin{tabular}{|c|c|c|c|c|c|c|c|c|c|c|}
\hline $\begin{array}{l}\text { Wire } \\
\text { no. } \\
\downarrow \\
\end{array}$ & $\begin{array}{l}\text { Angular } \\
\text { position }\end{array} \rightarrow$ & $0^{\circ}$ & $45^{\circ}$ & $90^{\circ}$ & $135^{\circ}$ & $180^{\circ}$ & $225^{\circ}$ & $270^{\circ}$ & $315^{\circ}$ & $\begin{array}{l}\text { Aver- } \\
\text { age }\end{array}$ \\
\hline $\begin{array}{l}11 \ldots \\
10 \ldots \\
9 \ldots \\
8 \ldots \\
7 \ldots \\
6 \ldots \\
5 \ldots \\
4 \ldots \\
3 \ldots \\
2 \ldots\end{array}$ & $2-2 x^{2}-2-2$ & $\begin{array}{rr}100 & 21 \\
90 & 21 \\
80 & 32 \\
70 & 27 \\
60 & 21 \\
50 & 13 \\
39 & 87 \\
30 & 13 \\
20 & 09 \\
10 & 05\end{array}$ & $\begin{array}{rr}100 & 30 \\
90 & 30 \\
80 & 52 \\
70 & 39 \\
60 & 33 \\
50 & 16 \\
40 & 16 \\
30 & 22 \\
20 & 23 \\
10 & 23\end{array}$ & $\begin{array}{rr}100 & 24 \\
90 & 30 \\
80 & 50 \\
70 & 40 \\
60 & 30 \\
50 & 24 \\
40 & 22 \\
30 & 27 \\
20 & 35 \\
10 & 26\end{array}$ & $\begin{array}{rr}100 & 29 \\
90 & 41 \\
80 & 51 \\
70 & 44 \\
60 & 32 \\
50 & 39 \\
40 & 33 \\
30 & 35 \\
20 & 43 \\
10 & 24\end{array}$ & $\begin{array}{rr}100 & 36 \\
90 & 40 \\
80 & 54 \\
70 & 40 \\
60 & 31 \\
50 & 40 \\
40 & 33 \\
30 & 34 \\
20 & 44 \\
10 & 24\end{array}$ & $\begin{array}{rr}100 & 27 \\
90 & 37 \\
80 & 32 \\
70 & 38 \\
60 & 29 \\
50 & 27 \\
40 & 24 \\
30 & 31 \\
20 & 27 \\
10 & 18\end{array}$ & $\begin{array}{rr}100 & 08 \\
90 & 29 \\
80 & 17 \\
70 & 28 \\
60 & 20 \\
50 & 23 \\
40 & 18 \\
30 & 12 \\
20 & 12 \\
10 & 09\end{array}$ & $\begin{array}{rr}100 & 05 \\
90 & 22 \\
80 & 18 \\
70 & 29 \\
60 & 29 \\
50 & 18 \\
40 & 17 \\
30 & 06 \\
20 & 14 \\
10 & 06\end{array}$ & $\begin{array}{rl}100 & 22 \\
90 & 31 \\
80 & 38 \\
70 & 36 \\
60 & 28 \\
50 & 25 \\
40 & 19 \\
30 & 22 \\
20 & 26 \\
10 & 17\end{array}$ \\
\hline
\end{tabular}

The cathetometer method was more accurate than the optical-lever method, which necessarily depended on the uniformity of the screw of the lathe. Only in its major aspects does curve I of figure 26, which was plotted from the optical-lever data, resemble either curve II or curve III, both of which were plotted from data obtained by the cathetometer method. Hence the correction to the inductance for the irregularities in winding was quite different by the two methods, being $-580 \mathrm{~m} \mu \mathrm{h}$ for the optical-lever data and $+80 \mathrm{~m} \mu \mathrm{h}$ for the cathetometer data. Because the screw was known to have slight irregularities, the correction as obtained by the cathetometer method has been given five times the weight of that by the optical-lever method, giving $-30 \mathrm{~m} \mu \mathrm{h}$ as the accepted correction.

The error produced by the irrgularities in winding may be larger than would be expected from the results by the two methods just described. The theory on which the formula for the correction was based assumed that an entire turn was displaced by a definite amount. Quite evidently there might have been turns in which the average displacement was zero, yet the actual displacements affected the inductance. It seems probable, however, that the error which might have been introduced by the irregularities in winding did not exceed $\pm 700 \mathrm{~m} \mu \mathrm{h}$, which is 10 parts in a million in the inductance.

(4) Diameter of Wire on the Quartz Inductor.-The diameter of the wire on the quartz inductor was measured by the same methods as those for the glass inductor. The measurement of the difference 
between the over-all diameter and the diameter of the form at each of the ends of this inductor did not give a useful result on account of the compression of the form caused by the winding. The data for the three useful methods are given in table 19 .

TABLE 19.-Diameter of the wire on the quart $z$ inductor

(a) COMPARISON WITH A 1.6-MM GAGE BLOCK BY A PRECISION MICROMETER READING TO $0.1 \mu$

[Length of block: $1.59999 \mathrm{~mm}$. Date: August 1, 1933]

\begin{tabular}{|c|c|c|c|c|c|c|}
\hline \multirow{3}{*}{ Axial position on wire } & \multicolumn{6}{|c|}{ Micrometer readings } \\
\hline & \multicolumn{3}{|c|}{ Sample from beginning of winding } & \multicolumn{3}{|c|}{ Sample from end of winding } \\
\hline & Position 1 & Position 2 & Position 3 & Position 1 & Position 2 & Position 3 \\
\hline $\begin{array}{c}\text { Degrees } \\
0 \\
450 \\
55\end{array}$ & $\begin{array}{r}0.2785 \\
86 \\
89 \\
89 \\
\end{array}$ & $\begin{array}{r}0.2793 \\
90 \\
92 \\
90 \\
\end{array}$ & $\begin{array}{r}0.2790 \\
88 \\
89 \\
85 \\
\end{array}$ & $\begin{array}{r}0.2792 \\
89 \\
90 \\
92 \\
\end{array}$ & $\begin{array}{r}0.2792 \\
88 \\
89 \\
92 \\
\end{array}$ & $\begin{array}{r}0.2795 \\
89 \\
90 \\
94 \\
\end{array}$ \\
\hline Mean & 0.2787 & 0.2791 & 0.2788 & 0.2791 & 0.2790 & 0.2702 \\
\hline Gage block_...--. & 1.1698 & 1.1698 & 1.1698 & 1.1698 & 1.1698 & 1. $\overline{1697}$ \\
\hline Wire diameter.......... & 0.7089 & 0.7093 & 0.7090 & 0.7093 & 0.7092 & 0.7095 \\
\hline \multicolumn{7}{|c|}{ 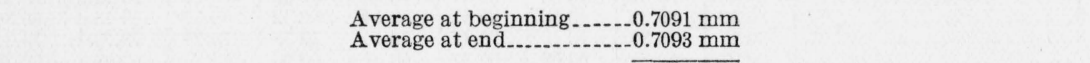 } \\
\hline \multicolumn{7}{|c|}{ A verage for all readings..$-0.7092 \mathrm{~mm}$} \\
\hline
\end{tabular}

(b) COMPUTATION FROM MEASUREMENTS OF LENGTH, MASS, AND DENSITY

\begin{tabular}{|c|c|c|c|c|}
\hline Sample & Length & Mass & Density & $\begin{array}{l}\text { Computed } \\
\text { diameter }\end{array}$ \\
\hline $\begin{array}{l}\text { Beginning of winding } \\
\text { End of winding }\end{array}$ & $\begin{array}{l}\mathrm{mm} \\
352.740 \\
528.873\end{array}$ & $\begin{array}{l}\mathrm{g} \\
12.358 \\
18.540\end{array}$ & $\begin{array}{l}\mathrm{g} / \mathrm{cm}^{3} \\
8.887 \\
8.888\end{array}$ & $\begin{array}{l}\mathrm{mm} \\
0.7085 \\
0.7088\end{array}$ \\
\hline Mean. & - . & .... & $-\cdots$ & 0.7086 \\
\hline
\end{tabular}

(c) MEASUREMENT BY GAGE SECTION* OF THIS BUREAU ON SAMPLES TAKEN FROM BEGINNING AND END OF WINDING

Average minimum diameter. $-0.7087 \mathrm{~mm}$
Average maximum diameter $-\frac{0.7097 \mathrm{~mm}}{0.7092 \mathrm{~mm}}$

[* Report states: "No appreciable difference in diameter of the two samples was observed, but there was a slight ellipticity."]

(d) SUMMARY OF RESULTS OF (a), (b) AND (c)

\begin{tabular}{|c|c|c|c|}
\hline & Method & Diameter & $\begin{array}{l}\text { Variation } \\
\text { from mean }\end{array}$ \\
\hline $\begin{array}{l}\text { Micrometer.-. } \\
\text { Density } \\
\text { Gage Section.-. }\end{array}$ & - & $\begin{array}{r}\mathrm{mm} \\
0.7092 \\
86 \\
92\end{array}$ & $\mu \begin{array}{r} \\
+0.2 \\
-0.4 \\
+0.2\end{array}$ \\
\hline Mean... & & 0.7090 & \pm 0.3 \\
\hline
\end{tabular}




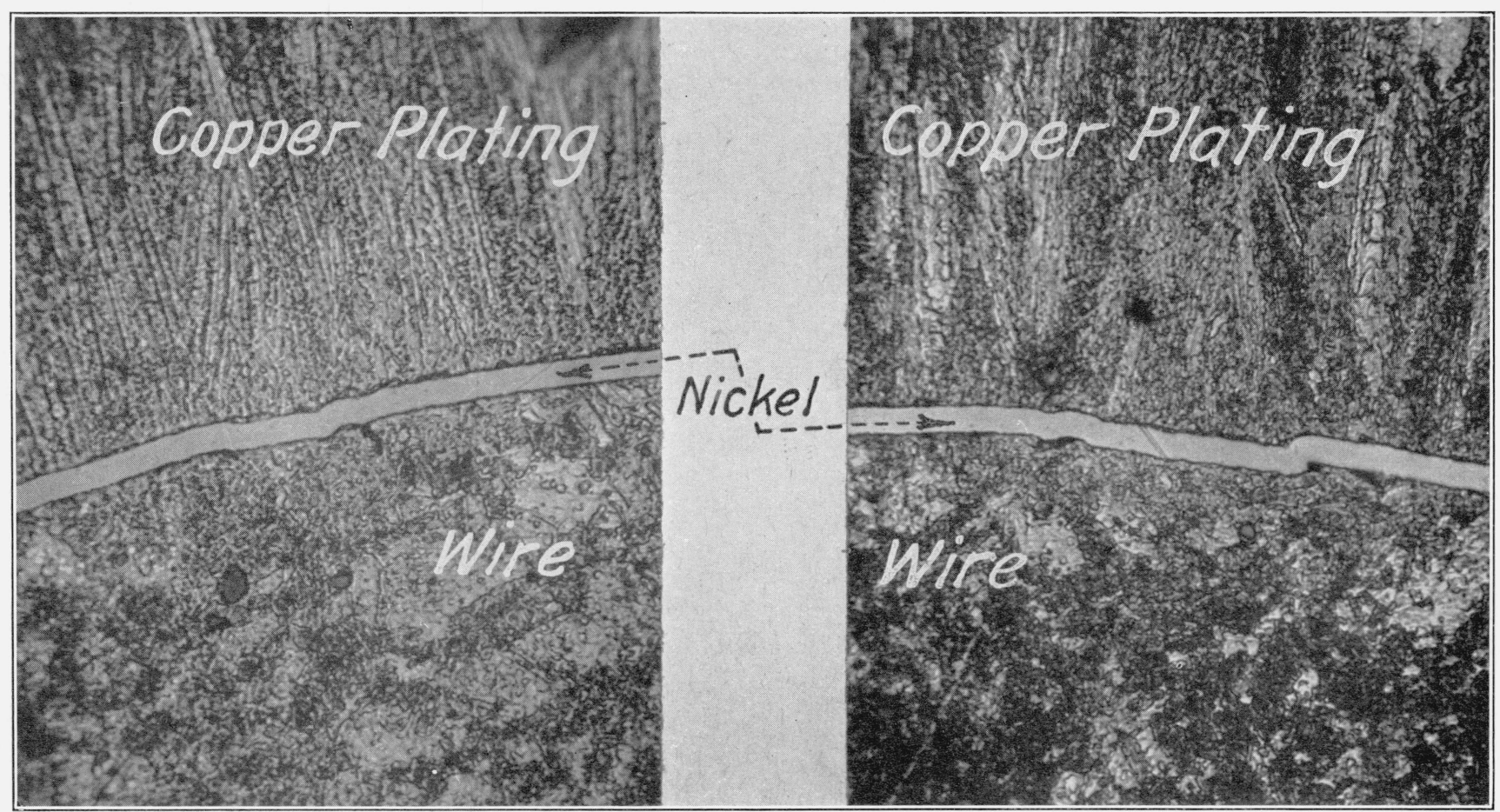

FIGURE 27.-Photomicrographs, with a magnification of 1000, of portions of transverse cross sections of the wire used in the quartz inductor. Before making a section, the wire was lightly nickel-plated, then heavily copper-plated. 
The final drawing of the wire for the quartz inductor was through a new sapphire die which had the same nominal size as the one used with the other inductors. The wire was very nearly round, the maximum difference in diameter at any position being $0.6 \mu$ by the micrometer readings, and $1.0 \mu$ as determined by the Gage Section of this Bureau. The density method gave a smaller diameter than the other methods, as was the case with the glass inductor, and for the same reason. This was supported by the photomicrographs of portions of two transverse cross sections which are reproduced in figure 27. The mean diameter, as given in table 19, was probably correct to $0.3 \mu$, which was the average deviation from the mean of the values by the different methods. This might introduce an uncertainty in the computed inductance of 3 parts in a million.

From a consideration of the errors in the measurements of the dimensions, the error in the computed inductance was estimated to be less than 15 parts in a million.

(b) COMPUTATION OF THE INDUCTANCE OF THE QUARTZ INDUCTOR

A computation of the inductance of the quartz inductor, using the constants determined in this section, has already been given as a numerical example of the application of eq 2.

The final value for the inductance of the helix only, without the correction for irregularities in winding, was:

$$
L_{\mathrm{h}}=69012249 \text { millimicrohenrys. }
$$

Corrected for irregularities in winding, the inductance of the helix $\bar{L}_{\mathrm{h}}$, was

$$
\bar{L}_{\mathrm{h}}=69012219 \text { millimicrohenrys. }
$$

The leads of the quartz inductor were made of wire having a diameter of $0.089 \mathrm{~cm}$; the different parts, indicated in figure 10, had the following lengths:

$$
\begin{aligned}
& \mathrm{PQ}=\mathrm{P}^{\prime} \mathrm{Q}^{\prime}=1.0 \mathrm{~cm} \\
& \mathrm{QR}=\mathrm{Q}^{\prime} \mathrm{R}^{\prime}=49.5 \mathrm{~cm} \\
& \mathrm{RS}=\mathrm{R}^{\prime} \mathrm{S}^{\prime}=34.3 \mathrm{~cm} \\
& \mathrm{RR}^{\prime}=\mathrm{SS}^{\prime}=1.0 \mathrm{~cm}
\end{aligned}
$$

The total computed inductance $L$, as indicated in eq 15 , was:

$$
\begin{aligned}
& \bar{L}_{\mathrm{h}}=69012219 \text { millimicrohenrys } \\
& 2 L_{\mathrm{PQ}}=\quad 12 \\
& 2 L_{\mathrm{QR}}=1362 \\
& 2 L_{\mathrm{Rs}}=\quad 903 \\
& 2 \mathrm{M}_{\mathrm{QQ} \mathbf{Q}^{\prime}}=\quad 128 \\
& -2 M_{\mathrm{ss}^{\prime}}=\quad-444 \\
& -4 M_{\mathrm{Rh}}=-707 \\
& L=69013473 \text { millimicrohenrys. }
\end{aligned}
$$

Correcting this value for the permeability of the form by the value given in table 2 ( -3 parts in a million) gave:

$$
L=69.013266 \text { millihenrys. }
$$


The substitution inductor used in connection with the quartz inductor differed from the one used with the glass inductor only in the length of the manganin wire, which was increased to $39.5 \mathrm{~cm}$. The computed inductance was $908 \mathrm{~m} \mu \mathrm{h}$. The computed value of the difference between the inductance of the helix with its leads, $L$, and the substitution inductance, $l_{\mathrm{s}}$, was, for the quartz inductor:

$$
L-l_{\mathrm{B}}=69.01236 \text { absolute millihenrys. }
$$

\section{(c) ELECTRICAL MEASUREMENTS ON THE QUARTZ INDUCTOR}

Three series of electrical measurements have been made on the quartz inductor. The first was made in 1932, the second in December 1934 and January 1935, and the third in February and March 1935. Before the second series, marked improvements were made in the measuring technique. All three series have been given the same weight in determining the final result, because the first series contained a much larger number of observations than either of the others.

(1) Effect of Frequency.-The effect of frequency on the inductance of the quartz inductor was determined on three occasions. The data are summarized in table 20. The observed differences are within experimental error, so that the inductance at either frequency has been assumed to be the same as at zero frequency.

TABLE 20.-Effect of frequency on the inductance of the quartz inductor

\begin{tabular}{|c|c|c|c|c|c|}
\hline \multicolumn{3}{|c|}{ Measurements at 24 or $25 \mathrm{c} / \mathrm{s}$} & \multicolumn{2}{|l|}{ Measurements at $100 \mathrm{c} / \mathrm{s}$} & \multirow{2}{*}{$\begin{array}{l}\text { Increase } \\
\text { in induc- } \\
\text { tance } \\
\text { from } 24 \\
\text { or } 25 \text { to } \\
100 \mathrm{c} / \mathrm{s}\end{array}$} \\
\hline Date & $\begin{array}{c}\text { Number } \\
\text { of } \\
\text { measure- } \\
\text { ments }\end{array}$ & $\begin{array}{c}\text { Fre- } \\
\text { quency }\end{array}$ & Date & $\begin{array}{c}\text { Number } \\
\text { of } \\
\text { measure- } \\
\text { ments }\end{array}$ & \\
\hline 1932 & & & 1932 & & $n$ \\
\hline $\begin{array}{l}\text { March and April } \\
\text { November }\end{array}$ & $\begin{array}{r}19 \\
4\end{array}$ & $\begin{array}{l}25 \\
25\end{array}$ & $\begin{array}{l}\text { April and May } \\
\text { October, November, and De- }\end{array}$ & $\begin{array}{l}16 \\
11\end{array}$ & $\frac{1}{5}$ \\
\hline 1935 & & & 1935 & & \\
\hline January to March... & 22 & 24 & March & 3 & -2 \\
\hline
\end{tabular}

As a further check, two observations were made at $1000 \mathrm{c} / \mathrm{s}$. These gave a measured inductance which was 18 parts in a million larger than at $25 \mathrm{c} / \mathrm{s}$. The most probable cause for this increase is the self capacitance of the inductor. The formula for computing the effective inductance $L_{\mathrm{f}}$, at any frequency $f$, when the inductance at zero frequency $L_{0}$, and the parallel capacitance $K$ are known, is, according to eq 41

$$
L_{\mathrm{i}}=L_{0}\left(1+4 \pi^{2} f^{2} L_{0} K\right)
$$

The value of $K$ as computed by this equation, from the measurements at 25 and $1000 \mathrm{c} / \mathrm{s}$ was $7 \mu \mu \mathrm{f}$. A parallel capacitance of this value would make the effective inductance at $25 \mathrm{c} / \mathrm{s}$ about a part in a hundred million greater than at zero frequency.

As a verification of eq. 51, a capacitance of $1500 \mu \mu \mathrm{f}$ was connected in parallel with the inductor, and measurements made of the effective inductance at 24 and $100 \mathrm{c} / \mathrm{s}$. The measured increase at $24 \mathrm{c} / \mathrm{s}$ was 
3 parts in a million and at $100 \mathrm{c} / \mathrm{s}$ was 32 parts in a million. The computed increase was 2 and 41 parts per million, respectively. This was considered a satisfactory check since each measured value resulted from a single determination.

(2) Effect of the Steel Reinforcement.-The effect of the steel reinforcing rods on the inductance of the quartz inductor, when its axis is vertical, is shown in figure 28 , in which the upper portion of the curve of figure 14 is plotted to a larger scale, as has already been done for the glass inductor in figure 24. The data for this curve, parts of which are given in table 23 on page 80 , were obtained by a series of absolute measurements, so that the points show a greater variation from the smooth curve than was the case for the glass inductor, where only relative measurements are plotted. When the curve of figure 28 is extrapolated, it becomes practically horizontal at about

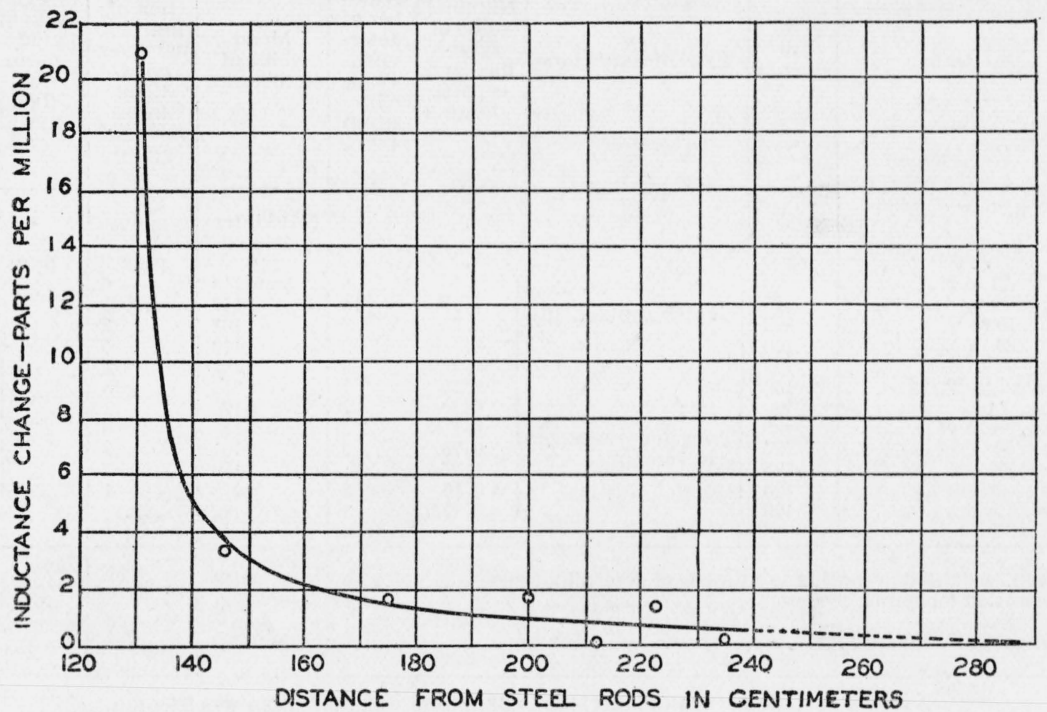

FIGURE 28.-Variation in inductance of quartz inductor (axis vertical) with distance from horizontal reinforcing rods of ordinary steel.

$300 \mathrm{~cm}$ from the ceiling reinforcement, at which distance it was assumed that the effect vanished. From the curve, it appears that, at a distance greater than $170 \mathrm{~cm}$, the effect of the steel reinforcing rods on the inductance is less than 2 parts in a million. Hence no correction has been applied to the results in table 23, as all the measurements on the quartz inductor there recorded were made at a greater distance than this from the ceiling, and far enough from the floor to be free from its influence.

In $\mathrm{R} 212 \mathrm{E}$, where there are steel reinforcing rods in both floor and ceiling, and where all measurements were made with the axis of the inductor vertical and the center at a height of $155 \mathrm{~cm}$ from the floor $(180 \mathrm{~cm}$ from the floor reinforcement and $200 \mathrm{~cm}$ from the ceiling reinforcement), the correction to the average result on the quartz inductor was estimated from the curve of figure 28 to be 3 parts in a million. 
(3) Measured Inductance.-There were 55 determinations of the inductance of the quartz inductor in the series made in 1932. These are summarized in table 21. A number of the variations in the conditions under which the determinations were made are indicated in the table. While the deviations in the results of the individual measurements were larger than in the later series, the mean value differed from the final average of the results of all the series by less than a part in a million.

TABLE 21.-Inductance determinations of quartz inductor; measured in 1932 in R212 E.

Center of the inductor at a height of $155 \mathrm{~cm}$ from the floor $(180 \mathrm{~cm}$ from the reinforcement of the floor and $200 \mathrm{~cm}$ from that of ceiling). Temperature of inductor $29.6^{\circ} \mathrm{C}$.

\begin{tabular}{|c|c|c|c|c|c|c|c|}
\hline Date & $\begin{array}{c}\text { Fre- } \\
\text { quency }\end{array}$ & Type of contactors & $\begin{array}{l}\text { Nominal } \\
\text { value of } \\
\text { inter- } \\
\text { mediary } \\
\text { capaci- } \\
\text { tance }\end{array}$ & $\begin{array}{l}\text { Num- } \\
\text { ber of } \\
\text { deter- } \\
\text { mina- } \\
\text { tions } \\
\text { in } \\
\text { group }\end{array}$ & $\begin{array}{l}\text { Mean } \\
\text { value of } \\
\text { inductance }\end{array}$ & $\begin{array}{l}\text { Average } \\
\text { devia- } \\
\text { tion of } \\
\text { individ- } \\
\text { ual deter- } \\
\text { mina- } \\
\text { tions } \\
\text { from } \\
\text { mean of } \\
\text { group }\end{array}$ & $\begin{array}{l}\text { Devia- } \\
\text { tion of } \\
\text { group } \\
\text { mean } \\
\text { from } \\
\text { final } \\
\text { mean }\end{array}$ \\
\hline $\begin{array}{l}\text { Mar. } 10 \text { to } 21 \\
\text { Mar. } 22 \text { to Apr. } 14 \\
\text { Apr. } 19 \text { to } 22 \\
\text { Apr. } 23 \text { to May } 10 \\
\text { May } 11 \text { to } 24 \\
\text { Oct. } 12 \text { to } 29 \\
\text { Nov. } 2 \text { to } 3 \\
\text { Nov. } 14 \text { to } 15 \\
\text { Nov. } 17 \\
\text { Nov. } 18 \\
\text { Nov. } 30 \text { and Dec. } 1 \\
\text { Dec. } 3\end{array}$ & $\begin{array}{r}\mathrm{c} / \mathrm{s} \\
25 \\
25 \\
100 \\
100 \\
100 \\
100 \\
100 \\
25 \\
25 \\
100 \\
100 \\
100\end{array}$ & $\left\{\begin{array}{l}\text { Copper contacts in } \\
\text { vacuum. } \\
\text { Tungsten contacts } \\
\text { in vacuum. }\end{array}\right.$ & $\left\{\begin{array}{l}\mu \mathrm{f} \\
0.1 \\
0.25 \\
0.25 \\
0.1 \\
0.25 \\
0.25 \\
0.1 \\
0.1 \\
0.25 \\
0.25 \\
\mathrm{a} 0.16 \\
\mathrm{a} 0.175\end{array}\right.$ & $\begin{array}{r}6 \\
14 \\
7 \\
6 \\
5 \\
7 \\
2 \\
2 \\
2 \\
1 \\
2 \\
1\end{array}$ & \begin{tabular}{|}
$\begin{array}{c}\text { NBS inter- } \\
\text { national } \\
\text { mh }\end{array}$ \\
68.98110 \\
147 \\
101 \\
140 \\
189 \\
213 \\
190 \\
141 \\
161 \\
170 \\
218 \\
182
\end{tabular} & $\begin{array}{r}\text { ppm } \\
6 \\
5 \\
2 \\
5 \\
2 \\
3 \\
1 \\
0 \\
3 \\
1\end{array}$ & $\begin{array}{c}\text { ppm } \\
-6 \\
-1 \\
-8 \\
-2 \\
+5 \\
+8 \\
+5 \\
-2 \\
+1 \\
+2 \\
+9 \\
+4\end{array}$ \\
\hline \multirow{2}{*}{\multicolumn{5}{|c|}{$\begin{array}{l}\text { Mean, weighted according to number of determinations } \\
\text { Correction for reinforcement } \\
\text { Corrected inductance }\end{array}$}} & $\begin{array}{r}68.98154 \\
-0.00021\end{array}$ & -- & \\
\hline & & & & & 68.98133 & - & \\
\hline
\end{tabular}

Average deviation of the 55 individual values from weighted mean was $5.9 \mathrm{ppm}$.

a Intermediary capacitance measured with 60 charges and discharges per second instead of 100 as normally used.

The second series of observations was made in 1934-35, also with the inductor in R212 E. The values obtained are given in table 22. The coils in the a-c bridge were all wound on Pyrex-glass tubes. Again the axis of the inductor was vertical and its center $155 \mathrm{~cm}$ from the floor. The absolute value of the intermediary capacitance was, in the majority of cases, measured with two independent bridges, in one of which were vacuum contactors, in the other, inertia contactors. There was no indication of any systematic difference between the results obtained with the two bridges. 
TABLE 22.-Inductance of quartz inductor as measured in R212 E during December 1934 and January 1935, with a frequency of $24 \mathrm{c} / \mathrm{s}$

Distance from floor: $155 \mathrm{~cm}$ ( $180 \mathrm{~cm}$ from floor reinforcement).

Temperature of inductor: $29.6^{\circ} \mathrm{C}$.

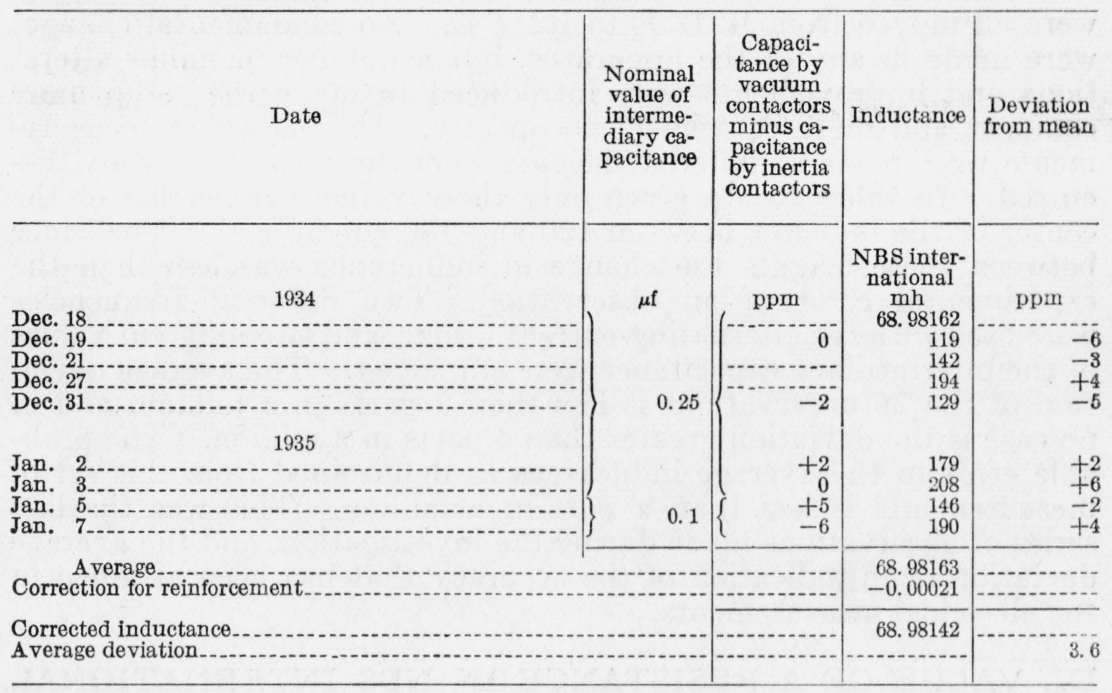

$\mathrm{T}_{\mathrm{ABLE}}$ 23.-Inductance of quartz inductor as measured in R214 E during February and March 1935

Temperature of inductor: $29.6^{\circ} \mathrm{C}$.

\begin{tabular}{|c|c|c|c|c|c|c|c|}
\hline \multirow[b]{2}{*}{ Date } & \multirow{2}{*}{$\begin{array}{l}\text { Fre- } \\
\text { quency }\end{array}$} & \multicolumn{2}{|c|}{$\begin{array}{l}\text { Distance of center } \\
\text { of inductor from- }\end{array}$} & \multirow{2}{*}{$\begin{array}{l}\text { Nominal } \\
\text { value of } \\
\text { interme- } \\
\text { diary ca- } \\
\text { pacitance }\end{array}$} & \multirow{2}{*}{$\begin{array}{c}\text { Capaci- } \\
\text { tance by } \\
\text { bridge with } \\
\text { vacuum } \\
\text { contactors } \\
\text { minus that } \\
\text { by bridge } \\
\text { with inertia } \\
\text { contactors }\end{array}$} & \multirow[b]{2}{*}{$\begin{array}{l}\text { Induct- } \\
\text { ance }\end{array}$} & \multirow{2}{*}{$\begin{array}{l}\text { Devia- } \\
\text { tion from } \\
\text { mean }\end{array}$} \\
\hline & & Floor & $\begin{array}{l}\text { Ceiling } \\
\text { reinforce- } \\
\text { ment }\end{array}$ & & & & \\
\hline 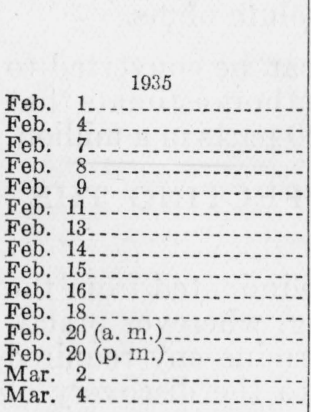 & \multirow[t]{2}{*}{$\mathrm{c} / \mathrm{s}$} & $\begin{array}{r}\mathrm{cm} \\
120 \\
120 \\
132 \\
132 \\
132 \\
132 \\
143 \\
143 \\
143 \\
155 \\
155 \\
180 \\
180 \\
180 \\
180\end{array}$ & \begin{tabular}{c|}
$\mathrm{cm}$ \\
235 \\
235 \\
223 \\
223 \\
223 \\
223 \\
212 \\
212 \\
212 \\
200 \\
200 \\
175 \\
175 \\
175 \\
175
\end{tabular} & 0.25 & $\left\{\begin{array}{r}0+2 \\
\hdashline+1 \\
\hdashline\end{array}\right.$ & $\begin{array}{c}\text { NBS in- } \\
\text { terna- } \\
\text { tional } \\
\text { mh } \\
68.98107 \\
157 \\
142 \\
143 \\
131 \\
145 \\
136 \\
129 \\
127 \\
138 \\
146 \\
134 \\
124 \\
150 \\
157\end{array}$ & $\begin{array}{r}\text { ppm } \\
-4 \\
+3 \\
+1 \\
+1 \\
0 \\
+2 \\
0 \\
-1 \\
-1 \\
+1 \\
+2 \\
0 \\
-1 \\
+2 \\
+3\end{array}$ \\
\hline $\begin{array}{l}\text { Mar. } 7 \ldots \ldots \\
\text { Mar. 11........ }\end{array}$ & & $\begin{array}{l}180 \\
180\end{array}$ & $\begin{array}{l}175 \\
175\end{array}$ & 0.1 & $\begin{array}{l}+5 \\
+6\end{array}$ & $\begin{array}{l}103 \\
111\end{array}$ & $\begin{array}{l}-4 \\
-3\end{array}$ \\
\hline $\begin{array}{l}\text { Mar. } 22 \\
\text { Mar. } 23 \\
\text { Mar. 26 }\end{array}$ & 100 & $\begin{array}{l}180 \\
180 \\
180\end{array}$ & $\begin{array}{l}175 \\
175 \\
175\end{array}$ & 0.25 & $\left\{\begin{array}{l}-1-1, \\
\hdashline-\cdots\end{array}\right.$ & $\begin{array}{l}105 \\
142 \\
137\end{array}$ & $\begin{array}{l}-4 \\
+1 \\
+1\end{array}$ \\
\hline $\begin{array}{l}\text { Average } \\
\text { Average deviation..... }\end{array}$ & . & - & $\ldots$. & -.... & - & 68.98133 & 1.8 \\
\hline
\end{tabular}


The third series of observations was made in February and March 1935 , with the inductor in R214 E. The inductor, the a-c bridge, the standard resistors with the Wheatstone bridge for comparing them, and the absolute capacitance bridge with inertia contactors, were all moved from R212 E to R214 E. No fundamental changes were made in any of the apparatus, but a number of minor alterations and improvements were introduced to make the setup more compact and more convenient to operate. In this series, measurements were made at different heights from the floor, as already discussed. In table 23 are given only those values for heights of the center of the inductor between 120 and $180 \mathrm{~cm}$ from the floor, since between these heights the change in inductance was less than the experimental error of an observation. Two different frequencies were used with the alternating-current bridge, and two different values of the intermediary capacitance were employed. The average deviation of the 20 observations is less than 2 parts in a million, and in no case is the deviation greater than 4 parts in a million. The probable error in the average inductance as determined from this set of measurements is less than a part in a million. This was the last series of observations made during the investigation, and the average deviation is an indication of the accuracy that has been attained in the electrical measurements.

\section{VALUE OF A RESISTANCE IN NBS INTERNATIONAL OHMS AND IN ABSOLUTE OHMS}

The value, in absolute ohms, of one NBS international ohm has been determined from measurements on three different inductors. The results for all three inductors are collected in table 24. The weights assigned to the results of the three inductors are, approximately, inversely proportional to the deviation from the unweighted mean. The weighting, however, had little influence on the final result, for the unweighted mean of the ratio is 1.000455 , which is only five parts in a million larger than the weighted mean.

The result of this investigation may be represented by the equality

\section{NBS international $\mathrm{ohm}=1.000450$ absolute ohms.}

Hence a resistance in NBS international ohms can be converted to absolute ohms by multiplying by 1.000450 . The authors estimate that this result differs from the true value by less than 20 parts in a million.

\section{$\mathrm{X}$. DISCUSSION OF UNCERTAINTIES AFFECTING THE RESULT}

So far as possible, systematic errors have been eliminated from the final result. This has been accomplished by using, wherever practicable, two or more instruments by which to determine any required constant. This procedure has several times led to the discovery of 
TABLE 24.-Ratio of the absolute ohm to the NBS international ohm

\begin{tabular}{|c|c|c|c|c|c|c|c|c|c|}
\hline 1 & 2 & 3 & 4 & 5 & 6 & 7 & 8 & 9 & 10 \\
\hline \multirow[b]{2}{*}{ Inductor } & \multirow{2}{*}{$\begin{array}{l}\text { Computed } \\
\text { inductance } \\
\left(L-l_{s}\right) \\
\text { corrected } \\
\text { for perme. } \\
\text { ability of } \\
\text { forms }\end{array}$} & \multicolumn{3}{|c|}{ Measured inductance } & \multirow{2}{*}{$\begin{array}{l}\text { A verage } \\
\text { deviation of } \\
\text { individual } \\
\text { observations } \\
\text { from mean } \\
\text { of group }\end{array}$} & \multirow{2}{*}{$\begin{array}{c}\text { Ratio of the } \\
\text { value of a } \\
\text { resistance } \\
\text { in absolute } \\
\text { ohms to the } \\
\text { value in } \\
\text { NBS inter- } \\
\text { national } \\
\text { ohms }\end{array}$} & \multirow{2}{*}{$\begin{array}{c}\text { Devia- } \\
\text { tion } \\
\text { from un- } \\
\text { weighted } \\
\text { mean }\end{array}$} & \multirow[b]{2}{*}{ Weight } & \multirow{2}{*}{$\begin{array}{c}\text { Devia- } \\
\text { tion } \\
\text { from } \\
\text { weighted } \\
\text { mean }\end{array}$} \\
\hline & & $\begin{array}{c}\text { Date of } \\
\text { obser- } \\
\text { vations }\end{array}$ & $\begin{array}{l}\text { Num- } \\
\text { ber of } \\
\text { obser- } \\
\text { vations }\end{array}$ & $\begin{array}{c}\text { Average } \\
\text { value }\end{array}$ & & & & & \\
\hline \multirow{2}{*}{$\begin{array}{l}\text { Porcelain . - } \\
\text { Glass...-... }\end{array}$} & $\begin{array}{c}\begin{array}{c}\text { Absolute } \\
\mathrm{mh}\end{array} \\
22.5895 \\
\end{array}$ & $1929-30$ & 110 & $\begin{array}{c}\text { NBS inter- } \\
\text { national } \\
\text { mh } \\
22.5788 \\
\end{array}$ & $\begin{array}{r}\mathrm{ppm} \\
13 \\
\end{array}$ & 1. 000475 & $\begin{array}{c}\mathrm{ppm} \\
+20 \\
\end{array}$ & 1 & $\begin{array}{l}\mathrm{ppm} \\
+25 \\
\end{array}$ \\
\hline & 30.86179 & $\left\{\begin{array}{c}1933-34 \\
1934\end{array}\right.$ & $\begin{array}{l}45 \\
20\end{array}$ & $\begin{array}{l}30.84822 \\
30.84807\end{array}$ & $\begin{array}{l}3.0 \\
2.8\end{array}$ & \begin{tabular}{|l}
$\ldots \ldots$ \\
\end{tabular} & - & - & - \\
\hline A verage_. & - & $-\ldots$ & - & 30.84814 & - n. & 1. $00044_{2}$ & -13 & 2 & -8 \\
\hline \multirow[t]{2}{*}{ Quartz..... } & 69.01236 & $\left\{\begin{array}{l}1932 \\
1934 \\
1935\end{array}\right.$ & $\begin{array}{r}55 \\
9 \\
20\end{array}$ & $\begin{array}{l}68.98133 \\
68.98142 \\
68.98133\end{array}$ & $\begin{array}{l}5.9 \\
3.6 \\
1.8\end{array}$ & 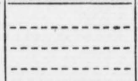 & 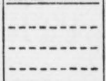 & $\cdots$ & 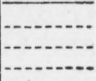 \\
\hline & & 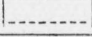 & $\ldots$ & 68. 98136 & $\ldots \ldots$ & 1. 000449 & -6 & 4 & -1 \\
\hline $\begin{array}{l}\text { Unweig } \\
\text { Weigh }\end{array}$ & meal & & & & & $\begin{array}{l}1.000455 \\
1.000450\end{array}$ & & & $\ldots$ \\
\hline
\end{tabular}

unexpected errors, all but one of which were rectified either by eliminating the cause or applying a suitable correction. The one exception was the diameter of the porcelain inductor which was somewhat too large, as has already been explained on page 51 .

The uncertainties that might have been introduced into the final result by accidental errors are given for each inductor in table 25 .

TABLE 25.-Effect of accidental errors on final result for each inductor [All values are in parts per million]

\begin{tabular}{|c|c|c|c|}
\hline \multirow{2}{*}{ Quantity affecting result. } & \multicolumn{3}{|c|}{ Accidental error for inductor } \\
\hline & Porcelain & Glass & Quartz \\
\hline $\begin{array}{l}\text { Diameter of helix } \\
\text { Diameter of wire } \\
\text { Pitch of winding } \\
\text { Irregularities in winding } \\
\text { Permeability of form } \\
\text { Distribution of current ( } \pm \text { term) } \\
\text { Reinforcement of building } \\
\text { Electrical measurements b }\end{array}$ & $\begin{array}{l}6 \\
10 \\
16 \\
1 \\
1.3 \\
2 \\
13\end{array}$ & $\begin{array}{l}1 \\
5 \\
15 \\
1 \\
0.5 \\
1 \\
6\end{array}$ & $\begin{array}{r}2 \\
3 \\
4 \\
10 \\
1 \\
1 \\
0 \\
5\end{array}$ \\
\hline Square root of sum of the squares. & 24 & 17 & 12 \\
\hline
\end{tabular}

The average deviation by two different methods. See text.

b Estimated from deviations of results.

The values given in table 25 show that the measurements on the quartz inductor were more precise than those on the other inductors. The largest errors for this inductor resulted from the uncertainty in the pitch and in its variations. This uncertainty in the pitch has limited the accuracy obtainable with the present inductors.

In the electrical measurements, the greatest uncertainty arose from the integration of the current by the galvanometer in the absolute measurement of capacitance. Two galvanometers in two different 
bridges, however, gave the same result within a few parts in a million. In fact, the electrical measurements have been so perfected that the need for more reliable standards of resistance has become apparent.

The agreement of the results given in table 25 might be interpreted as indicating that the error in the final result is probably small. However, because of the uncertainties just enumerated, the authors feel that the error in the final result may be as large as 20 parts in a million.

\section{RESULTS OF RECENT INVESTIGATIONS}

The most recent of the previously published values ${ }^{38}$ of the ohm are those of Smith at the National Physical Laboratory, published in 1914, and of Grüneisen and Giebe at the Physikalisch-Technische Reichsanstalt, completed in 1914, but not published until 1920. The published results were:

Smith - $1 \mathrm{NPL}$ international ohm $=1.00052$ absolute ohms.

Grüneisen
and Giebe 1 PTR international ohm =1.000 51 absolute ohms.

An intercomparison of resistance standards, however, showed that the international ohm, as maintained at the two laboratories, differed by 30 parts in a million in the direction to make a difference of 40 parts in a million between the results of these two absolute determinations. An exact comparison of these results with that herein reported is not possible, since the amounts by which the units of resistance of the various countries have changed in the last 20 years are not accurately known.

Investigations on the absolute value of the ohm are now in progress at the National Physical Laboratory of England, and at the Electrotechnical Laboratory of Japan. Preliminary values have been published as follows:

1 NPL Int. Ohm ${ }^{39}=\left\{\begin{array}{l}1.00049 \text { absolute ohms-Lorenz method. } \\ 1.00047 \text { absolute ohms-Campbell method. }\end{array}\right.$ 1 ETL Int. Ohm ${ }^{40}=1.00046$ absolute ohms-Campbell method.

Measurements made at the International Bureau of Weights and Measures indicate that the maximum difference in the international ohm, as maintained at the National Physical Laboratory (NPL), the Electrotechnical Laboratory (ETL), and the National Bureau of Standards (NBS), is 3 parts in a million. Hence the above results can be directly compared with the result of this investigation.

The authors wish to express their indebtedness to many members of the staff of this Bureau for helpful cooperation. Mention has already been made of important contributions by several sections. In addition, the Resistance Section loaned the standard resistors and frequently compared them with the primary standards of resistance of this Bureau, and the Length Section calibrated the line standards in terms of the standard meter.

Washington, October 22, 1935.

38 F. E. Smith, Phil. Trans. 214A, 27 (1914); Grüneisen and Giebe, Ann. Phys. 368, 179 (1920). 301934 Annual Report of the National Physical Laboratory, page 57.

40 Comité International des Poids et Mesures. Procés-verbaux 16, 28 (1933). 